\title{
The Flo Adhesin Family
}

\author{
Ronnie G. Willaert ${ }^{1,2,3, * \mathbb{D}}$, Yeseren Kayacan ${ }^{1,2,3,4}$ and Bart Devreese $2,3,4,5$ (D) \\ 1 Research Group Structural Biology Brussels (SBB), Vrije Universiteit Brussel (VUB), 1050 Brussels, Belgium; \\ yeserenk@gmail.com \\ 2 Alliance Research Group VUB-UGent NanoMicrobiology (NAMI), 1050 Brussels, Belgium; \\ Bart.Devreese@ugent.be \\ 3 International Joint Research Group VUB-EPFL NanoBiotechnology \& NanoMedicine (NANO), \\ Vrije Universiteit Brussel (VUB), 1050 Brussels, Belgium \\ 4 Ecole Polytechnique Fédérale de Lausanne, 1015 Lausanne, Switzerland \\ 5 Laboratory for Microbiology, Gent University (UGent), 9000 Gent, Belgium \\ * Correspondence: Ronnie.Willaert@vub.be; Tel.: +32-2629-1846
}

check for updates

Citation: Willaert, R.G.; Kayacan, Y.; Devreese, B. The Flo Adhesin Family. Pathogens 2021, 10, 1397. https:// doi.org/10.3390/pathogens10111397

Academic Editor: Peter N. Lipke

Received: 2 September 2021

Accepted: 25 October 2021

Published: 28 October 2021

Publisher's Note: MDPI stays neutral with regard to jurisdictional claims in published maps and institutional affiliations.

Copyright: (C) 2021 by the authors. Licensee MDPI, Basel, Switzerland. This article is an open access article distributed under the terms and conditions of the Creative Commons Attribution (CC BY) license (https:/ / creativecommons.org/licenses/by/ $4.0 /)$.

\begin{abstract}
The first step in the infection of fungal pathogens in humans is the adhesion of the pathogen to host tissue cells or abiotic surfaces such as catheters and implants. One of the main players involved in this are the expressed cell wall adhesins. Here, we review the Flo adhesin family and their involvement in the adhesion of these yeasts during human infections. Firstly, we redefined the Flo adhesin family based on the domain architectures that are present in the Flo adhesins and their functions, and set up a new classification of Flo adhesins. Next, the structure, function, and adhesion mechanisms of the Flo adhesins whose structure has been solved are discussed in detail. Finally, we identified from Pfam database datamining yeasts that could express Flo adhesins and are encountered in human infections and their adhesin architectures. These yeasts are discussed in relation to their adhesion characteristics and involvement in infections.
\end{abstract}

Keywords: Flo adhesin family; pathogenic yeasts; Candida glabrata; Saccharomyces cerevisiae; host-pathogen interaction; abiotic surface adhesion; adhesin structure; adhesin architecture

\section{Introduction}

Fungal infections are an extremely important growing health problem since they kill over 1.6 million people worldwide per year [1-3]. Fungi are present everywhere in our environment and are, usually, harmless for healthy people. Fungal infections can be topical and local, such as surface infections on the skin or in the vaginal tract. Systemic infections arise when the fungi enter and proliferate in the bloodstream. Systemic fungal infections affect people with an altered immune system due to medical interventions, i.e., cancer therapy, organ transplantation, asthma and the use of immune-modulatory medications, immunosuppressive diseases (such as Acquired Immune Deficiency Syndrome (AIDS)) [4], or malnutrition (under- and overnutrition) [5-7]. In addition, viral pneumonia increases patients' susceptibility to fungal superinfections. During the recent COVID-19 pandemic, COVID-19-associated pulmonary aspergillosis was responsible for a substantial increased mortality [8-12].

The contribution of fungal infections to the global burden of disease is largely unrecognised [1,13-15]. It is estimated that around 1.7 billion people have superficial fungal infections such as skin, hair and nail infections $[1,15,16]$. Mucosal fungal infections of the oral and genital tracts are also an extremely burden, especially vulvovaginal candidiasis. It was estimated that around 50 to $75 \%$ of women in their childbearing years suffer from at least one episode of vulvovaginitis, and 5 to $8 \%$ (around 75 million women) have at least four episodes annually [15,17]. Recent global estimates have found 3,000,000 cases of chronic pulmonary aspergillosis, $\sim 223,100$ cases of cryptococcal meningitis complicating HIV / AIDS, 700,000 cases of invasive candidiasis, 500,000 cases of Pneumocystis jirovecii 
pneumonia, $\sim 250,000$ cases of invasive aspergillosis, $\sim 100,000$ cases of disseminated histoplasmosis, over 10,000,000 cases of fungal asthma and $\sim 1,000,000$ cases of fungal keratitis occur annually [1]. Invasive fungal infections are of great concern because they are associated with unacceptable high mortality rates [15]. The epidemiology of invasive fungal infection is evolving [18-20]. A growing population of immunosuppressed patients has resulted in increasingly frequent diagnoses of invasive fungal infections, including those caused by unusual yeasts. The incidence of non-albicans species of Candida is increasing compared with that of $C$. albicans, and several species, such as C. glabrata, C. lusitaniae, C. auris, C. inconspicua and C. krusei, may be resistant to antifungal therapy.

Early accurate diagnosis allows prompt antifungal therapy; this is, however, often delayed or unavailable leading to high mortality rates, serious chronic illness or blindness [1]. The choice of available antifungal drugs to treat invasive fungal infections is limited, since only three structural classes of compounds are available, i.e., polyenes, azoles, and echinocandins [21]. Additionally, current antifungal drugs can show significant limitations, such as amphotericin B that displays a considerable toxicity and undesirable side effects [22,23], issues with pharmacokinetic properties and activity spectrum, a small number of targets [24,25], and they can interact with other drugs, such as chemotherapy agents and immunosuppressants [26,27]. Recently, there is an increased interest in the development of new antifungal compounds and multiple compounds are in clinical development stage [28-34].

Cell adhesion proteins are critical to fungal cell interactions in development, symbiosis, and pathogenesis [35]. They are specifically found on the outside of the cell wall [36]. They participate in mating, colony morphology changes, biofilm formation, fruiting body development, and interactions with mammalian and plant hosts. Many fungi contain a family of cell wall glycoproteins, called "adhesins" that confer them unique adhesion properties [37-39]. These molecules are required for the interactions of fungal cells with each other (flocculation, filamentation and biofilm formation) [37,38,40,41], inert surfaces such as agar and plastics $[40,42-44]$ and host tissues $[45,46]$. Selective cell adhesion is also needed for fungal pathogenesis. The majority of these functionally characterized fungal adhesins are glycoproteins with a common architecture. A high-complexity cell surface exposed $\mathrm{N}$-terminal adhesion domain for ligand recognition and binding. Followed by a large, low complexity domain characterized by a variable number of tandem repeats with significant intraspecies length polymorphisms and a C-terminal domain harbouring a glycosylphosphatidylinositol (GPI) anchor that mediates attachment to the glucan layer of cell walls $[36,39,47-49]$.

Fungal cell wall adhesins are involved in the first step in pathogenesis, i.e., the adherence to host tissue or abiotic medical devices. This first step is critical for colonization leading to invasion and damage of host tissue or biofilm formation. Adherence of pathogenic fungi to host tissues can occur at different sites in the human body. In the case of epithelial and endothelial tissues, one of the potential adhesion targets is represented by the glycocalyx, i.e., the extracellular mesh of carbohydrate-rich molecules bound to the cell membranes or secreted by cells in the external medium [50]. The microbial adhesion to components of the glycocalyx, such as glycosylated host receptors or other glycoproteins, is often mediated by adhesion proteins endowed with lectin activity [51-53].

The most common yeast infection is candidiasis caused by Candida spp., while many other fungal species are also medically important [54]. Candida spp. can adhere to different surfaces such as skin and mucosal tissue as well as abiotic surfaces, an important step in establishment of infection [55,56]. Additionally, Candida cells are capable of 'flocculating' with other Candida cells as well as interacting with other microbes in the human microflora, forming large communities with reduced susceptibility to antifungals [57]. The most frequently encountered Candida species is Candida albicans; however, the incidence of nonalbicans species, such as C. glabrata, C. tropicalis, C. parapsilosis, C. intermedia, C. Iusitaniae, C. haemuloni, and C. auris has increased over recent decades due to the long-term use and limited options of antifungal drugs [58-62]. 
The Flo adhesin family was initially discovered in brewer's yeast. Flo adhesins are involved for ages in ale (Saccharomyces cerevisiae) and lager (S. pastorianus) beer fermentation since cells "flocculate" (aggregate) at the end of the primary fermentation and the flocs sediment (lager beer) rapidly from the medium, or rise to the liquid surface and form a yeast layer [63]. Later, it was also found that Flo proteins are involved in processes where $S$. cerevisiae switch from a planktonic lifestyle to a complex multicellular structure such as-besides flocs-filaments, mats, flors, and biofilms in response to changes in the environment and its genetic background [64]. The potential of individual yeast cells to switch between different growth modes in nature is advantageous for optimal dissemination, protection, substrate colonization and escape unfavourable conditions at the population level [64-67]. Originally, the composition of the Flo adhesin family was based on the flocculation proteins/genes discovered in S. cerevisiae, i.e., Flo1p, Flo5p, Flo9p and Flo10p (and de transcription factor Flo8p) [37]. Later on, 2 subgroups were defined [38]. The members of the first subgroup are encoded by genes, including FLO1, FLO5, FLO9, and FLO10, which share considerable sequence homology. The gene products of FLO1, FLO5, FLO9, and-to a lesser extent-FLO10 [44] promote cell-cell adhesion and contribute to the formation of multicellular clumps (flocs), and, therefore, these adhesins were called flocculins [68]. The members of the second group of the Flo family, including Flo11p, Fig2p, and Aga1p, have a domain structure such as that of the first, but with quite unrelated amino acid sequences. Flo11p also promotes cell-cell adhesion, but does this only weakly $[44,69]$. Flo11p is mainly required for diploid pseudohyphal formation, haploid invasive growth [40,70], mat [71] and biofilm formation [72,73]. N-Flo11p does not bind mannose, which contrasts with the other Flo proteins. However, N-Flo11p can interact with N-Flo11p (homophilic adhesion ability), explaining the weak-flocculation characteristic [74,75]. Fig2p and Aga1p are induced during mating [76,77]. Aga1p, linked by disulphides to the soluble peptide, Aga2p [78], is required on the surface of MAT $\alpha$ cells for them to adhere to the protein Sag1p on the surface of MAT $\alpha$ cells [79].

In this review, we redefine the Flo adhesin family based on the protein architecture of the Flo proteins sensu stricto. Based on this new definition, we reviewed the adhesins containing these Flo protein architectures that were found to be present in yeasts that have been isolated from human infections. We discuss the structure, function, and binding mechanisms of members of the Flo adhesin family of which the protein structure has been solved. Next, we review and discuss the yeasts that express Flo protein type adhesins.

\section{Redefinition of the Flo Adhesin Family Based on the Protein Architecture}

The Flo adhesin Family can be redefined based on the domain architectures present in Flo adhesins since these domains will define the functional properties of the adhesins. The Flo family is composed of 2 flocculation adhesin classes, i.e., the Flo-type and the Flo11type adhesins. The Flo type can be further divided into the Flo adhesins that contain a PA14 or GLEYA lectin domain and a flocculin domain (P00624) and/or a flocculin type 3 repeat (flocculin_t3) (PF13928) belong to the lectin type flocculins. The N-terminal PA14/GLEYA domain is the essential domain since it contributes most to the adhesion strength via its lectin function.

The Flo11 type adhesins can be subdivided into architectures containing only the Flo11 domain, the Flo 11 domain and the flocculin domain or the flocculin type 3 repeat, and the Flo 11 domain and another adhesin structural domain (Figure 1). Based on this definition of the Flo adhesin family, Fig2 and Aga1p do not belong anymore to this family since Fig2p (Pfam: FIG2_YEAST, P25653) does not contain a Flo11 domain (nor a PA14 or GLEYA domain); it does contain only a Flocculin_t3 domain. Aga1p (Pfam: AGA1_YEAST, P32323) does not contain any of the specified domains for flocculation adhesins.

The flocculin repeat domains (P00624) were initially found in the Ser/Thr-rich central region of Flo1p, Lg-Flo1p, Flo5p, Flo9p and Flo10p and correspond to the tandem repeats, which are important for proper cell wall targeting and presentation of the adhesins $[37,49,80]$. The Ser and Thr amino acids are prone to extensive O-glycosylation 
during post-translational modification and enable the adhesins to attain a long, semi-rigid rod-like structure [81]. An increasing number of tandem repeats increases the strength of the adhesion [82-84]. The repeats trigger frequent recombination events within the gene or between the gene and a pseudogene, resulting in expansion and contraction in the gene size, which affects the adhesion properties of the cells [82].

The flocculin type 3 repeat (PF13928) was initially found in Flo5p, Flo9p, and LgFlo1p close to the C-terminus of the adhesin. The presence of these domains on the functional characteristics of the adhesin and on the cell adhesion properties has not yet been investigated.

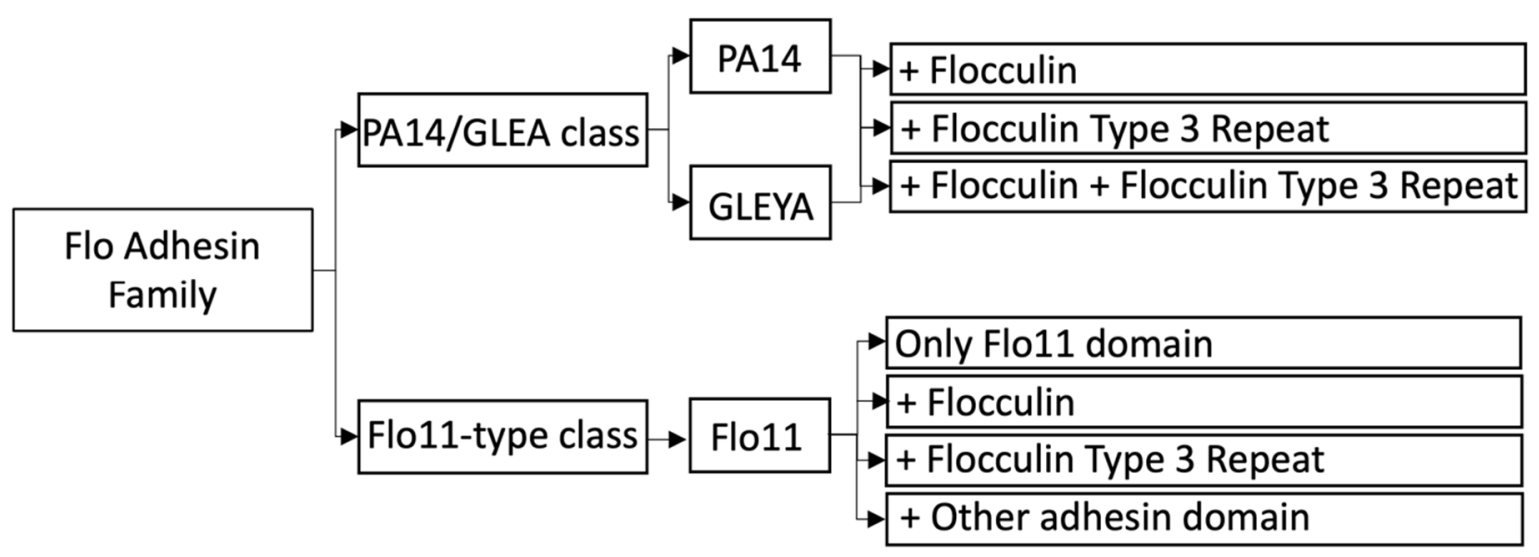

Figure 1. Definition of the Flo adhesin family based on the structural architectures of the Flo adhesins.

\section{Structure and Function of Flocculation Adhesins}

The member proteins of the adhesin family have a modular configuration that consists of three domains (N-terminal, central and C-terminal domain) and an amino-terminal secretory sequence that must be removed when the protein moves to the plasma membrane through the secretory pathway $[35,49,85,86]$. The GPI anchor is modified as the proteins become linked to $\beta-1,6$-glucan in the wall. Despite the intensive research on yeast adhesion, a relative low number of adhesin structures have been investigated at the molecular level and their structure solved [86] (Table 1).

\subsection{PA14/GLEYA Flo Type Adhesin Structure}

The adhesins that belong to this type, contain a PA14 domain (Pfam family PA14, PF07691) or a GLEYA domain (Pfam family GLEYA, PF10528) in the N-terminal part of the adhesin. The PA14 domain family was discovered based on the sequence analysis of an insert in bacterial $\beta$-glucosidases, which was also found in other glycosidases, glycosyltransferases, proteases, amidases, yeast adhesins, and bacterial toxins [87]. The insert is a 14-kDa region of $\mathrm{PA}_{20}$, which is a fragment of the protective antigen (PA) from anthrax toxin, has a $\beta$-barrel structure [88]. The PA14 domain is present in 2448 species, 974 protein architectures, and in 54 solved protein structures (Pfam 34.0, March 2021). The presence of a calcium-dependent carbohydrate-binding pocket is a common element in the PA14 domain family $[89,90]$. The GLEYA domain is structurally related to lectin-like binding domains found in fungal adhesins such as the $S$. cerevisiae Flo proteins and the C. glabrata Epa proteins [91]. The distinction is not always clear as can be noted from the Uniprot description of the adhesins containing a GLEYA domain (Table 1). An EYDGA pentapeptide motif belonging to the PA14 domain was identified [92] and was found to be present in the N-terminal domain of Epa1 from C. glabrata, where it is involved in carbohydrate binding. This motif is comparable to the VSWGT pentapeptide in Flo1p from S. cerevisiae [91]. The VSWGT motif of Flo1p and the EYDGA motif are present in the same position within a hypervariable region of the PA14 domain [93]. The VSWGT/KVLAR motif of Flo1p/Lg-Flo1p and the EYDGA motif of Epa1p represent a surface loop between 
two $\beta$-strands, 9 and 10, in the structure of the anthrax toxin PA domain [88]. Adhesins with a GLEYA domain possess a typical N-terminal signal peptide and a domain of conserved sequence repeats but lack GPI anchor attachment signals [91]. However, it was demonstrated for Epa1 that the GPI anchor is essential both for cross-linking in the cell wall and for Epa1-mediated adherence [45,94]. The GLEYA domain contains a conserved motif $\mathrm{G}(\mathrm{M} / \mathrm{L})(\mathrm{E} / \mathrm{A} / \mathrm{N} / \mathrm{Q}) Y A$, hence the name GLEYA. Based on sequence homology, it was suggested that the GLEYA domain would predominantly contain $\beta$-sheets, which was later confirmed by the solved structures of Epa1p and Epa9p (Table 1) [92,95]. 
Table 1. Protein structures of flocculation adhesins deposited in the Protein Data Bank (PDB, ww.rcsb.org accessed on 2 September 2021).

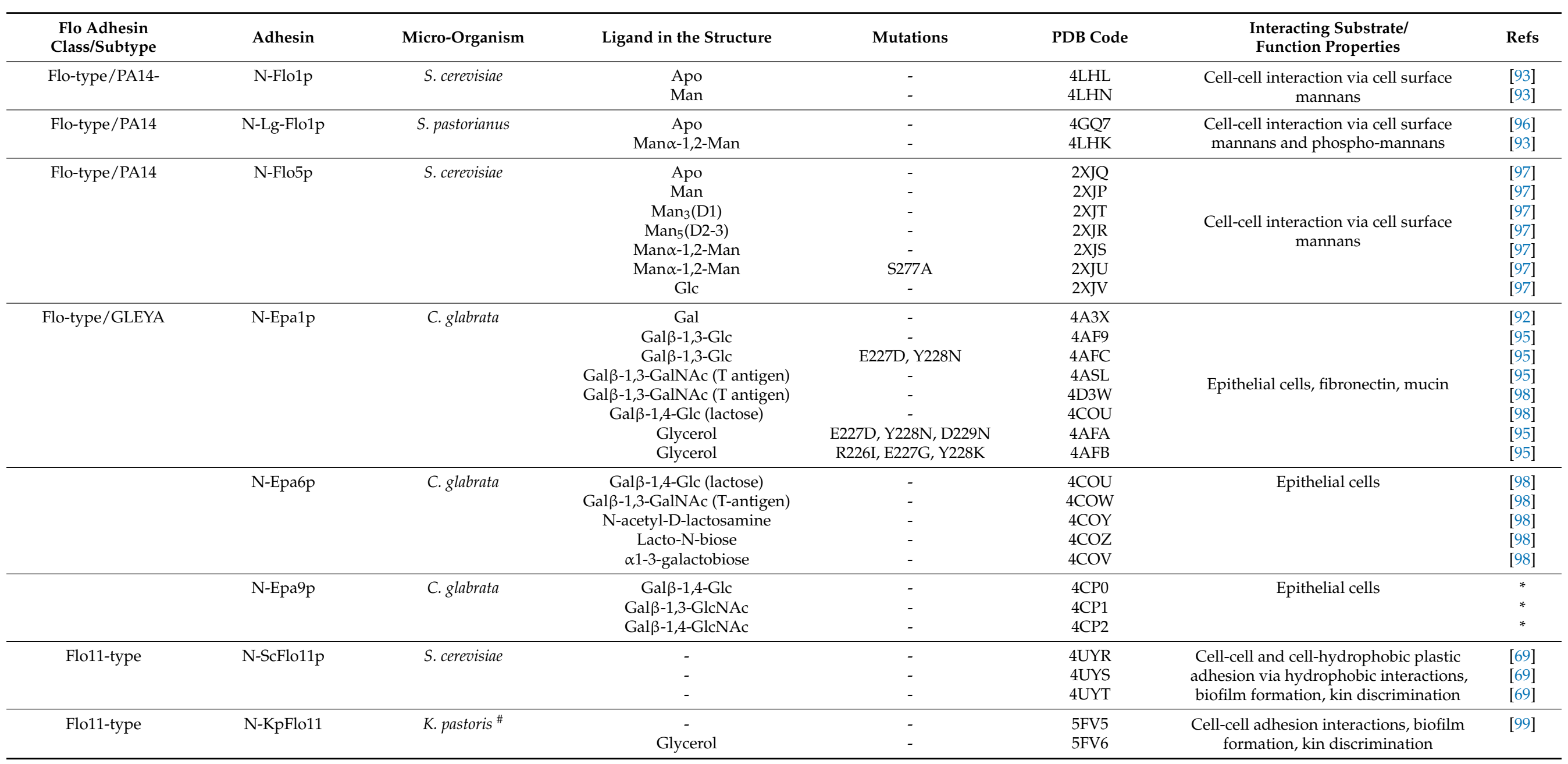

${ }^{*}$ Deposited in PDB but not yet published. ${ }^{\#}$ Komagataella pastoris. 
Several of the N-terminal adhesion domains of the PA14 type Flo proteins were solved (Table 1), i.e., N-Flo5p [100] and N-Flo1p from S. cerevisiae [93] (Figure 2A), and N-LgFlo1p from S. pastorianus $[93,96]$. The atomic structures of N-Flo1p, N-Lg-Flo1p, N-Flo5p, N-Epa1p, N-Epa6p, and N-Epa9p are very similar (Figure 2). The main body of these proteins, i.e., the PA14/GLEYA domain, is a $\beta$-sandwich fold made up of two antiparallel $\beta$-sheets and an L-shaped region composed of the $\mathrm{N}$ and C-terminal regions (Figure 2A,B). $\mathrm{N}$-Flo1p and N-Flo5p contain a protruding $\beta$-sheet subdomain (the Flo1/Flo5 subdomain) that is located at one end of the protein, close to the carbohydrate binding site (Figure 2A1). In Lg-Flo1p and N-Epa1, this subdomain is replaced by a short highly flexible loop $2[95,96,99]$. The high flexible loop 3 (L3) is present in N-Flo1p and N-Lg-Flo1 (Figure 2A), as well as in N-Flo5p and N-Epa1 (Figure 2B); and has a significant effect on carbohydrate recognition. In contrast to N-Flo5p, this loop of N-Flo1p is closer to the binding side and lysine 194 (K194) from this loop interacts directly with the carbohydrate, which results in a three-fold increase in affinity for mannose compared to N-Flo5p. In Epa1p, the L3 loop establishes stronger stacking interactions with the ligands galactose and galactose-terminating glycans via tryptophan 194 (W194) (which corresponds to K194 in Flo1p) [92,95]. The carbohydrate-binding pocket of N-Lg-Flo1p is more enclosed than the one of N-Flo1p, which results in a 10 times higher affinity for the ligand mannose [93]. Mannose disaccharides and high-mannose glycans fit differently in the binding sites of N-Flo1p and N-Flo5p, which results in a different specificities and affinities. Longer mannose-containing oligosaccharides do not interact well with N-Lg-Flo1p due to the steric hindrance encountered in the binding site.

The binding site of these proteins contains a calcium ion that is directly involved in carbohydrate binding (Figure 2). In N-Flo1p and N-Flo5p, $\mathrm{Ca}^{2+}$ is coordinated on carbohydrate binding loop 1 by cis peptides aspartic acid 160 (D160) and D161 (indicated as "DcisD" motif) (Figure 2A1), and on CBL2 by the asparagine 224 (N224) side chain and the carbonyl groups of valine 226 (V226) and W228. These residues are strongly conserved in the Flo and Epa adhesin families due to their importance for metal binding (Figure 2A3,B3) [95,100].

Flocculation cell-cell binding in floc or biofilm formation is based on the lectin function of the PA14/GLEYA Flo type adhesins. N-Flo1p and N-Flo5p binds specifically to D-mannose glycans $[93,100,101]$. The affinity for these lectins is around 10 times larger than for monosaccharides [86]. N-Lg-Flo1p displays a broader specificity towards sugars $[93,96]$. Expressed PA14/GLEYA Flo type adhesins are the dominant cell wall proteins that stick out of the cell wall [102]. On flocculating cells, N-Flo1p interacts homophilically with the glycans of N-Flo1p of the interacting cell in the presence of $\mathrm{Ca}^{2+}$ [93]. In addition, it was demonstrated that glycan-glycan interactions with the involvement of $\mathrm{Ca}^{2+}$ interactions contribute to cell-cell interactions [93], and that these interactions are likely involved in the first intercellular contacts $[103,104]$. These results pointed to a two-step cell-cell adhesion mechanism, where in the first step the long, flexible glycans have a high probability of interaction when the cells are moving close to each other and initially serve to stabilize cell-cell interactions. In the next step, the non-reducing glycan end enter the binding pocket of the lectin and binds to the protein. In both steps, $\mathrm{Ca}^{2+}$ is crucial for the interactions. 

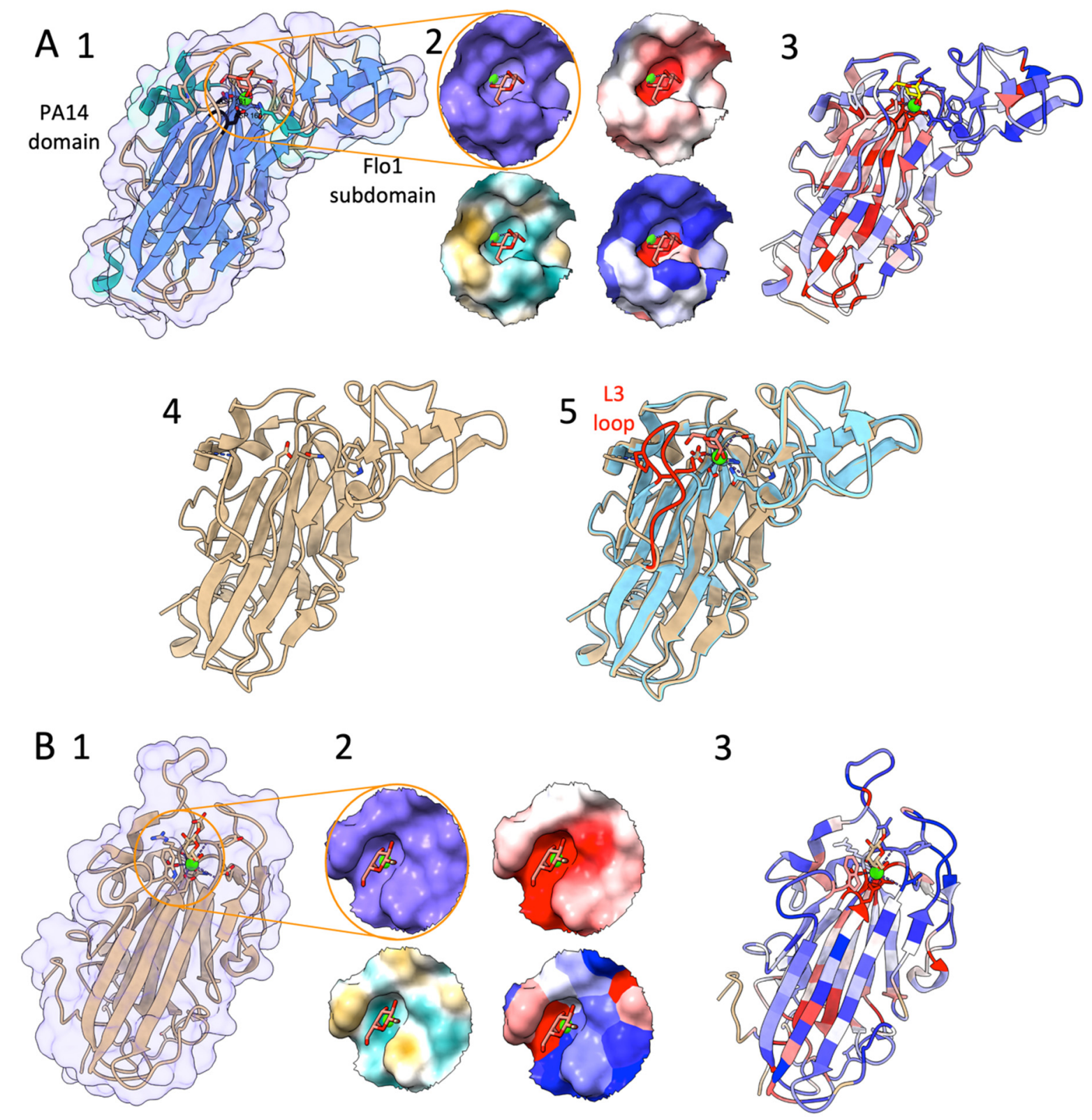

Figure 2. (A) 1. Structure of the N-terminal part of Flo1p (from PDB entry 4LHN). The "DcisD" motif is indicated in black by the residues Asp160 and Asp161. 2. Mannose-binding pocket surface zoomed view (top left), electrostatic surface (top right), hydrophobic (brown)-hydrophilic (cyan blue) surface (bottom left), conserved amino acids coloured surface (bottom right). 3. Colouring of the structure by sequence conservation; low to high conservation: from blue (-1.8) to white to red (1.9) (calculated via the ConSurf server $[105,106])$. 4. The apo structure (from PDB entry 4LHL). 5. Projection of the conformations containing the mannose ligand (blue coloured; PDB 4LHN) to the apo conformation (blown coloured; PDB 4LHN). Loop L3 (red coloured) closes upon mannose binding. (B) 1. Structure of N-Epa1p (from PDB entry 4A3X). 2. Galactose-binding pocket surface zoomed view (top left), electrostatic surface (top right), hydrophobic (brown)-hydrophilic (cyan blue) surface (bottom left), conserved amino acids coloured surface (bottom right). 3. Colouring of the structure by sequence conservation; low to high conservation: from blue $(-1.4)$ to white to red $(2.1)$ (calculated via the ConSurf server $[105,106])$.

It has been recently discovered that amyloid-like bonds can contribute to C. albicans cell-cell interactions via the Als adhesins [107-109]. These intercellular bonds show properties of cross- $\beta$ aggregation and in addition to the interactions that cluster the adhesins on yeast cell surfaces [110]. Data on Flo1p also support the formation of cross- $\beta$ bonds in trans between expressing cells [109]. The N-Flo1p domain is followed by a variable number of 
tandem repeats that are predicted to have anti-parallel $\beta$-sheet structure, and these repeats unfold under extension or shear force $[110,111]$.

\subsection{Flo11 Type Adhesin Structure}

The expression of the S. cerevisiae flocculation protein Flo11p can play a role in lifestyles involving complex multicellular structures such as flocs, filaments, mats, and flors a major role in these lifestyles, which give yeast selective advantages to survive in specific growth conditions $[40,64,70,112,113]$. When the carbon source (e.g., glucose) is depleted in the growth medium, FLO11 is expressed, which makes haploid S. cerevisiae cells adherent and allows them to invade into semi-solid agar medium; this is called "invasive growth" [44,66,114]. Diploid cells will adopt-when nitrogen becomes limiting in the growth medium - an elongated shape and form filaments that grow from the colony edge; this is called diploid pseudohyphal growth [44,115-117]. Flo11p can also be involved in the formation of mats, which are complex colony-like structures on a low-density $(0.3 \%)$ semi-solid medium (that resembles the environment of rotting fruit on which these yeasts can grow [118]) $[43,71,119,120]$; the formation of a flor (or velum), which is the airliquid interfacial cellular aggregation in the process of wine (beer) fermentations [121-124]. The adherence of cells to solid surfaces (such as glass, stainless steel, agar, and plastics) can also lead to the development of biofilms $[43,44,125,126]$. Cell-cell interaction (floc formation) can also be based on Flo11p interaction $[44,49,69,72,74,75,112,127]$. Many parameters influence the expression of FLO11 and flocculation activity such as the cell density, surface charge, and $\mathrm{pH}$, and environmental factors such as oxygen limitation, nutrient limitation, and cell surface hydrophobicity [127-130]. Flo11p mediates different processes in different strains $[38,66,72,74,112,127]$, and strain-specific differences in the level of flocculation result from significant sequence differences in the FLO11 alleles, and do not depend on quantitative differences in FLO11 expression or surface hydrophobicity [131].

The structures of two N-terminal adhesion domains of Flo11p have been solved by using X-ray crystallography (Table 1), i.e., the one of Flo11p from S. cerevisiae (N-ScFlo11p) [69] and recently the one from Komagataella pastoris (N-KpFlo11p) [99]. Despite a sequence identity between-N-KpFlo11p and N-ScFlo11p of only $32 \%$, their overall structures showed a high degree of similarity after superposition [99] (Figure 3B2). Three subdomains can be distinguished: a hydrophobic apical region, a $\beta$ sandwich of the fibronectin type III domain (FN3-like domain), and the neck subdomain (Figure 3A1,B1). The core domain is the $\beta$ sandwich that is formed by the antiparallel $\beta$ sheets I and II and was assigned to the class of fibronectin type-III-like domains (FNIII). This core domain showed the highest degree of similarity between the two N-Flo1p adhesin domains [99], and this domain is well conserved (Figure 3A3,B3). The FNIII fold forms a large family within the immunoglobulin (Ig) superfamily that includes cell adhesion proteins, cell surface hormone and cytokine receptors, chaperones, and carbohydrate-binding domains [132]. The FNIII-like domain subtype shows a seven-stranded strand-switched type, where sheet I consist of three strands and sheet II of four strands (Figure 3A1,B1). The FNIII fold differs from other Ig folds by its fourth strand, which is part of the second, but not the first, $\beta$ sheet [69]. 
A 1

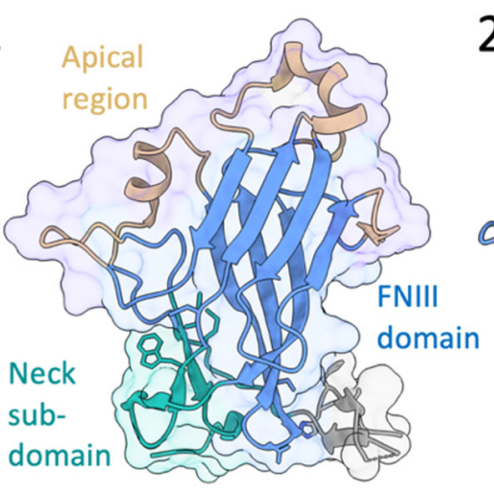

2

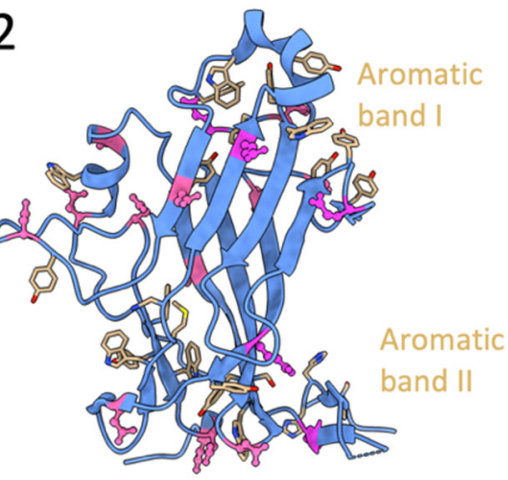

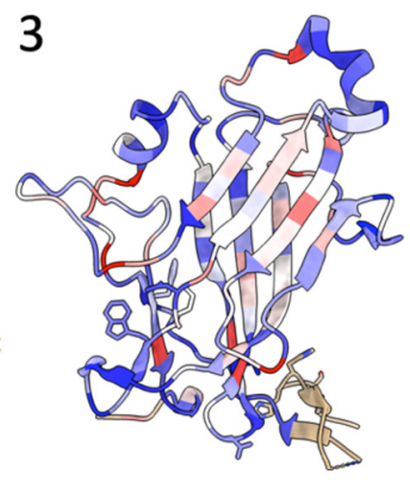

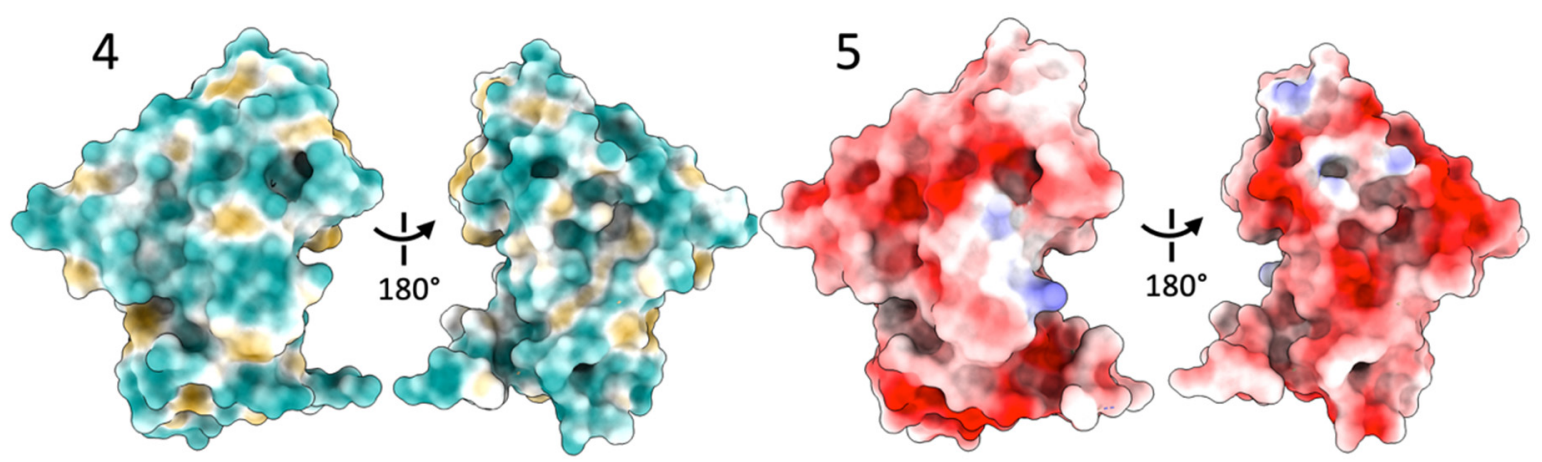

B 1

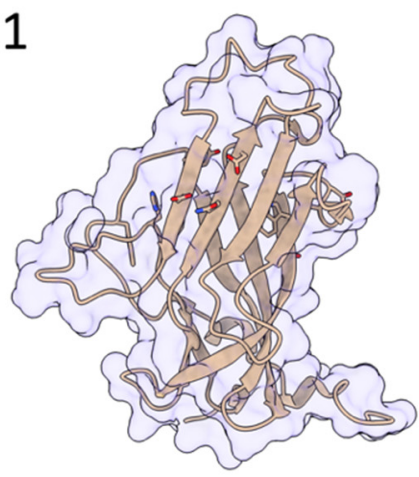

2

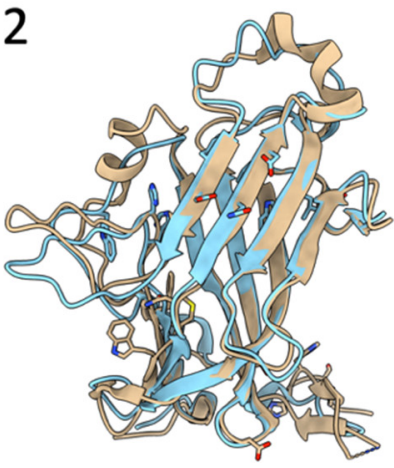

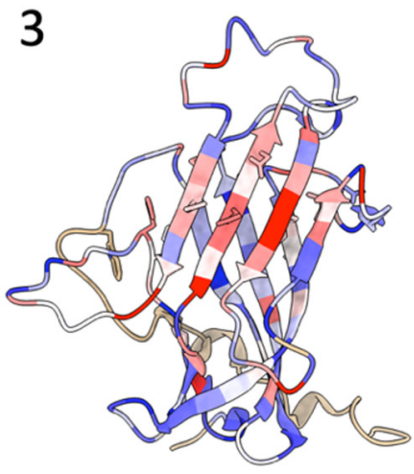

Figure 3. (A) 1. Structure of the N-terminal part of S. cerevisiae Flo11p (N-ScFlo11p) (from PDB entry 4UYR). 2. Indication of the aromatic residues Trp and Tyr (in brown), and the acid residues Asp (in pink) and Glu (in magenta). 3. Colouring of the structure by sequence conservation; low to high conservation: from blue (-1.6) to white to red (1.8) (calculated via the ConSurf server [105,106]). 4. Hydrophobic (brown)-hydrophilic (cyan blue) surface (PDB 4UYT), and 5. electrostatic surface (PDB 4UYR). (B) 1. Structure of the N-terminal part of K. pastoris Flo11p (N-KpFlo11p) (from PDB entry 5FV5). 2. Matching the conformation of N-KpFlo11p (PDB 5FV5) (blue) to the one of N-ScFlo11p (PDB 4UYR) (brown). 3. Colouring of the structure by sequence conservation; low to high conservation: from blue $(-1.6)$ to white to red (2.3) (calculated via the ConSurf server [105,106]).

The FNIII-like domain contains by two surface aromatic bands at the apical region and the neck subdomain (Figure 3A2) [69,99]. These aromatic bands are well conserved (Figure 3A3,B3). Hydrophobic interactions between these aromatic surface features, whose propensity for interaction is ameliorated in a $\mathrm{pH}$-dependent manner by co-distributed acidic residues (Figure 3A2,A5), mostly determine the homophilic recognition by the Flo11 adhesin domains (Figure 3A4). Even though these hydrophobic interactions are less specific than the lectin-carbohydrate interactions of the other Flo adhesins, they can excel by their long range of attractive forces. Single-cell force spectroscopy showed that these N-Flo11p domains confer remarkably strong adhesion forces between cells, leading to efficient cell aggregation 
and biofilm formation [99]. The co-alignment of Flo11 fibres from opposing yeast cells could be observed by scanning electron microscopy, indicating that Flo11p acts as a spacer-like, $\mathrm{pH}$-sensitive adhesin that resembles a membrane-tethered hydrophobin [69].

As for Flo1p, data on Flo11p also support the involvement of this adhesin in the formation of cross- $\beta$ bonds in trans between cells [109]. There are potential amyloid core sequences in the post N-terminal domain and C-terminal regions [133]. As for Flo1 and Als adhesins, the ability to form cellular aggregates can be induced by shear force.

\section{Yeasts Expressing Flo Proteins Involved in Human Infections}

\subsection{Pathogenic Candida Species}

\subsubsection{Candida glabrata}

C. glabrata strains were originally classified in the genus Cryptococcus and next Torulopsis due to its lack of filaments formation, and was in 1978 classified in the genus Candida due to it human pathogenicity $[134,135]$. C. glabrata is more closely related to S. cerevisiae than to C. albicans [59,134,136-139]. It is a major opportunistic human fungal pathogen that has become the second most frequent cause of Candida infections [134,140-143]. It is a nondimorphic yeast that exist as small blastoconidia under all environmental conditions as a pathogen (it does not form pseudohyphae at temperatures above $37^{\circ} \mathrm{C}$ ) [134]. C. glabrata can cause superficial and life-threatening dissemination infections reaching high mortalities of around 40\% [144]. Immunocompromised, cancer and diabetic patients are particularly susceptible [18,54,142,145-147]. C. glabrata shows a high antifungal resistance against azole antifungal agents [24]. It can adhere to host tissues cells as well as to abiotic surfaces and colonize them as biofilms, which further increase the antifungal resistance and evade the host immune defences [144,148-152]. Biofilms on medical devices (e.g., indwelling catheters or prosthetic heart valves) can result in failure of the device and the cells in the biofilm can initiate future continuing infections [153-157].

C. glabrata can express many adhesin-encoding genes and genome comparisons with closely related species, including $S$. cerevisiae, revealed a correlation between the number of adhesin-encoding genes and pathogenicity [152,158,159]. The adhesins from the Epa ("epithelial adhesion") family are up-to-now the best characterised adhesins from C. glabrata; the structures of N-Epa1p [92,95,98], N-Epa6p [98], and N-Epa9p [98] have been solved recently [86]. These N-terminal Epa adhesin domains contain a GLEYA domain with lectin activity, which is $\mathrm{Ca}^{2+}$ dependent, and recognizes a wide variety of glycans with terminal galactose residues linked via $\alpha$ - or $\beta$-glycosidic bonds to a secondary sugar for conferring epithelial cell adhesion $[53,98]$ C. glabrata can also express Epa23p, which can be classified as a PA14/GLEYA-type flocculin since the adhesin architecture is composed of a PA14 domain and 5 flocculin repeat domains (Table 2). In the other members of the Epa family, such as Epa1p, Epa2p, Epa3p, Epa6p and Epa 9p, only the GLEYA domain is present in the N-terminal region of the adhesin. 
Table 2. Examples of fungi expression Flo adhesins of the Flo-type class and adhesin architecture with indication of pathogenic fungi (From Pfam and InterPro database).

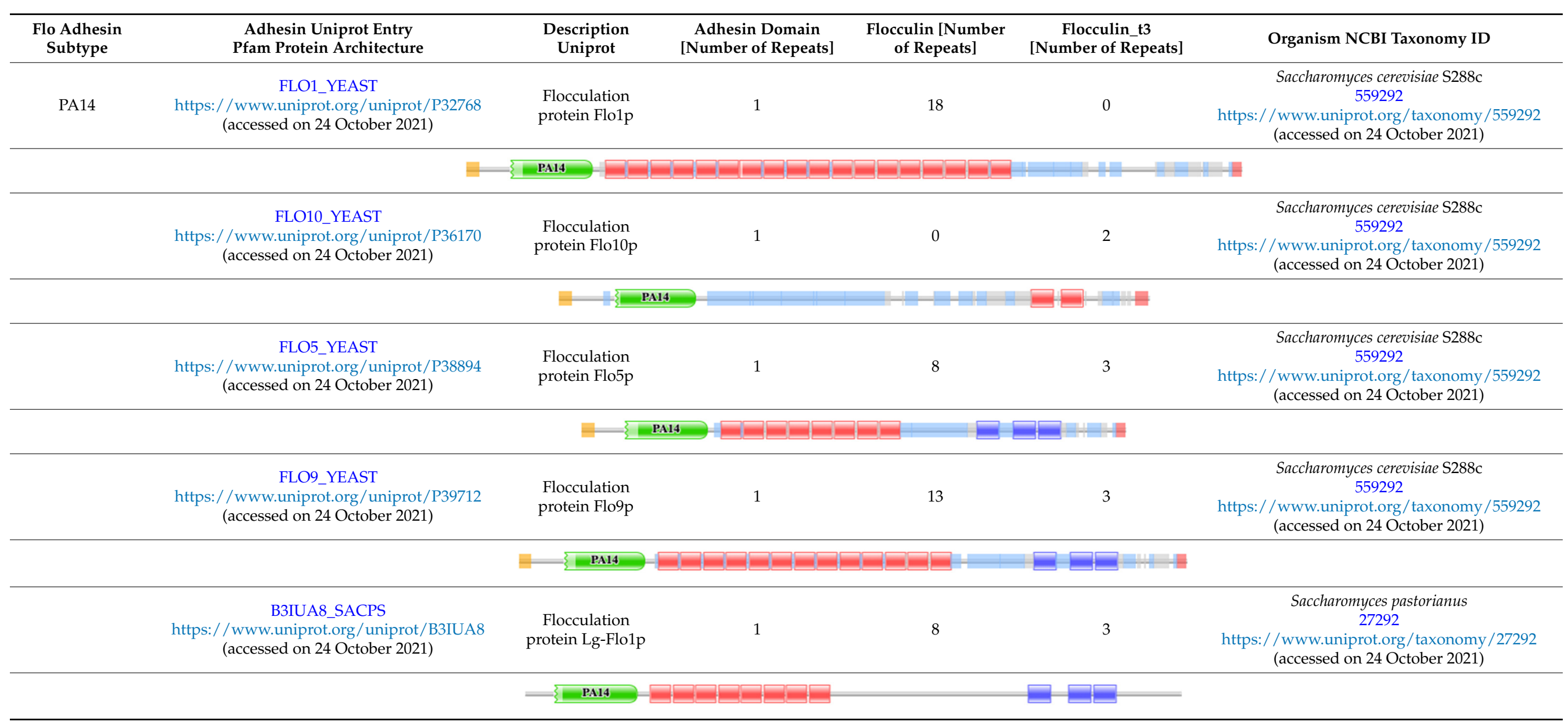


Table 2. Cont.

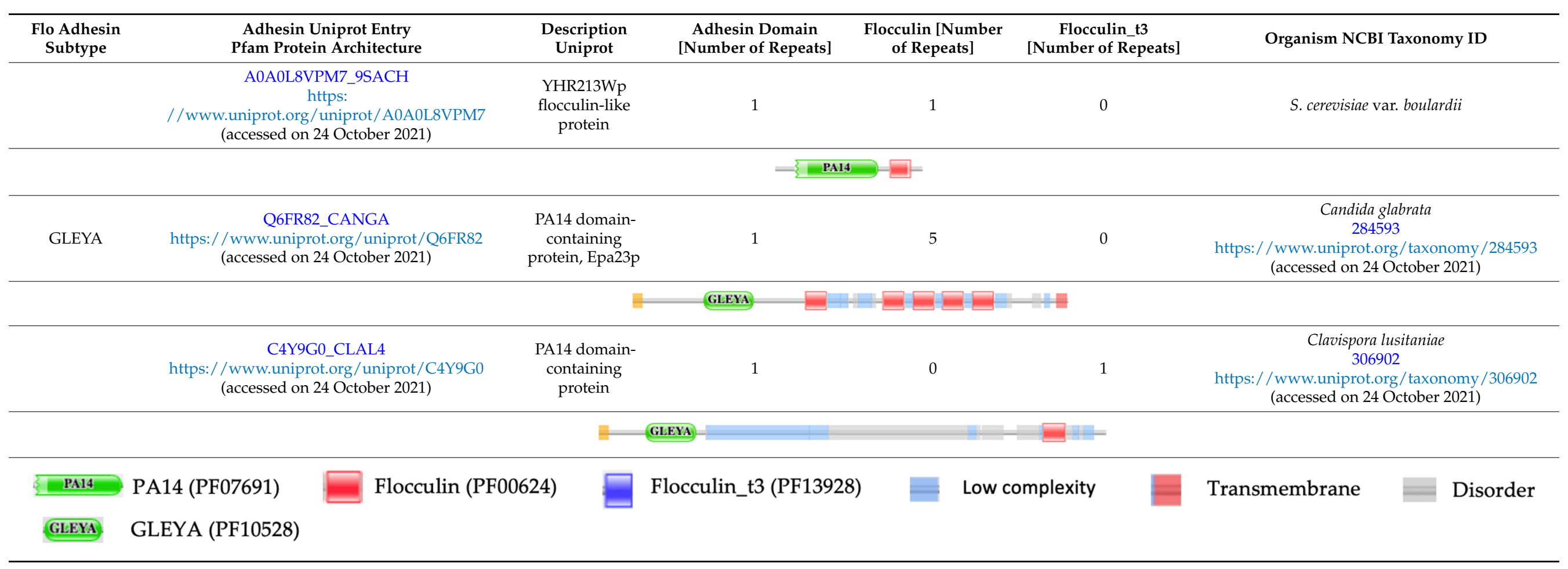


Epa adhesins mediate adherence to human epithelial and endothelial cells by recognizing glycans containing terminal galactose residues [47] and show the highest affinity for the Thomsen-Friedenreich (T or TF) antigen (Gal $\beta-1,3-G a l N A c)$, which likely mediates N-Epa$\mathrm{p}$ adherence to highly glycosylated proteins such as mucins [95]. It was also demonstrated that N-Epa1p binds to fibronectin from human plasma [53,160] as well as to mucin [53]. Many other human receptors of Epa adhesins have been predicted by constructing their lectin-glycan interaction (LGI) network, which is an approach that is based on linking glycan array screening results of the adhesins to a human glycoprotein database [53]. The Epa1p, Epa6p and Epa7p LGI network revealed that a large set of receptors are present in body fluids or displayed on human cells in various body systems; receptors included several mucins (urogetinal, respiratory, exocrine and digestive system), $\mathrm{k}$-casein (exocrine system), epidermal growth factor receptor (EGFR, urogenital system), cadherin-5 (CD144, urogenital system), lactotransferrin (LTF, exocrine system), serotransferrin (TF, hemic system), immunoglobulin M (IgM, hemic system), tumor necrosis factor alpha (TNF$\alpha$, hemic system), P-selectin glycoprotein ligand (PSGL-1, hemic system), leukosialin (CD43, respiratory system), receptor-type tyrosine-protein phosphatase C (CD45, hemic system), von Willebrand factor (vWF, hemic system), $\beta$-secretase 1 (BACE1, urogenital system), lysosome-associated membrane glycoprotein $\frac{1}{2}$ (LAMP1/2, hemic system), plasminogen (PLG, urogenital system).

\subsubsection{Candida lusitaniae (Clavispora lusitaniae)}

Clavispora lusitaniae, which is the teleomorph of C. lusitaniae, is an environmental saprophytic yeast that belongs to the CTG clade of Candida [161] (Table 2). C. lusitaniae can behave rarely as an opportunistic pathogen in humans, and its most common risk factors include immunocompromised patients often with an underlying malignancy [162]. However, nosocomial acquisition secondary to an indwelling urinary catheter [163], and catheterassociated C. Iusitaniae candidemia [164] have also been reported. Amphotericin B resistance among isolates of C. lusitaniae has distinguished it among Candida species [165]. The adhesion of C. lusitaniae to abiotic surfaces (polystyrene and steel surfaces) has been demonstrated [166].

C. lusitaniae strains can express adhesins that contain an N-terminal GLEYA domain and a flocculin repeat domain (Table 2), as well as adhesins that contain one or more N-terminal Flo11 domains and none or multiple flocculin type 3 repeats (Table 2). It is expected that multiple Flo11 adhesin domains will increase the interaction strength. Currently, these adhesins have not been characterized at the molecular nor cellular level, and very little is known about their role in the adhesion process. Recently, it was shown that when the Flo11 domain from C. Lusitaniae was expressed in an S. cerevisiae expression system, adhesive growth was conferred to $S$. cerevisiae [99].

\subsubsection{Candida parapsilosis and Candida tropicalis}

C. parapsilosis can be isolated from domestic animals, insects, the soil and marine environments $[167,168]$. C. parapsilosis (sensu lato) was reclassified as a fungal complex formed by three genotypically distinguishable species, i.e., C. parapsilosis (sensu stricto), C. orthopsilosis and C. metapsilosis [169]. The opportunistic yeast C. parapsilosis is responsible for $20-30 \%$ of all fungal infections, particularly those related to the usage of catheter and other medical devices, and it became the second most frequently opportunistic yeast isolated from bloodstream infections in different clinical settings around the world, especially in Latin America and Asia [170-182]. C. parapsilosis is associated with a pronounced capacity to adhere to plastic surfaces and several other implanted devices, and consequently to the development of candidaemia related to catheters $[153,183]$. The adhesion of $C$. parapsilosis to polystyrene and steel surfaces has been demonstrated [166]. Pseudohyphal formation was also positively correlated with adhesion of C. parapsilosis complex strains abiotic surfaces, such as polystyrene and glass [183], and acrylic surfaces [184]. Cell surface hydrophobicity can have a significant effect on the initial events leading to adherence [185] and it has been 
shown that it can make C. albicans and C. glabrata more virulent [186]. An elevated cell hydrophobicity has been recorded for clinical C. parapsilosis complex strains $[183,187]$.

C. tropicalis is a diploid dimorphic yeast, which lives either as budding cells or as a pseudomycelium; in rare cases it can form true hyphae (as for C. albicans) $[188,189]$. It is taxonomically close to C. albicans and shares many pathogenic traits [190]. It is one of the three most commonly isolated non-albicans Candida species [168,191-197]. It is mainly isolated from blood and urine samples [192,198,199]. It is also often detected in patients requiring prolonged catherization, receiving broad-spectrum antibiotics and with cancer [195,198,200-202]. In addition, C. tropicalis displayed a higher potential for dissemination in neurotropenic individuals compared to C. albicans and other non-albicans Candida species [195].

A bioinformatic search of pathogen-specific gene families of Candida species (C. parapsilosis, C. tropicalis, L. elongispora, C. guilliemondii) revealed several genes for putative cell wall adhesins-like proteins such as Als-like adhesins, Hyr/Iff proteins, and Pga30-like proteins (predicted glycosylphosphatidyl-inositol-anchored protein 30) [203,204]. Genome data also allowed to identify five genes homologous to the $A L S$ (agglutinin-like sequence) gene family of C. albicans in C. parapsilosis, three in C. orthopsilosis and four in C. metapsilosis [205]. Considerable variation was noted in relative gene expression for isolates of the same species. It was shown that the gene CPALS7 showed a positive correlation with adhesion to extracellular matrix proteins under fluid shear stress [206]. Site-specific deletion of CPALS7 reduced the adhesion of $C$. parapsilosis to buccal epithelial cells and significantly attenuated virulence in a murine model of urinary tract infection [207].

One C. parapsilosis Flo11-type adhesin and one in C. tropicalis were found in the Pfam database (Table 3). They both have the same protein architectures since besides the Flo11 domain they contain also two flocculin type 3 repeats. Their molecular characterization, virulence, and role of these adhesins in the adhesion process is currently not yet known and needs further investigation. These Flo11-type adhesions could play a role in biofilm formation since it was shown that C. parapsilosis and C. tropicalis displayed a high biofilm formation ability as well as a high adhesion ability [208]. 
Table 3. Examples of fungi expression Flo adhesins of the Flo11-type class and adhesin architecture with indication of pathogenic fungi (Pfam database, InterPro database).

\begin{tabular}{|c|c|c|c|c|c|c|}
\hline $\begin{array}{l}\text { Adhesin Uniprot Entry } \\
\text { Pfam Protein Architecture }\end{array}$ & Description Uniprot & $\begin{array}{l}\text { Flo11 Domain } \\
\text { [Number of } \\
\text { Repeats] }\end{array}$ & $\begin{array}{l}\text { Flocculin } \\
\text { [Number of } \\
\text { Repeats] }\end{array}$ & $\begin{array}{l}\text { Flocculin_t3 } \\
\text { [Number of } \\
\text { Repeats] }\end{array}$ & $\begin{array}{c}\text { Other Adhesin } \\
\text { Domain [Number] } \\
\text { [Pfam ID] }\end{array}$ & Organism NCBI Taxonomy ID \\
\hline $\begin{array}{l}\text { A0A1L0DFL1_9ASCO https: } \\
\text { //www.uniprot.org/uniprot/A0A1L0DFL1 } \\
\text { (accessed on 24 October 2021) }\end{array}$ & CIC11C00000002180 & 1 & 0 & 0 & - & $\begin{array}{c}\text { Candida intermedia } \\
45354 \\
\text { https:/ / www.uniprot.org/taxonomy /45354 } \\
\text { (accessed on 24 October 2021) }\end{array}$ \\
\hline \multicolumn{7}{|c|}{ Floll } \\
\hline $\begin{array}{c}\text { A0A367Y9C2_9ASCO https: } \\
\text { // www.uniprot.org/uniprot/A0A367Y9C2 } \\
\text { (accessed on 24 October 2021) }\end{array}$ & $\begin{array}{l}\text { Cell wall protein } \\
\text { RTB1 }\end{array}$ & 1 & 0 & 0 & - & $\begin{array}{c}\text { Candida viswanathii } \\
5486 \text { https:/ / www.uniprot.org/taxonomy/5486 } \\
\text { (accessed on } 24 \text { October 2021) }\end{array}$ \\
\hline \multicolumn{7}{|c|}{$=11\{$ Flo11 } \\
\hline $\begin{array}{c}\text { C4YAK2_CLAL4 } \\
\text { https:/ / www.uniprot.org/uniprot/C4YAK2 } \\
\text { (accessed on 24 October 2021) }\end{array}$ & $\begin{array}{c}\text { Flo11 } \\
\text { domain-containing } \\
\text { protein }\end{array}$ & 1 & 0 & 0 & - & $\begin{array}{c}\text { Clavispora lusitaniae } \\
306902 \\
\text { https: / / www.uniprot.org/taxonomy/306902 } \\
\text { (accessed on 24 October 2021) }\end{array}$ \\
\hline \multicolumn{7}{|c|}{ Floll } \\
\hline \multicolumn{7}{|c|}{ Floll } \\
\hline $\begin{array}{c}\text { Q6BXK5_DEBHA } \\
\text { https:/ / www.uniprot.org/uniprot/Q6BXK5 } \\
\text { (accessed on 24 October 2021) }\end{array}$ & DEHA2B02222p & 1 & 0 & 0 & - & $\begin{array}{c}\text { Debaryomyces hansenii } \\
284592 \\
\text { https: / / www.uniprot.org/taxonomy / } 284592 \\
\text { (accessed on 24 October 2021) }\end{array}$ \\
\hline \multicolumn{7}{|c|}{ Floll } \\
\hline $\begin{array}{c}\text { A5DNK5_PICGU } \\
\text { https:/ / www.uniprot.org/uniprot/A5DNK5 } \\
\text { (accessed on 24 October 2021) }\end{array}$ & $\begin{array}{l}\text { Flo11 } \\
\text { domain-containing } \\
\text { protein }\end{array}$ & 1 & 0 & 0 & - & $\begin{array}{c}\text { Meyerozyma guilliermondii } \\
294746 \\
\text { https: / / www.uniprot.org/taxonomy / } 294746 \\
\text { (accessed on 24 October 2021) }\end{array}$ \\
\hline \multicolumn{7}{|c|}{ Floll } \\
\hline
\end{tabular}


Table 3. Cont.

\begin{tabular}{|c|c|c|c|c|c|c|}
\hline $\begin{array}{l}\text { Adhesin Uniprot Entry } \\
\text { Pfam Protein Architecture }\end{array}$ & Description Uniprot & $\begin{array}{l}\text { Flo11 Domain } \\
\text { [Number of } \\
\text { Repeats] }\end{array}$ & $\begin{array}{l}\text { Flocculin } \\
\text { [Number of } \\
\text { Repeats] }\end{array}$ & $\begin{array}{l}\text { Flocculin_t3 } \\
\text { [Number of } \\
\text { Repeats] }\end{array}$ & $\begin{array}{c}\text { Other Adhesin } \\
\text { Domain [Number] } \\
\text { [Pfam ID] }\end{array}$ & Organism NCBI Taxonomy ID \\
\hline $\begin{array}{c}\text { A0A2U9R2I2_PICKU https: } \\
\text { / / www.uniprot.org/ uniprot/A0A2U9R2I2 } \\
\text { (accessed on 24 October 2021) }\end{array}$ & $\begin{array}{l}\text { Flo11 } \\
\text { domain-containing } \\
\text { protein }\end{array}$ & 1 & 0 & 0 & - & $\begin{array}{c}\text { Pichia kudriavzevii } \\
4909 \text { https: / / www.uniprot.org/taxonomy / } 4909 \\
\text { (accessed on 24 October 2021) }\end{array}$ \\
\hline \multicolumn{7}{|c|}{$=$ Floll } \\
\hline $\begin{array}{l}\text { FLO11_YEAST } \\
\text { https:// /www.uniprot.org/uniprot/P08640 } \\
\text { (accessed on 24 October 2021) }\end{array}$ & $\begin{array}{l}\text { Flocculation protein } \\
\text { Flo11p }\end{array}$ & 1 & 0 & 0 & - & $\begin{array}{l}\text { Saccharomyces cerevisiae } \\
559292 \\
\text { https://www.uniprot.org/taxonomy/559292 } \\
\text { (accessed on 24 October 2021) }\end{array}$ \\
\hline \multicolumn{7}{|c|}{ Flo11 } \\
\hline $\begin{array}{c}\text { A0A1L0BS11_9ASCO https: } \\
\text { //www.uniprot.org/uniprot/A0A1L0BS11 } \\
\text { (accessed on 24 October 2021) }\end{array}$ & CIC11C00000003144 & 6 & 0 & 5 & - & $\begin{array}{l}\text { Candida intermedia } \\
45354 \\
\text { https://www.uniprot.org/taxonomy/45354 } \\
\text { (accessed on 24 October 2021) }\end{array}$ \\
\hline \multicolumn{7}{|c|}{ Flo11 } \\
\hline $\begin{array}{c}\text { G8B9T8_CANPC } \\
\text { https:/ / www.uniprot.org/uniprot/G8B9T8 } \\
\text { (accessed on 24 October 2021) }\end{array}$ & $\begin{array}{l}\text { Flo11 } \\
\text { domain-containing } \\
\text { protein }\end{array}$ & 1 & 0 & 2 & - & $\begin{array}{c}\text { Candida parapsilosis } \\
578454 \\
\text { https: / / www.uniprot.org/taxonomy /578454 } \\
\text { (accessed on 24 October 2021) }\end{array}$ \\
\hline \multicolumn{7}{|c|}{ Floll $\}$} \\
\hline $\begin{array}{c}\text { C5M338_CANTT } \\
\text { https:/ / www.uniprot.org/uniprot/C5M338 } \\
\text { (accessed on 24 October 2021) }\end{array}$ & $\begin{array}{l}\text { Flo11 } \\
\text { domain-containing } \\
\text { protein }\end{array}$ & 1 & 0 & 2 & - & $\begin{array}{c}\text { Candida tropicalis } \\
294747 \\
\text { https: / / www.uniprot.org/taxonomy/294747 } \\
\text { (accessed on 24 October 2021) }\end{array}$ \\
\hline
\end{tabular}


Table 3. Cont

\begin{tabular}{|c|c|c|c|c|c|c|}
\hline $\begin{array}{l}\text { Adhesin Uniprot Entry } \\
\text { Pfam Protein Architecture }\end{array}$ & Description Uniprot & $\begin{array}{l}\text { Flo11 Domain } \\
\text { [Number of } \\
\text { Repeats] }\end{array}$ & $\begin{array}{l}\text { Flocculin } \\
\text { [Number of } \\
\text { Repeats] }\end{array}$ & $\begin{array}{c}\text { Flocculin_t3 } \\
\text { [Number of } \\
\text { Repeats] }\end{array}$ & $\begin{array}{c}\text { Other Adhesin } \\
\text { Domain [Number] } \\
\text { [Pfam ID] }\end{array}$ & Organism NCBI Taxonomy ID \\
\hline $\begin{array}{c}\text { C4XZ24_CLAL4 } \\
\text { https: / / www.uniprot.org/uniprot/C4XZ24 } \\
\text { (accessed on 24 October 2021) }\end{array}$ & $\begin{array}{l}\text { Uncharacterized } \\
\text { protein }\end{array}$ & 3 & 0 & 4 & - & $\begin{array}{c}\text { Clavispora lusitaniae } \\
306902 \\
\text { https:/ / www.uniprot.org/taxonomy/306902 } \\
\text { (accessed on 24 October 2021) }\end{array}$ \\
\hline
\end{tabular}

Floll Floll Floll

\begin{tabular}{|c|c|c|c|c|c|c|}
\hline $\begin{array}{c}\text { A0A1E4RJE3_9ASCO https: } \\
\text { // www.uniprot.org/uniprot/A0A1E4RJE3 } \\
\text { (accessed on 24 October 2021) }\end{array}$ & $\begin{array}{c}\text { Flo11 } \\
\text { domain-containing } \\
\text { protein }\end{array}$ & 1 & 0 & 1 & - & $\begin{array}{c}\text { Hyphopichia burtonii } \\
984485 \\
\text { https:/ / www.uniprot.org/taxonomy/984485 } \\
\text { (accessed on 24 October 2021) }\end{array}$ \\
\hline \multicolumn{7}{|c|}{ Floll } \\
\hline $\begin{array}{c}\text { A5E4F6_LODEL } \\
\text { https:/ / www.uniprot.org/uniprot/A5E4F6 } \\
\text { (accessed on 24 October 2021) }\end{array}$ & $\begin{array}{c}\text { Flo11 } \\
\text { domain-containing } \\
\text { protein }\end{array}$ & 1 & 0 & 2 & - & $\begin{array}{c}\text { Lodderomyces elongisporus } \\
379508 \text { https://www.uniprot.org/taxonomy/37 } \\
9508 \text { (accessed on } 24 \text { October 2021) }\end{array}$ \\
\hline \multicolumn{7}{|c|}{ Flo11 $\xi=$} \\
\hline $\begin{array}{c}\text { A5DGW9_PICGU } \\
\text { https:/ / www.uniprot.org/uniprot/A5DGW9 } \\
\text { (accessed on 24 October 2021) }\end{array}$ & $\begin{array}{c}\text { Flo11 } \\
\text { domain-containing } \\
\text { protein }\end{array}$ & 1 & 0 & 1 & - & $\begin{array}{c}\text { Meyerozyma guilliermondii } \\
294746 \\
\text { https: / / www.uniprot.org/taxonomy/294746 } \\
\text { (accessed on 24 October 2021) }\end{array}$ \\
\hline \multicolumn{7}{|c|}{ Floll } \\
\hline $\begin{array}{c}\text { A0A2H1A319_CANAR https: } \\
\text { / / www.uniprot.org/uniprot/A0A2H1A319 } \\
\text { (accessed on 24 October 2021) }\end{array}$ & $\begin{array}{c}\text { Flo11 } \\
\text { domain-containing } \\
\text { protein }\end{array}$ & 1 & 0 & 0 & $\begin{array}{c}\text { Collagen }{ }^{1} \\
1 \\
\text { PF01391 }\end{array}$ & $\begin{array}{c}\text { Candida auris } \\
498019 \\
\text { https: / / www.uniprot.org/taxonomy / } 498019 \\
\text { (accessed on 24 October 2021) }\end{array}$ \\
\hline \multicolumn{7}{|c|}{ Floll } \\
\hline $\begin{array}{l}\text { A0A2V1B0R1_9ASCO https: } \\
\text { //www.uniprot.org/uniprot/A0A2V1B0R1 } \\
\text { (accessed on 24 October 2021) }\end{array}$ & $\begin{array}{l}\text { Flo11 } \\
\text { domain-containing } \\
\text { protein }\end{array}$ & 1 & 0 & 0 & $\begin{array}{c}\text { Collagen }^{1} \\
1 \\
\text { PF01391 }\end{array}$ & $\begin{array}{c}\text { Candida haemuloni } \\
45357 \\
\text { https: / / www.uniprot.org/taxonomy/45357 } \\
\text { (accessed on 24 October 2021) }\end{array}$ \\
\hline
\end{tabular}


Table 3. Cont.

\begin{tabular}{|c|c|c|c|c|c|c|}
\hline $\begin{array}{l}\text { Adhesin Uniprot Entry } \\
\text { Pfam Protein Architecture }\end{array}$ & Description Uniprot & $\begin{array}{l}\text { Flo11 Domain } \\
\text { [Number of } \\
\text { Repeats] }\end{array}$ & $\begin{array}{l}\text { Flocculin } \\
\text { [Number of } \\
\text { Repeats] }\end{array}$ & $\begin{array}{l}\text { Flocculin_t3 } \\
\text { [Number of } \\
\text { Repeats] }\end{array}$ & $\begin{array}{c}\text { Other Adhesin } \\
\text { Domain [Number] } \\
\text { [Pfam ID] }\end{array}$ & Organism NCBI Taxonomy ID \\
\hline $\begin{array}{l}\text { A0A4T0 } \times \text { 4H6_9ASCO https: } \\
/ / \text { www.uniprot.org/uniprot/A0A4T0X4H6 } \\
\text { (accessed on } 24 \text { October 2021) }\end{array}$ & $\begin{array}{l}\text { Uncharacterized } \\
\text { protein }\end{array}$ & 1 & 0 & 0 & $\begin{array}{l}\text { CMB_1 }^{2} \\
3 \\
\text { PF00734 }\end{array}$ & $\begin{array}{c}\text { Candida inconspicua } \\
52247 \\
\text { https:/ / www.uniprot.org/taxonomy /52247 } \\
\text { (accessed on 24 October 2021) }\end{array}$ \\
\hline \multicolumn{7}{|c|}{ Floll $=\square$} \\
\hline $\begin{array}{c}\text { A5E3T4_LODEL } \\
\text { https: / / www.uniprot.org/uniprot/A5E3T4 } \\
\text { (accessed on 24 October 2021) }\end{array}$ & $\begin{array}{l}\text { Flo11 } \\
\text { domain-containing } \\
\text { protein }\end{array}$ & 1 & 0 & 0 & $\begin{array}{c}\text { Candida_ALS }{ }^{3} \\
20 \\
\text { PF05792 }\end{array}$ & $\begin{array}{c}\text { Lodderomyces elongisporus } \\
379508 \\
\text { https: / / www.uniprot.org/taxonomy/379508 } \\
\text { (accessed on 24 October 2021) }\end{array}$ \\
\hline \multicolumn{7}{|c|}{ E- Floll } \\
\hline $\begin{array}{l}\text { A0A099NZM2_PICKU https: } \\
\text { / / www.uniprot.org/uniprot/A0A099NZM2 } \\
\text { (accessed on 24 October 2021) }\end{array}$ & $\begin{array}{l}\text { Flocculation protein } \\
\text { Flo11p }\end{array}$ & 1 & 0 & 0 & $\begin{array}{c}\mathrm{CMB}_{-} 1^{2} \\
2 \\
\text { PF00734 }\end{array}$ & $\begin{array}{c}\text { Pichia kudriavzevii } \\
4909 \text { https: / / www.uniprot.org/taxonomy / } 4909 \\
\text { (accessed on 24 October 2021) }\end{array}$ \\
\hline \multicolumn{7}{|c|}{ Floll $=$} \\
\hline $\begin{array}{l}\text { A0A1E3NVU9_WICAA https: } \\
/ / \text { www.uniprot.org/uniprot/A0A1E3NVU9 } \\
\text { (accessed on } 24 \text { October 2021) }\end{array}$ & $\begin{array}{l}\text { Uncharacterized } \\
\text { protein }\end{array}$ & 1 & 0 & 0 & $\begin{array}{l}\text { CMB_1 } \\
2 \\
\text { PF00734 }\end{array}$ & $\begin{array}{c}\text { Wickerhamomyces anomalus } \\
683960 \\
\text { https: / / www.uniprot.org/taxonomy / } 683960 \\
\text { (accessed on 24 October 2021) }\end{array}$ \\
\hline \multicolumn{7}{|c|}{ Floll $=\square=$} \\
\hline Flo11 & Flo11 (PF10182) & Flocculin_t3 (PF13928) & 3) $\mathrm{Lc}$ & Low complexity & Transmembrane & Disorder \\
\hline$\square$ & Collagen (PF01391) & CMB_1 (PF00734) & $\square \mathrm{C}^{2}$ & Candida_ALS (PF05792) & & \\
\hline
\end{tabular}

${ }^{1}$ Collagen: Collagen triple helix repeat; ${ }^{2}$ CMB_1: Carbohydrate-binding module, fungal cellulose binding domain; ${ }^{3}$ Candida_ALS: Candida agglutinin-like (ALS). 


\subsubsection{Candida auris}

C. auris was first described in 2009 in Japan [209]. It is an emerging multidrugresistant fungal pathogen of the Candida/Clavispora clade that is becoming a worldwide public health treat over the past decade due severe invasive infections with high mortality rates [210-214]. Due to its capability of nosocomial transmission and forming adherent biofilms on clinically important substrates, a high number of related hospital outbreaks have been reported worldwide [215]. Recently, genomic analyses revealed that early contemporaneously detected cases of $C$. auris were geographically stratified into four major clades [216]. While Clades I, III, and IV are responsible for ongoing outbreaks of invasive and multidrug-resistant infections, Clade II, also termed the East Asian clade, consists primarily of cases of ear infection, is often susceptible to all antifungal drugs, and has not been associated with outbreaks.

The virulence factors associated with $C$. auris infections are not yet completely understood [217]. C. auris pathogenic attributes that have been identified include pathways required for cell wall modelling and nutrient acquisition, two-component systems, the production of hydrolytic enzymes such as phospholipases and proteinases that are likely involved in the adherence and invasion of host cells and tissues during infections, other mechanisms of tissue invasion, and immune evasion and multidrug efflux systems [217-223]. Other adhesin genes identified in C. auris include orthologs of C. albicans $A L S$ genes such as ALS3 and ALS4, while Als3p was identified on C. auris cell surface by anti-C. albicans Als3p antibodies [218,224]. Subtelomeric dynamics and the conservation of cell surface proteins (including Hyr/Iff-like and novel candidate cell wall proteins, and an Als-like adhesin) in the clades responsible for global outbreaks causing invasive infections suggest an explanation for the different phenotypes observed between clades [216].

C. auris can form biofilms on several indwelling medical devices, such as catheters, central/peripheral line tips, and neurological shunts $[223,225,226]$. Biofilm formation protects $C$. auris from triazoles, polyenes, and echinocandins antifungal drugs $[227,228]$. It was shown. That seven adhesin genes (IFF4, CSA1, PGA26, PGA52, PGA7, HYR3 and ALS5) were upregulated during biofilm formation [227]. The GPI-anchored cell wall genes (IFF4, CSA1, $P G A 26, P G A 52)$ were upregulated at all time points during in vitro biofilm formation, while HYR3 and ALS5 were only upregulated in mature biofilms [227,229]. Additionally, key role genes involved in biofilm extracellular matrix formation, such as encoding efflux pumps (MDR and CDR homologs) and glucan-modifying enzymes, were upregulated during biofilm formation, and their inhibition improved the susceptibility of biofilms to fluconazole [228-230].

We found one Flo11 type adhesin in the Pfam database (Table 3). In addition to the N-terminal Flo11 domain, it contains a collagen triple helix repeat (Collagen (PF01391)) in the middle-C-terminal region of the protein. The collagen triple helix or type-2 helix is the primary secondary structure of various types of fibrous collagen, including type I collagen $[231,232]$. It consists of a triple helix made of the repetitious amino acid sequence glycine- $X-Y$, where $X$ and $Y$ are frequently proline or hydroxyproline. This Collagen domain could mechanically stabilize the adhesin allowing it to stick out as a straight rod from the cell surface reaching for receptors/surfaces to interact with. As Flo11p in S. cerevisiae is involved in pseudohyphal growth, one suggestion is that this adhesin also plays a role in pseudohyphal-like aggregate formation in C. auris. These aggregates of pseudohyphal-like cells cannot be disrupted physically or chemically with detergents [223]. The ability to aggregate was shown to be an inducible trait since aggregate formation was stimulated by the prior exposure of C. auris to triazoles or echinocandins [233]. Aggregative phenotypes have been predominantly isolated from colonized patients and have higher capacity for biofilm formation than non-aggregative phenotypes $[234,235]$. A study showed that aggregate formation may help C. auris to evade immune recognition and thus facilitate its persistence in tissues [225]. This contrasted with another study where mice survived a high-dose $C$. auris intravenous challenge, even after cyclophosphamide -induced immunosuppression, in C5 complement deficiency in A/J mice and mice deficient in neutrophil elastase [236]. 
These contrasting results are likely due to differences in virulence of the tested strains and/or the infection model [217].

\subsubsection{Candida Species That Rarely Cause Infections}

Meyerozyma guilliermondii (anamorph C. guilliermondii) is an ascomycetous yeast, which is widely distributed in nature, the human skin and the mucosal microflora $[237,238]$. Isolates identified as C. guilliermondii (teleomorph Pichia guilliermondii) were included in the new Meyerozyma genus by Kurtzman and Suzuki in 2010 [239]. The M. guilliermondii complex is a genetically heterogeneous complex comprising several phenotypically indistinguishable taxa, including M. guilliermondii, C. fermentati, C. carpophila, and C. xestobi [240-242]. With several unique characteristics and physiology, such as the wide substrates spectrum and capability of various chemicals synthesis, M. guilliermondii has been recognized for its biotechnological applications such as industrial enzyme production, metabolites synthesis and biocontrol capacity [243]. The incidence of human infections is low (ranges from 1 to 3\% depending on the geographic region [244-246]), but cases of candidemia (especially in patients with cancer), endocarditis and invasive disease have been reported and increased over the years [237,246-263]. Despite the low incidence of candidaemia caused by this organism, $M$. guilliermondii is of particular clinical significance as it exhibits increased resistance to antifungal agents (azoles and echinocandins), compared to other Candida species [244,264].

We found two Flo11-type M. guilliermondii adhesins in the Pfam database: in one strain the protein contained only the Flo11 domain whereas in the other strain an additional flocculin type 3 repeat was present. These Flo11-type adhesins could play a role in surface adhesion and biofilm formation since it was demonstrated that M. guilliermondii has a high adhesion ability (comparable to the ones of $C$. tropicalis and C. parapsilosis) as well as a high biofilm formation ability [208]. Recently, the N-terminal region (containing the Flo11 domain) of a Flo11-type adhesin from M. guilliermondii was introduced into an S. cerevisiae expression system based on the S. cerevisiae Flo11p and allowing the presentation of the adhesin domain at the cell surface for functional analysis [99]. It was shown that the Flo11 domain from M. guilliermondii was competent to confer adhesive growth. In addition, the expression of the Flo11 N-terminal domains from C. lusitaniae (see above), S. paradoxus, Kluyveromyces lactis, Torulospora delbrueckii, and Komagataella pastoris were expressed and conferred also adhesive growth to $S$. cerevisiae, which indicates that the capacity of the Flo11 domains for conferring cellular adhesion is highly conserved in Saccharomycetales.

C. intermedia is rarely reported as a human pathogen. Catheter-related fungemia caused by $C$. intermedia, which were treated successfully with fluconazole and catheter removal, have been reported [265]. Misidentification of C. duobushaemulonii (which is also a human pathogen) as C. intermedia has also been reported recently [266]. We found two Flo11-type adhesins in the Pfam database: one that contains only one Flo11 domain and one that contains six Flo11 domains in the $\mathrm{N}$-terminal region of the protein as well as five flocculin type 3 repeats at the $\mathrm{C}$-terminal region (Table 3 ). These adhesions could play a role in catheter adhesion and biofilm formation.

C. viswanathii was isolated from cerebrospinal fluid (CSF) of a fatal case of meningitis, and was reported as a new yeast species by Viswanathan and Randhawa in 1959 [267]. Later, the yeast was also found in routine sputum cultures and a detailed description of the fungus including the Latin diagnosis was provided, and its taxonomic nomenclature validated [268]. A recent study evaluating the pathogenicity for normal and cortisonetreated mice showed that $C$. viswanathii is an opportunistic pathogen [269]. Due to a lack of mycological expertise for comprehensive phenotypic characterization in a vast majority of laboratory diagnostic centres, the prevalence of $C$. viswanathii in clinical and environmental samples is currently likely underestimated. We identified one Flo11-type adhesin that contained only one Flo11 domain in the N-terminal region, in the Pfam database.

C. fabianii (teleomorph Cyberlindnera fabianii) is an ascomycetous yeast of the Phaffomycetaceae family. It has been described under the genus Hansenula, Pichia and Lindnera [270], 
and next as Cyberlindnera along with 20 other taxa since the genus Lindnera was a later homonym of an already published genus Lindnera in 1866 [271]. C. fabianii rarely been reported as a human pathogen, but due to advanced diagnostic methods and therapeutic techniques, infection has been increasingly recognised [272-288]. One Flo11-type adhesin that contains two Flo11 domains in the N-terminal region, was found in the Pfam database (Table 3).

C. haemulonii is a rare Candida subtype that is an emerging and virulent yeast pathogen. C. haemuloni infection have been wide spread, ranging from South America, Asia, the Middle East and Europe [289]. The first case report of C. haemulonii infection in the United States was in 1991 [289], a second in 2020 [62]. Species identification is difficult due to phenotypic similarity to other Candida subtypes, such that there is a high risk of inappropriate antimicrobial administration and worsening of emerging resistance patterns. C. haemulonii has a proclivity for infection of chronic lower extremity wounds particularly in diabetic patients [62]. One Flo11-type adhesin that contains one Flo11 domains in the N-terminal region and collagen triple helix repeat, was found in the Pfam database (Table 3).

C. inconspicua was firstly described as Torulopsis inconspicua and later reclassified in Candida [290]. The species belongs to the Pichia cactophila clade, together with P. $\mathrm{ku}$ driavzevii (synonym C. krusei [291]), Pichia norvegensis, P. cactophila, and Pichia pseudocactophila [292,293]. C. inconspicua is genetically similar and phenotypically identical to $P$. cactophila and it has been suggested that they represent different sexual stages of the same species $[270,294]$. Genome sequencing of the type strain (CBS180) and several clinical isolates uncovered the hybrid origin of C. inconspicua [292]. C. inconspicua is a an emerging pathogen responsible for infections that are more prominent in European countries [294-296]. Most of the infections are associated with osteomyelitis, oropharyngeal and esophageal candidiasis in HIV positive patients, as well as with candidemia in patients with hematological malignancies $[295,297,298]$. C. inconspicua showed a low susceptibility to fluconazole and other antifungals [291-301]. One Flo11-type adhesin that contains one Flo11 domains in the N-terminal region and three CMB_1 (Carbohydrate-binding module, fungal cellulose binding domain) domains, was found in the Pfam database (Table 3). In the protein architecture of hydrolytic enzymes that degrade polysaccharides, one or more non-catalytic CMBs are present besides the catalytic modules [302-304]. The CBMs have been shown to increase the proximity of the enzyme to its substrate, especially for insoluble substrates.

P. kudriazvevii is widely distributed in the environment that is used in traditional food and beverage fermentations [305,306]. P. kudriavzevii is exceptionally tolerant to stresses and, therefore, has been used to produce bioethanol [307,308], succinic acid [309], and glycerol (under the name C. glycerinogenes) [310]. P. kudriazvevii can be pathogenic for humans. Recently, an outbreak of fungaemia in a neonatal intensive care unit due to P. kudriavzevii (a teleomorph of C. krusei) was reported [311]. P. kudriavzevii can adhere to intestinal cells although this is strongly strain dependent [312,313] as well as to abiotic surfaces such as polystyrene and stainless-steel surfaces [166]. We found two Flo11-type adhesins in the Pfam database: one that contains only one Flo11 domain and one that contains a Flo11 domain in the N-terminal region of the protein as well as two CMB_1 domains (Table 3).

Wickerhamomyces anomalus is a heterothallic, ascomycetous yeast, forming one to four hat-shaped ascospores [314]. W. anomalus (synonym C. pelliculosa, formerly also known as Pichia anomala and Hansenula anomala) was recently assigned to the genus Wickerhamomyces based on phylogenetic analysis of gene sequences [315]. This species has a wide biotechnological potential [316] for its use in the fermentation of wines [317,318], as a biopreservation or biocontrol agent, and the production of biofuels and therapeutic molecules used in human medicine [319-321]. It shows a wide spectrum antimicrobial activity, being active against a variety of microorganisms including other yeasts, filamentous fungi and bacteria [316]. W. anomalus is a very rare pathogen causing blood stream infections in 
neonates [275,322-325]. It has been shown that $W$. anomalus can form biofilms on abiotic surfaces of a brewery plant [326] as well as on polystyrene and steel surfaces in vitro [166].

Lodderomyces elongisporus has been isolated from a variety of fruit concentrates, fresh fruits and soft drinks, wine [327] and insects [328]. It was considered as a teleomorph of C. parapsilosis, but $18 \mathrm{~S}$ rRNA sequencing revealed that $L$. elongisporus represents a distinct species $[329,330]$. Recently, it was identified in catheter-related bloodstream infections, where it was isolated from both blood and catheter tip cultures from patients [60,331-337]. The adhesion of L. elongisporus to polystyrene and steel surfaces in vitro has been demonstrated [166]. We found one Flo11-type adhesin that contains one Flo11 domain in the $\mathrm{N}$-terminal region of the protein as well as two flocculin type 3 repeats, in the Pfam database (Table 3).

Hyphopichia burtonii is a yeast that is responsible for the spoilage of food bakery products, cookies and cured meat [338,339]. It has been reported causing cutaneous infection in Barbastelle bats [340]. Recently, the first human infection caused by H. burtonii, resulting in peritonitis in a patient on peritoneal dialysis initially diagnosed as sterile peritonitis, resulting in delayed diagnosis and treatment [341]. We found one Flo11-type adhesin that contains one Flo11 domain in the $\mathrm{N}$-terminal region of the protein as well as one flocculin type 3 repeats, in the Pfam database (Table 3).

Debaryomyces hansenii (Torulaspora hansenii) (teleomorph C. famata) is a hemiascomycetous marine yeast that is usually found in natural substrates and in various cheese due to its high tolerance to salt and growth at low temperatures [342]. It has also been detected in human infections [343-345]. However, C. guilliermondii and other Candida have been misidentified as $D$. hansenii/C. famata $[346,347]$ since they are extremely difficult to differentiate phenotypically [348,349]. The adhesion of D. hansenii to intestinal cells has been demonstrated [312]. One Flo11-type adhesin that contains one Flo11 domains in the $\mathrm{N}$-terminal region, was identified in the Pfam database (Table 3).

\subsection{Non-Pathogenic S. cerevisiae Encountered in Rare Infections}

The Flo adhesins were first discovered in S. cerevisiae and S. pastorianus. They have been studied intensely, mainly due to their role during the beer fermentation process. S. cerevisiae and S. patorianus (Table 2) can be found in many natural environments including fruits, trees, and soil, and has been used for centuries for the production of beer [63,350], wine, and bread. S. cerevisiae is designated as a GRAS ("Generally Recognized as Safe") yeast. Despite its ubiquity and long association with humans, S. cerevisiae is rarely implicated as a causative agent of infections in healthy individuals. S. cerevisiae can be present in the skin, oral cavities, oropharynx, duodenal mucosa, digestive tract and vagina of healthy persons [351-353]. However, S. cerevisiae has been recognized as an emerging fungal pathogen for immunocompromised individuals in recent decades [354]. Since the 1990s [351], there have been a growing number of reports about $S$. cerevisiae invasive infections, and novel strains continue to be developed [355,356]. S. cerevisiae infections have been often associated with administration of probiotic $S$. cerevisiae var. boulardii strains or certain strains of S. cerevisiae [357-366] (Table 2).

S. cerevisiae adhesion is the first step in the infection process. Adhesion can be on biotic or abiotic surfaces such as plastics, stainless steel or glass surfaces, which can lead to the development of biofilms $[45,129,130]$. The rise in systemic fungal infections does also coincide with the increasing use of implants such as plastic catheters, prosthetic heart valves, cardiac pacemakers, endotracheal tubes, dentures, and cerebrospinal fluid shunts $[367,368]$. Access of fungi to the bloodstream and internal organs results from their ability to adhere to these prostheses, and next, to various surface receptors of host tissue cells. Prostheses can also serve as a carrier for fungal biofilms and thus provide an internal reservoir of highly resistant infective cells. It has been demonstrated that the adhesion to abiotic surfaces is mediated by Flo11p (Table 1) (see also Section 3.2) [69]. It is well known that microorganisms growing as biofilms are more resistant to various drugs and treatments than solitary cells and biofilms show an enhanced protection from host defences $[369,370]$. 
The involvement of the lectin-type Flo proteins in the development of $S$. cerevisiae biofilms has not yet been described. Based on the binding mechanism of the lectin-type Flo proteins, i.e., binding to mannose containing glycans (i.e., mannose, Man $\alpha-1,2-M a n$, Man $\alpha-1,3-M a n$ and Man $\alpha-1,6-$ Man glycan determinants), it can be hypothesized that $S$. cerevisiae cells expressing these flocculins could bind to cell receptors with high mannose N-glycans.

S. boulardii (Table 2) is a probiotic yeast that is often used for the treatment of gastrointestinal (GI) tract disorders such as diarrhea symptoms or chronic diseases such as inflammatory bowel disease [365,371,372]. Even though $S$. boulardii is generally regarded as safe [373], fungemia and sepsis are possible concerns, particularly in immunocompromised patients [371]. Rare occurrences of fungemia have been reported in people receiving therapeutic doses of $S$. boulardii or post-surgery [357,358,368,374,375]. These cases make it evident that $S$. boulardii fungemia is a distinct but rare possibility in patients with severely compromised health conditions, especially those involving the GI tract or the circulatory system [371]. S. boulardii and S. cerevisiae are genetically very similar, each containing 16 chromosomes with greater than $99 \%$ relatedness by average nucleotide identity [376]. One of the important differences include the genes expressing some flocculation proteins, which contribute to a different adhesion profile of $S$. boulardii when compared to $S$. cerevisiae [377]. Complete flocculin genes were identified in the whole genomes of $S$. boulardii where the repeats and their copies were varying even within S. boulardii genomes [376]. S. boulardii harbours the flocculin genes FLO1, FLO10 and FLO11 as well as the (nontruncated) FLO8 gene involved in the regulation of the expression of the FLO genes. These genes are located at telomeres and are highly repetitive, and the maximum number of repeats identified in the strains of $S$. boulardii could be conferring higher adhesive properties to the organism.

\section{Conclusions}

Yeast adhesion proteins play a fundamental role in many processes where cell-cell or cell-substrate interactions are involved such as switching from a unicellular lifestyle to a multicellular one. They are also critical in pathogenic yeast-host interactions. The first step in the infection of fungal pathogens in humans is the adhesion of the pathogen to host tissue cells or abiotic surfaces such as catheters. One of the main players involved in this are the expressed cell wall adhesins. Here, we reviewed the Flo adhesins that could be involved in human yeast infections.

The Flo adhesin family was originally subdivided into two subgroups. Based on the recent knowledge of the protein architecture of the Flo adhesins, we redefined these two subgroups into a PA/GLEYA Flo adhesin class and a Flo11-type class. These both classes are further subdivided according to the presence of 1 or more additional "Flo" domains. In this way, the PA14/GLEYA Flo adhesin class could be further subdivided into adhesins that besides a PA14 domain or GLEYA domain also contains a flocculin domain or/and a flocculin type 3 repeat domain. The Flo11-type adhesins could be further subdivided into architectures containing only the Flo11 domain, the Flo 11 domain and the flocculin domain or the flocculin type 3 repeat, and the Flo 11 domain and another adhesin structural domain.

Pfam database mining based on this new definition of the Flo adhesin family, identified Flo adhesin architectures in many pathogenic yeasts such as several emerging non-albicans Candida species that are becoming a major threat to humans due to their resistance to antifungals and high mortality. In some cases, a critical role of the identified adhesin has been elucidated during recent research. However, in many cases the role of these adhesins in the infections process has still to be unravelled. For a detailed understanding of binding mechanism of these adhesins and to develop strategies to inhibit them, the atomic structure of the adhesins should be solved. Until now, the structures of only a few yeast adhesins involved in human infections have been solved (see also [86]). Structural studies will have to be complemented with biophysical interaction studies on the molecular and cellular level. 
Additionally, the contribution of the Flo adhesins in relation to other expressed adhesins should be investigated to elucidate its role in the overall adhesion process of the infection.

Author Contributions: Conceptualization, R.G.W.; writing-review and editing, R.G.W., Y.K. and B.D.; visualization, R.G.W.; funding acquisition, R.G.W. and B.D. All authors have read and agreed to the published version of the manuscript.

Funding: This research was funded by the Belgian Federal Science Policy Office (Belspo) and the European Space Agency (ESA), grant number PRODEX project Yeast Bioreactor and FLUMIAS Nanomotion; Research Foundation Flanders (FWO), grant numbers AUGE/13/19 and I002620; FWO-SNSF (Swiss National Science foundation), grant number 310030L_197946.

Institutional Review Board Statement: Not applicable.

Informed Consent Statement: Not applicable.

Data Availability Statement: Not applicable.

Acknowledgments: The Research Council of the Vrije Universiteit Brussel (VUB) (Belgium) and the University of Gent (Belgium) are acknowledged to support the Alliance Research Group VUB-UGent NanoMicrobiology (NAMI), and the International Joint Research Group (IJRG) VUB-EPFL (Ecole Polytechnique Fédérale de Lausanne) BioNanotechnology \& NanoMedicine (NANO).

Conflicts of Interest: The authors declare no conflict of interest.

\section{References}

1. Bongomin, F.; Gago, S.; Oladele, R.O.; Denning, D.W. Global and multi-national prevalence of fungal diseases-Estimate precision. J. Fungi 2017, 3, 57. [CrossRef]

2. Denning, D.W. Calling upon all public health mycologists: To accompany the country burden papers from 14 countries. Eur. J. Clin. Microbiol. Infect. Dis. 2017, 36, 923-924. [CrossRef] [PubMed]

3. Geddes-McAlister, J.; Shapiro, R.S. New pathogens, new tricks: Emerging, drug-resistant fungal pathogens and future prospects for antifungal therapeutics. Ann. N. Y. Acad. Sci. 2019, 1435, 57-78. [CrossRef] [PubMed]

4. Richardson, M.D. Changing patterns and trends in systemic fungal infections. J. Antimicrob. Chemother. 2005, 56, i5-i11. [CrossRef]

5. Huttunen, R.; Syrjänen, J. Obesity and the risk and outcome of infection. Int. J. Obes. 2013, 37, 333-340. [CrossRef]

6. Rytter, M.J.H.; Kolte, L.; Briend, A.; Friis, H.; Christensen, V.B. The immune system in children with malnutrition-A systematic review. PLOS ONE 2014, 9, e105017.

7. Ibrahim, M.K.; Zambruni, M.; Melby, C.L.; Melby, P.C. Impact of childhood malnutrition on host defense and infection. Clin. Microbiol. Rev. 2017, 30, 919-971. [CrossRef] [PubMed]

8. Koehler, P.; Cornely, O.A.; Böttiger, B.W.; Dusse, F.; Eichenauer, D.A.; Fuchs, F.; Hallek, M.; Jung, N.; Klein, F.; Persigehl, T.; et al. COVID-19 associated pulmonary aspergillosis. Mycoses 2020, 63, 528-534. [CrossRef] [PubMed]

9. Alanio, A.; Dellière, S.; Fodil, S.; Bretagne, S.; Mégarbane, B. Prevalence of putative invasive pulmonary aspergillosis in critically ill patients with COVID-19. Lancet Respir. Med. 2020, 8, e48-e49. [CrossRef]

10. van Arkel, A.L.E.; Rijpstra, T.A.; Belderbos, H.N.A.; van Wijngaarden, P.; Verweij, P.E.; Bentvelsen, R.G. COVID-19-associated pulmonary aspergillosis. Am. J. Respir. Crit. Care Med. 2020, 202, 132-135. [CrossRef] [PubMed]

11. Arastehfar, A.; Carvalho, A.; van de Veerdonk, F.L.; Jenks, J.D.; Koehler, P.; Krause, R.; Cornely, O.A.; Perlin, D.S.; Lass-Flörl, C.; Hoenigl, M. COVID-19 associated pulmonary aspergillosis (CAPA)—From immunology to treatment. J. Fungi $2020,6,91$. [CrossRef]

12. Koehler, P.; Bassetti, M.; Chakrabarti, A.; Chen, S.C.A.; Colombo, A.L.; Hoenigl, M.; Klimko, N.; Lass-Flörl, C.; Oladele, R.O.; Vinh, D.C.; et al. Defining and managing COVID-19-associated pulmonary aspergillosis: The 2020 ECMM/ISHAM consensus criteria for research and clinical guidance. Lancet Infect. Dis. 2021, 21, e149-e162. [CrossRef]

13. Vos, T.; Flaxman, A.D.; Naghavi, M.; Lozano, R.; Michaud, C.; Ezzati, M.; Shibuya, K.; Salomon, J.A.; Abdalla, S.; Aboyans, V.; et al. Years lived with disability (YLDs) for 1160 sequelae of 289 diseases and injuries 1990-2010: A systematic analysis for the Global Burden of Disease Study 2010. Lancet 2012, 380, 2163-2196. [CrossRef]

14. Brown, G.D.; Denning, D.W.; Levitz, S.M. Tackling human fungal infections. Science 2012, 336, 647. [CrossRef] [PubMed]

15. Brown, G.D.; Denning, D.W.; Gow, N.A.R.; Levitz, S.M.; Netea, M.G.; White, T.C. Hidden killers: Human fungal infections. Sci. Transl. Med. 2012, 4, 165rv13. [CrossRef]

16. Havlickova, B.; Czaika, V.A.; Friedrich, M. Epidemiological trends in skin mycoses worldwide. Mycoses 2008, 51, 2-15. [CrossRef] [PubMed]

17. Sobel, J.D. Vulvovaginal candidosis. Lancet 2007, 369, 1961-1971. [CrossRef]

18. Castón-Osorio, J.J.; Rivero, A.; Torre-Cisneros, J. Epidemiology of invasive fungal infection. Int. J. Antimicrob. Agents 2008, 32, S103-S109. [CrossRef]

19. Miceli, M.H.; Díaz, J.A.; Lee, S.A. Emerging opportunistic yeast infections. Lancet Infect. Dis. 2011, 11, 142-151. [CrossRef] 
20. Galimberti, R.; Torre, A.C.; Baztán, M.C.; Rodriguez-Chiappetta, F. Emerging systemic fungal infections. Clin. Dermatol. 2012, 30, 633-650. [CrossRef] [PubMed]

21. Willaert, R. Micro- and Nanoscale Approaches in Antifungal Drug Discovery. Fermentation 2018, 4, 43. [CrossRef]

22. Lemke, A.; Kiderlen, A.F.; Kayser, O. Amphotericin, B. Appl. Microbiol. Biotechnol. 2005, 68, 151-162. [CrossRef]

23. Bellmann, R. Pharmacodynamics and Pharmacokinetics of Antifungals for Treatment of Invasive Aspergillosis. Curr. Pharm. Des. 2013, 19, 3629-3647. [CrossRef] [PubMed]

24. Pfaller, M.A. Antifungal Drug Resistance: Mechanisms, Epidemiology, and Consequences for Treatment. Am. J. Med. 2012, 125, S3-S13. [CrossRef] [PubMed]

25. Pianalto, K.M.; Alspaugh, J.A. New horizons in antifungal therapy. J. Fungi 2016, 2, 26. [CrossRef] [PubMed]

26. Nivoix, Y.; Ubeaud-Sequier, G.; Engel, P.; Leveque, D.; Herbrecht, R. Drug-Drug Interactions of Triazole Antifungal Agents in Multimorbid Patients and Implications for Patient Care. Curr. Drug Metab. 2009, 10, 395-409. [CrossRef]

27. Lewis, R.E. Current concepts in antifungal pharmacology. In Proceedings of the Mayo Clinic Proceedings; Elsevier Ltd: Amsterdam, The Netherlands, 2011; Volume 86, pp. 805-817.

28. McCarthy, M.W.; Walsh, T.J. Drugs currently under investigation for the treatment of invasive candidiasis. Expert Opin. Investig. Drugs 2017, 26, 825-831. [CrossRef] [PubMed]

29. Perfect, J.R. The antifungal pipeline: A reality check. Nat. Rev. Drug Discov. 2017, 16, 603-616. [CrossRef] [PubMed]

30. Fuentefria, A.M.; Pippi, B.; Dalla Lana, D.F.; Donato, K.K.; de Andrade, S.F. Antifungals discovery: An insight into new strategies to combat antifungal resistance. Lett. Appl. Microbiol. 2018, 66, 2-13. [CrossRef]

31. Silva, L.N.; de Mello, T.P.; de Souza Ramos, L.; Branquinha, M.H.; dos Santos, A.L.S. New and Promising Chemotherapeutics for Emerging Infections Involving Drug-resistant Non-albicans Candida Species. Curr. Top. Med. Chem. 2019, 19, $2527-2553$. [CrossRef] [PubMed]

32. Sousa, F.; Ferreira, D.; Reis, S.; Costa, P. Current insights on antifungal therapy: Novel nanotechnology approaches for drug delivery systems and new drugs from natural sources. Pharmaceuticals 2020, 13, 248. [CrossRef] [PubMed]

33. Mota Fernandes, C.; Dasilva, D.; Haranahalli, K.; McCarthy, J.B.; Mallamo, J.; Ojima, I.; Del Poeta, M. The Future of Antifungal Drug Therapy: Novel Compounds and Targets. Antimicrob. Agents Chemother. 2021, 65, 65. [CrossRef]

34. Scorzoni, L.; Fuchs, B.B.; Junqueira, J.C.; Mylonakis, E. Current and promising pharmacotherapeutic options for candidiasis. Expert Opin. Pharmacother. 2021, 22, 867-887. [CrossRef] [PubMed]

35. Dranginis, A.M.; Rauceo, J.M.; Coronado, J.E.; Lipke, P.N. A Biochemical Guide to Yeast Adhesins: Glycoproteins for Social and Antisocial Occasions. Microbiol. Mol. Biol. Rev. 2007, 71, 282-294. [CrossRef]

36. de Groot, P.W.J.; Bader, O.; de Boer, A.D.; Weig, M.; Chauhan, N. Adhesins in Human Fungal Pathogens: Glue with Plenty of Stick. Eukaryot. Cell 2013, 12, 470-481. [CrossRef]

37. Teunissen, A.W.R.H.; Steensma, H.Y. The dominant flocculation genes of Saccharomyces cerevisiae constitute a new subtelomeric gene family. Yeast 1995, 11, 1001-1013. [CrossRef]

38. Guo, B.; Styles, C.A.; Feng, Q.; Fink, G.R. A Saccharomyces gene family involved in invasive growth, cell-cell adhesion, and mating. Proc. Natl. Acad. Sci. USA 2000, 97, 12158-12163. [CrossRef]

39. Hoyer, L.L. The ALS gene family of Candida albicans. Trends Microbiol. 2001, 9, 176-180. [CrossRef]

40. Lo, W.-S.; Dranginis, A.M. The Cell Surface Flocculin Flo11 Is Required for Pseudohyphae Formation and Invasion by. Mol. Biol. Cell 1998, 9, 161-171. [CrossRef] [PubMed]

41. Vyas, V.K.; Kuchin, S.; Berkey, C.D.; Carlson, M. Snf1 Kinases with Different $\beta$-Subunit Isoforms Play Distinct Roles in Regulating Haploid Invasive Growth. Mol. Cell. Biol. 2003, 23, 1341-1348. [CrossRef]

42. Gaur, N.K.; Klotz, S.A. Expression, cloning, and characterization of a Candida albicans gene, ALA1, that confers adherence properties upon Saccharomyces cerevisiae for extracellular matrix proteins. Infect. Immun. 1997, 65, 5289-5294. [CrossRef]

43. Reynolds, T.B.; Fink, G.R.; TB, R.; GR, F. Bakers' yeast, a model for fungal biofilm formation. Science 2001, 291, 878-881. [CrossRef]

44. Van Mulders, S.E.; Christianen, E.; Saerens, S.M.G.G.; Daenen, L.; Verbelen, P.J.; Willaert, R.; Verstrepen, K.J.; Delvaux, F.R. Phenotypic diversity of Flo protein family-mediated adhesion in Saccharomyces cerevisiae. FEMS Yeast Res. 2009, 9, 178-190. [CrossRef] [PubMed]

45. Cormack, B.P. An Adhesin of the Yeast Pathogen Candida glabrata Mediating Adherence to Human Epithelial Cells. Science 1999, 285, 578-582. [CrossRef] [PubMed]

46. Li, F.; Palecek, S.P. EAP1, a Candida albicans Gene Involved in Binding Human Epithelial Cells. Eukaryot. Cell 2003, 2, $1266-1273$. [CrossRef]

47. Zupancic, M.L.; Frieman, M.; Smith, D.; Alvarez, R.A.; Cummings, R.D.; Cormack, B.P. Glycan microarray analysis of Candida glabrata adhesin ligand specificity. Mol. Microbiol. 2008, 68, 547-559. [CrossRef]

48. Verstrepen, K.J.; Fink, G.R. Genetic and epigenetic mechanisms underlying cell-surface variability in protozoa and fungi. Annu. Rev. Genet. 2009, 43, 1-24. [CrossRef] [PubMed]

49. Goossens, K.; Willaert, R. Flocculation protein structure and cell-cell adhesion mechanism in Saccharomyces cerevisiae. Biotechnol. Lett. 2010, 32, 1571-1585. [CrossRef] [PubMed]

50. Reitsma, S.; Slaaf, D.W.; Vink, H.; Van Zandvoort, M.A.M.J.M.J.; Oude Egbrink, M.G.A.A.; Zandvoort, M.A.M.J.; Oude Egbrink, M.G.A.A. The endothelial glycocalyx: Composition, functions, and visualization. Pflügers Arch.—Eur. J. Physiol. 2007, 454, 345-359. [CrossRef] 
51. Critchley, I.A.; Douglas, L.J. Role of glycosides as epithelial cell receptors for Candida albicans. J. Gen. Microbiol. 1987, 133, 637-643. [CrossRef] [PubMed]

52. Vardar-Ünlü, G.; McSharry, C.; Douglas, L.J. Fucose-specific adhesins on germ tubes of Candida albicans. FEMS Immunol. Med. Microbiol. 1998, 20, 55-67. [CrossRef]

53. Ielasi, F.S.; Alioscha-Perez, M.; Donohue, D.; Claes, S.; Sahli, H.; Schols, D.; Willaert, R.G. Lectin-glycan interaction network-based identification of host receptors of microbial pathogenic adhesins. MBio 2016, 7. [CrossRef]

54. Perlroth, J.; Choi, B.; Spellberg, B. Nosocomial fungal infections: Epidemiology, diagnosis, and treatment. Med. Mycol. 2007, 45, 321-346. [CrossRef] [PubMed]

55. Ramage, G.; Martínez, J.P.; López-Ribot, J.L. Candida biofilms on implanted biomaterials: A clinically significant problem. FEMS Yeast Res. 2006, 6, 979-986. [CrossRef] [PubMed]

56. Busscher, H.J.; Rinastiti, M.; Siswomihardjo, W.; Van Der Mei, H.C. Biofilm formation on dental restorative and implant materials. J. Dent. Res. 2010, 89, 657-665. [CrossRef] [PubMed]

57. Ramage, G.; Culshaw, S.; Jones, B.; Williams, C. Are we any closer to beating the biofilm: Novel methods of biofilm control. Curr. Opin. Infect. Dis. 2010, 23, 560-566. [CrossRef] [PubMed]

58. Pfaller, M.A. Epidemiology of candidiasis. J. Hosp. Infect. 1995, 30, 329-338. [CrossRef]

59. Pfaller, M.A.; Diekema, D.J. Epidemiology of invasive candidiasis: A persistent public health problem. Clin. Microbiol. Rev. 2007, 20, 133-163. [CrossRef]

60. Pfaller, M.A.; Diekema, D.J.; Steele-Moore, L.; Denys, G.; Staley, C.; Dipersio, J.R.; Saubolle, M.; Wilson, M.L.; Overturf, G.D.; Peterson, L.R.; et al. Twelve years of fluconazole in clinical practice: Global-trends in species distribution and fluconazole susceptibility of bloodstream isolates of Candida. Clin. Microbiol. Infect. 2004, 10, 11-23. [CrossRef]

61. García-Martos, P.; Domínguez, I.; Marín, P.; García-Agudo, R.; Aoufi, S.; Maria, J. Antifungal susceptibility of emerging yeast pathogens. Enferm. Infecc. Microbiol. Clin. 2001, 19, 249-256. [CrossRef]

62. Coles, M.; Cox, K.; Chao, A. Candida haemulonii: An emerging opportunistic pathogen in the United States? IDCases 2020, 21, e00900. [CrossRef]

63. Willaert, R.; Section, V. Beverages: The Beer Brewing Process: Wort Production and Beer Fermentation. In Handbook of Food Products Manufacturing; John Wiley \& Sons, Inc.: Hoboken, NJ, USA, 2006; Volume 1, pp. 443-506. ISBN 9780470049648.

64. Brückner, S.; Mösch, H.-U.U. Choosing the right lifestyle: Adhesion and development in Saccharomyces cerevisiae. FEMS Microbiol. Rev. 2011, 36, 25-58. [CrossRef] [PubMed]

65. Gimeno, C.J.; Ljungdahl, P.O.; Styles, C.A.; Fink, G.R. Unipolar cell divisions in the yeast S. cerevisiae lead to filamentous growth: Regulation by starvation and RAS. Cell 1992, 68, 1077-1090. [CrossRef]

66. Cullen, P.J.; Sprague, G.F. Glucose depletion causes haploid invasive growth in yeast. Proc. Natl. Acad. Sci. USA 2000, 97, 1-6. [CrossRef] [PubMed]

67. Palková, Z. Multicellular microorganisms: Laboratory versus nature. EMBO Rep. 2004, 5, 470-476. [CrossRef] [PubMed]

68. Stratford, M.; Assinder, S. Yeast flocculation: Flo1 and NewFlo phenotypes and receptor structure. Yeast 1991, 7, 559-574. [CrossRef] [PubMed]

69. Kraushaar, T.; Brückner, S.; Veelders, M.; Rhinow, D.; Schreiner, F.; Birke, R.; Pagenstecher, A.; Mösch, H.U.; Essen, L.O. Interactions by the fungal Flo11 adhesin depend on a fibronectin type III-like adhesin domain girdled by aromatic bands. Structure 2015, 23, 1005-1017. [CrossRef]

70. Lambrechts, M.G.; Bauer, F.F.; Marmur, J.; Pretorius, I.S. MUC1, a mucin-like protein that is regulated by MSS10, is critical for pseudohyphal differentiation in yeast. Proc. Natl. Acad. Sci. USA 1996, 93, 8419-8424. [CrossRef]

71. Reynolds, T.B. Going with the flo: The role of flo11-dependent and independent interactions in yeast mat formation. J. Fungi 2018, 4, 132. [CrossRef] [PubMed]

72. Purevdorj-Gage, B.; Orr, M.E.; Stoodley, P.; Sheehan, K.B.; Hyman, L.E. The role of FLO11 in Saccharomyces cerevisiae biofilm development in a laboratory based flow-cell system. FEMS Yeast Res. 2007, 7, 372-379. [CrossRef] [PubMed]

73. Bojsen, R.K.; Andersen, K.S.; Regenberg, B. Saccharomyces cerevisiae-A model to uncover molecular mechanisms for yeast biofilm biology. FEMS Immunol. Med. Microbiol. 2012, 65, 169-182. [CrossRef]

74. Douglas, L.M.; Li, L.; Yang, Y.; Dranginis, A.M. Expression and Characterization of the Flocculin Flo11/Muc1, a Saccharomyces cerevisiae Mannoprotein with Homotypic Properties of Adhesion. Eukaryot. Cell 2007, 6, 2214-2221. [CrossRef]

75. Goossens, K.V.Y.; Willaert, R.G. The N-terminal domain of the Flo11 protein from Saccharomyces cerevisiae is an adhesin without mannose-binding activity. FEMS Yeast Res. 2012, 12, 78-87. [CrossRef] [PubMed]

76. Erdman, S.; Lin, L.; Malczynski, M.; Snyder, M. Pheromone-regulated genes required for yeast mating differentiation. J. Cell Biol. 1998, 140, 461-483. [CrossRef] [PubMed]

77. Roy, A.; Lu, C.F.; Marykwas, D.L.; Lipke, P.N.; Kurjan, J. The AGA1 product is involved in cell surface attachment of the Saccharomyces cerevisiae cell adhesion glycoprotein a-agglutinin. Mol. Cell. Biol. 1991, 11, 4196-4206. [CrossRef] [PubMed]

78. Cappellaro, C.; Hauser, K.; Mrśa, V.; Watzele, M.; Watzele, G.; Gruber, C.; Tanner, W. Saccharomyces cerevisiae a- and alphaagglutinin: Characterization of their molecular interaction. EMBO J. 1991, 10, 4081-4088. [CrossRef] [PubMed]

79. Lipke, P.N.; Wojciechowicz, D.; Kurjan, J. AG alpha 1 is the structural gene for the Saccharomyces cerevisiae alpha-agglutinin, a cell surface glycoprotein involved in cell-cell interactions during mating. Mol. Cell. Biol. 1989, 9, 3155-3165. [CrossRef] 
80. Caro, L.H.P.; Tettelin, H.; Vossen, J.H.; Ram, A.F.J.; Van Den Ende, H.; Klis, F.M. In silicio identification of glycosylphosphatidylinositol-anchored plansma-membrane and cell wall proteins of Saccharomyces cerevisiae. Yeast 1997, 13, $1477-1489$. [CrossRef]

81. Jentoft, N. Why are proteins O-glycosylated? Trends Biochem. Sci. 1990, 15, 291-294. [CrossRef]

82. Verstrepen, K.J.; Jansen, A.; Lewitter, F.; Fink, G.R. Intragenic tandem repeats generate functional variability. Nat. Genet. 2005, 37, 986-990. [CrossRef]

83. Liu, N.; Wang, D.; Wang, Z.Y.; He, X.P.; Zhang, B. Genetic basis of flocculation phenotype conversion in Saccharomyces cerevisiae. FEMS Yeast Res. 2007, 7, 1362-1370. [CrossRef]

84. Westman, J.O.; Mapelli, V.; Taherzadeh, M.J.; Franzén, C.J. Flocculation causes inhibitor tolerance in Saccharomyces cerevisiae for second-generation bioethanol production. Appl. Environ. Microbiol. 2014, 80, 6908-6918. [CrossRef] [PubMed]

85. Verstrepen, K.J.; Klis, F.M. Flocculation, adhesion and biofilm formation in yeasts. Mol. Microbiol. 2006, 60, 5-15. [CrossRef]

86. Willaert, R.G. Adhesins of yeasts: Protein structure and interactions. J. Fungi 2018, 4, 119. [CrossRef]

87. Rigden, D.J.; Mello, L.V.; Galperin, M.Y. The PA14 domain, a conserved all- $\beta$ domain in bacterial toxins, enzymes, adhesins and signaling molecules. Trends Biochem. Sci. 2004, 29, 335-339. [CrossRef] [PubMed]

88. Petosa, C.; Collier, R.J.; Klimpel, K.R.; Leppla, S.H.; Liddington, R.C. Crystal structure of the anthrax toxin protective antigen. Nature 1997, 385, 833-838. [CrossRef]

89. Yoshida, E.; Hidaka, M.; Fushinobu, S.; Koyanagi, T.; Minami, H.; Tamaki, H.; Kitaoka, M.; Katayama, T.; Kumagai, H. Role of a PA14 domain in determining substrate specificity of a glycoside hydrolase family $3 \beta$-glucosidase from Kluyveromyces marxianus. Biochem. J. 2010, 431, 39-49. [CrossRef]

90. Silipo, A.; Larsbrink, J.; Marchetti, R.; Lanzetta, R.; Brumer, H.; Molinaro, A. NMR spectroscopic analysis reveals extensive binding interactions of complex xyloglucan oligosaccharides with the Cellvibrio japonicus glycoside hydrolase family $31 \alpha$-xylosidase. Chem.-Eur. J. 2012, 18, 13395-13404. [CrossRef]

91. Linder, T.; Gustafsson, C.M. Molecular phylogenetics of ascomycotal adhesins-A novel family of putative cell-surface adhesive proteins in fission yeasts. Fungal Genet. Biol. 2008, 45, 485-497. [CrossRef] [PubMed]

92. Ielasi, F.S.; Decanniere, K.; Willaert, R.G. The epithelial adhesin 1 (Epa1p) from the human-pathogenic yeast Candida glabrata: Structural and functional study of the carbohydrate-binding domain. Acta Crystallogr. Sect. D Biol. Crystallogr. 2012, 68, 210-217. [CrossRef] [PubMed]

93. Goossens, K.V.Y.; Ielasi, F.S.; Nookaew, I.; Stals, I.; Alonso-sarduy, L.; Daenen, L.; Nielsen, J.; Devreese, B.; Willaert, G. Molecular Mechanism of Flocculation Self-Recognition in Yeast and. MBio 2015, 6, 1-16. [CrossRef]

94. Frieman, M.B.; McCaffery, J.M.; Cormack, B.P. Modular domain structure in the Candida glabrata adhesin Epa1p, a $\beta 1,6$ glucan-cross-linked cell wall protein. Mol. Microbiol. 2002, 46, 479-492. [CrossRef] [PubMed]

95. Maestre-Reyna, M.; Diderrich, R.; Veelders, M.S.; Eulenburg, G.; Kalugin, V.; Brückner, S.; Keller, P.; Rupp, S.; Mösch, H.U.; Essen L.O. Structural basis for promiscuity and specificity during Candida glabrata invasion of host epithelia. Proc. Natl. Acad. Sci. USA 2012, 109, 16864-16869. [CrossRef] [PubMed]

96. Sim, L.; Groes, M.; Olesen, K.; Henriksen, A. Structural and biochemical characterization of the N-terminal domain of flocculin Lg-Flo1p from Saccharomyces pastorianusreveals a unique specificity for phosphorylated mannose. FEBS J. 2013, 280, 1073-1083. [CrossRef] [PubMed]

97. Kock, M.; Brückner, S.; Wozniak, N.; Maestre-Reyna, M.; Veelders, M.; Schlereth, J.; Mösch, H.-U.; Essen, L.-O. Structural and Functional Characterization of PA14/Flo5-Like Adhesins From Komagataella pastoris. Front. Microbiol. 2018, 9, 2581. [CrossRef] [PubMed]

98. Diderrich, R.; Kock, M.; Maestre-Reyna, M.; Keller, P.; Steuber, H.; Rupp, S.; Essen, L.O.; Mösch, H.U. Structural Hot Spots Determine Functional Diversity of the Candida glabrata Epithelial Adhesin Family. J. Biol. Chem. 2015, 290, 19597-19613. [CrossRef]

99. Brückner, S.; Schubert, R.; Kraushaar, T.; Hartmann, R.; Hoffmann, D.; Jelli, E.; Drescher, K.; Müller, D.J.; Essen, L.O.; Mösch, H.U. Kin discrimination in social yeast is mediated by cell surface receptors of the flo11 adhesin family. Elife 2020, 9. [CrossRef] [PubMed]

100. Veelders, M.; Brückner, S.; Ott, D.; Unverzagt, C.; Mösch, H.U.; Essen, L.O. Structural basis of flocculin-mediated social behavior in yeast. Proc. Natl. Acad. Sci. USA 2010, 107, 22511-22516. [CrossRef] [PubMed]

101. Goossens, K.V.Y.Y.; Stassen, C.; Stals, I.; Donohue, D.S.; Devreese, B.; de Greve, H.; Willaert, R.G. The N-terminal domain of the flo1 flocculation protein from Saccharomyces cerevisiae binds specifically to mannose carbohydrates. Eukaryot. Cell 2011, 10, 110-117. [CrossRef] [PubMed]

102. Bony, M.; Thines-Sempoux, D.; Barre, P.; Blondin, B. Localization and Cell Surface Anchoring of the Saccharomyces cerevisiae Flocculation Protein Flo1p. J. Bacteriol. 2011, 179, 1-8. [CrossRef] [PubMed]

103. Bucior, I.; Burger, M.M. Carbohydrate-carbohydrate interactions in cell recognition. Curr. Opin. Struct. Biol. 2004, $14,631-637$. [CrossRef] [PubMed]

104. Fernàndez-Busquets, X.; Körnig, A.; Bucior, I.; Burger, M.M.; Anselmetti, D. Self-Recognition and Ca2+-Dependent CarbohydrateCarbohydrate Cell Adhesion Provide Clues to the Cambrian Explosion. Mol. Biol. Evol. 2009, 26, 2551-2561. [CrossRef] [PubMed] 
105. Glaser, F.; Pupko, T.; Paz, I.; Bell, R.E.; Bechor-Shental, D.; Martz, E.; Ben-Tal, N. ConSurf: Identification of functional regions in proteins by surface-mapping of phylogenetic information. Bioinformatics 2003, 19, 163-164. [CrossRef] [PubMed]

106. Landau, M.; Mayrose, I.; Rosenberg, Y.; Glaser, F.; Martz, E.; Pupko, T.; Ben-Tal, N. ConSurf 2005: The projection of evolutionary conservation scores of residues on protein structures. Nucleic Acids Res. 2005, 33. [CrossRef] [PubMed]

107. Dehullu, J.; Vorholt, J.A.; Lipke, P.N.; Dufrêne, Y.F. Fluidic Force Microscopy Captures Amyloid Bonds between Microbial Cells. Trends Microbiol. 2019, 27, 728-730. [CrossRef] [PubMed]

108. Dehullu, J.; Valotteau, C.; Herman-Bausier, P.; Garcia-Sherman, M.; Mittelviefhaus, M.; Vorholt, J.A.; Lipke, P.N.; Dufrêne, Y.F.; Jérô Me Dehullu, J.; Valotteau, C.; et al. Fluidic Force Microscopy Demonstrates That Homophilic Adhesion by Candida albicans Als Proteins Is Mediated by Amyloid Bonds between Cells. Nano Lett. 2019, 19, 3846-3853. [CrossRef]

109. Lipke, P.N.; Mathelié-Guinlet, M.; Viljoen, A.; Dufrêne, Y.F. A New Function for Amyloid-Like Interactions: Cross-Beta Aggregates of Adhesins form Cell-to-Cell Bonds. Pathogens 2021, 10, 1013. [CrossRef] [PubMed]

110. Lipke, P.N.; Klotz, S.A.; Dufrene, Y.F.; Jackson, D.N.; Garcia-Sherman, M.C. Amyloid-Like $\beta$-Aggregates as Force-Sensitive Switches in Fungal Biofilms and Infections. Microbiol. Mol. Biol. Rev. 2018, 82. [CrossRef] [PubMed]

111. El-Kirat-Chatel, S.; Beaussart, A.; Vincent, S.P.; Flos, M.A.; Hols, P.; Lipke, P.N.; Dufrêne, Y.F. Forces in yeast flocculation. Nanoscale 2015, 7, 1760-1767. [CrossRef]

112. Lo, W.S.; Dranginis, A.M. FLO11, a yeast gene related to the STA genes, encodes a novel cell surface flocculin. J. Bacteriol. 1996, 178, 7144-7151. [CrossRef]

113. Rupp, S. MAP kinase and cAMP filamentation signaling pathways converge on the unusually large promoter of the yeast FLO11 gene. EMBO J. 1999, 18, 1257-1269. [CrossRef] [PubMed]

114. Roberts, R.L.; Fink, G.R. Elements of a single map kinase cascade in Saccharomyces cerevisiae mediate two developmental programs in the same cell type: Mating and invasive growth. Genes Dev. 1994, 8, 2974-2985. [CrossRef] [PubMed]

115. Kron, S.J.; Styles, C.A.; Fink, G.R. Symmetric cell division in pseudohyphae of the yeast Saccharomyces cerevisiae. Mol. Biol. Cell 1994, 5, 1003-1022. [CrossRef]

116. Mösch, H.U. Pseudohyphal development of Saccharomyces cerevisiae. Contrib. Microbiol. 2000, 5, 185-200. [PubMed]

117. Strittmatter, A.W.; Fischer, C.; Kleinschmidt, M.; Braus, G.H. FLO11 mediated filamentous growth of the yeast Saccharomyces cerevisiae depends on the expression of the ribosomal RPS26 genes. Mol. Genet. Genomics 2006, 276, 113-125. [CrossRef] [PubMed]

118. Pitoniak, A.; Birkaya, B.; Dionne, H.M.; Vadaie, N.; Cullen, P.J. The signaling mucins Msb2 and Hkr1 differentially regulate the filamentation mitogen-activated protein kinase pathway and contribute to a multimodal response. Mol. Biol. Cell 2009, 20, 3101-3114. [CrossRef] [PubMed]

119. Reynolds, T.B.; Jansen, A.; Peng, X.; Fink, G.R. Mat formation in Saccharomyces cerevisiae requires nutrient and pH gradients. Eukaryot. Cell 2008, 7, 122-130. [CrossRef] [PubMed]

120. Sarode, N.; Davis, S.E.; Tams, R.N.; Reynolds, T.B. The Wsclp cell wall signaling protein controls biofilm (Mat) formation independently of Flo11p in Saccharomyces cerevisiae. G3 Genes Genomes Genet. 2014, 4, 199-207. [CrossRef] [PubMed]

121. Ishigami, M.; Nakagawa, Y.; Hayakawa, M.; Iimura, Y. FLO11 is the primary factor in flor formation caused by cell surface hydrophobicity in wild-type flor yeast. Biosci. Biotechnol. Biochem. 2006, 70, 660-666. [CrossRef]

122. Zara, S.; Bakalinsky, A.T.; Zara, G.; Pirino, G.; Demontis, M.A.; Budroni, M. FLO11-Based Model for Air-Liquid Interfacial Biofilm Formation by Saccharomyces cerevisiae. Appl. Environ. Microbiol. 2005, 71, 2934-2939. [CrossRef]

123. Ishigami, M.; Nakagawa, Y.; Hayakawa, M.; Iimura, Y. FLO11 is essential for flor formation caused by the C-terminal deletion of NRG1 in Saccharomyces cerevisiae. FEMS Microbiol. Lett. 2004, 237, 425-430. [CrossRef] [PubMed]

124. Alexandre, H. Flor yeasts of Saccharomyces cerevisiae-Their ecology, genetics and metabolism. Int. J. Food Microbiol. 2013, 167, 269-275. [CrossRef] [PubMed]

125. Mortensen, H.D.; Dupont, K.; Jespersen, L.; Arneborg, N. The Flo11p-deficient Saccharomyces cerevisiae strain background S288c can adhere to plastic surfaces. Colloids Surf. B Biointerfaces 2007, 60, 131-134. [CrossRef]

126. Mortensen, H.D.; Dupont, K.; Jespersen, L.; Willats, W.G.T.; Arneborg, N. Identification of amino acids involved in the Flo11pmediated adhesion of Saccharomyces cerevisiae to a polystyrene surface using phage display with competitive elution. J. Appl. Microbiol. 2007, 103, 1041-1047. [CrossRef] [PubMed]

127. Bayly, J.C.; Douglas, L.M.; Pretorius, I.S.; Bauer, F.F.; Dranginis, A.M. Characteristics of Flo11-dependent flocculation in Saccharomyces cerevisiae. FEMS Yeast Res. 2005, 5, 1151-1156. [CrossRef] [PubMed]

128. Smit, G.; Straver, M.H.; Lugtenberg, B.J.J.; Kijne, J.W. Flocculence of Saccharomyces cerevisiae cells is induced by nutrient limitation, with cell surface hydrophobicity as a major determinant. Appl. Environ. Microbiol. 1992, 58, 3709-3714. [CrossRef] [PubMed]

129. Straver, M.H.; Aar, P.C.V.D.; Smit, G.; Kijne, J.W. Determinants of flocculence of brewer's yeast during fermentation in wort. Yeast 1993, 9, 527-532. [CrossRef] [PubMed]

130. Wilcocks, K.L.; Smart, K.A. The importance of surface charge and hydrophobicity for the flocculation of chain-forming brewing yeast strains and resistance of these parameters to acid washing. FEMS Microbiol. Lett. 1995, 134, 293-297. [CrossRef] [PubMed]

131. Barua, S.; Li, L.; Lipke, P.N.; Dranginis, A.M. Molecular Basis for Strain Variation in the Saccharomyces cerevisiae Adhesin Flo11p. mSphere 2016, 1. [CrossRef]

132. Koide, A.; Bailey, C.W.; Huang, X.; Koide, S. The fibronectin type III domain as a scaffold for novel binding proteins. J. Mol. Biol. 1998, 284, 1141-1151. [CrossRef] 
133. Ramsook, C.B.; Tan, C.; Garcia, M.C.; Fung, R.; Soybelman, G.; Henry, R.; Litewka, A.; O’Meally, S.; Otoo, H.N.; Khalaf, R.A.; et al. Yeast Cell Adhesion Molecules Have Functional Amyloid-Forming Sequences. Eukaryot. Cell 2010, 9, 393-404. [CrossRef]

134. Fidel, P.L.; Vazquez, J.A.; Sobel, J.D. Candida glabrata: Review of Epidemiology, Pathogenesis, and Clinical Disease with Comparison to C. albicans. Clin. Microbiol. Rev. 1999, 12, 80-96. [CrossRef]

135. Kumar, K.; Askari, F.; Sahu, M.S.; Kaur, R. Candida glabrata: A Lot More Than Meets the Eye. Microorganisms 2019, 7, 39. [CrossRef] [PubMed]

136. Silva, S.S.; Negri, M.; Henriques, M.; Oliveira, R.; Williams, D.W.; Azeredo, J. Adherence and biofilm formation of non-Candida albicans Candida species. Trends Microbiol. 2011, 19, 241-247. [CrossRef] [PubMed]

137. Brunke, S.; Hube, B. Two unlike cousins: Candida albicans and C.glabrata infection strategies. Cell. Microbiol. 2013, 15, 701-708. [CrossRef] [PubMed]

138. Kaur, R.; Domergue, R.; Zupancic, M.L.; Cormack, B.P. A yeast by any other name: Candida glabrata and its interaction with the host. Curr. Opin. Microbiol. 2005, 8, 378-384. [CrossRef]

139. Roetzer, A.; Gabaldón, T.; Schüller, C. From Saccharomyces cerevisiae to Candida glabrata in a few easy steps: Important adaptations for an opportunistic pathogen. FEMS Microbiol. Lett. 2010, 314, 1-9. [CrossRef]

140. Pfaller, M.A.; Moet, G.J.; Messer, S.A.; Jones, R.N.; Castanheira, M. Candida bloodstream infections: Comparison of species distributions and antifungal resistance patterns in community-onset and nosocomial isolates in the SENTRY Antimicrobial Surveillance Program, 2008-2009. Antimicrob. Agents Chemother. 2011, 55, 561-566. [CrossRef] [PubMed]

141. Guinea, J. Global trends in the distribution of Candida species causing candidemia. Clin. Microbiol. Infect. 2014, 20, 5-10. [CrossRef] [PubMed]

142. Hassan, Y.; Chew, S.Y.; Than, L.T.L. Candida glabrata: Pathogenicity and Resistance Mechanisms for Adaptation and Survival. J. Fungi 2021, 7, 667. [CrossRef] [PubMed]

143. Zarb, P.; Coignard, B.; Griskeviciene, J.; Muller, A.; Vankerckhoven, V.; Weist, K.; Goossens, M.M.; Vaerenberg, S.; Hopkins, S.; Catry, B.; et al. The European Centre for Disease Prevention and Control (ECDC) pilot point prevalence survey of healthcareassociated infections and antimicrobial use. Eurosurveillance 2012, 17, 20316. [CrossRef] [PubMed]

144. Mota, S.; Alves, R.; Carneiro, C.; Silva, S.; Brown, A.J.; Istel, F.; Kuchler, K.; Sampaio, P.; Casal, M.; Henriques, M.; et al. Candida glabrata susceptibility to antifungals and phagocytosis is modulated by acetate. Front. Microbiol. 2015, 6, 919. [CrossRef] [PubMed]

145. Kale, P.; Johnson, L.B. Second-generation azole antifungal agents. Drugs Today 2005, 41, 91-105. [CrossRef] [PubMed]

146. Richardson, M.; Lass-Flörl, C. Changing epidemiology of systemic fungal infections. Clin. Microbiol. Infect. 2008, 14, 5-24. [CrossRef]

147. Cohen, Y.; Karoubi, P.; Adrie, C.; Gauzit, R.; Marsepoil, T.; Zarka, D.; Clec'H, C. Early prediction of Candida glabrata fungemia in nonneutropenic critically ill patients. Crit. Care Med. 2010, 38, 826-830. [CrossRef]

148. Nobile, C.J.; Schneider, H.A.; Nett, J.E.; Sheppard, D.C.; Filler, S.G.; Andes, D.R.; Mitchell, A.P. Complementary Adhesin Function in C. albicans Biofilm Formation. Curr. Biol. 2008, 18, 1017-1024. [CrossRef] [PubMed]

149. Silva, S.; Henriques, M.; Martins, A.; Oliveira, R.; Williams, D.; Azeredo, J. Biofilms of non-Candida albicans Candida species: Quantification, structure and matrix composition. Med. Mycol. 2009, 47, 681-689. [CrossRef] [PubMed]

150. Rodrigues, C.F.; Rodrigues, M.E.; Silva, S.; Henriques, M. Candida glabrata Biofilms: How Far Have We Come? J. Fungi $2017,3,11$. [CrossRef] [PubMed]

151. Norimatsu, Y.; Morii, D.; Kogure, A.; Hamanaka, T.; Kuwano, Y.; Yokozawa, T.; Oda, T. A case of breakthrough Candida parapsilosis fungemia during micafungin therapy for a Candida glabrata bloodstream infection. Med. Mycol. Case Rep. 2017, 16, 1-3. [CrossRef] [PubMed]

152. Timmermans, B.; Las Peñas, A.D.; Castaño, I.; Van Dijck, P. Adhesins in candida glabrata. J. Fungi 2018, 4, 60. [CrossRef] [PubMed]

153. Douglas, L.J. Candida biofilms and their role in infection. Trends Microbiol. 2003, 11, 30-36. [CrossRef]

154. Kojic, E.M.; Darouiche, R.O. Candida Infections of Medical Devices. Clin. Microbiol. Rev. 2004, 17, 255-267. [CrossRef]

155. Ramage, G.; Saville, S.P.; Thomas, D.P.; López-Ribot, J.L. Candida biofilms: An update. Eukaryot. Cell 2005, 4, 633-638. [CrossRef]

156. Chaudhary, S.; Gupta, C.; Das, S.; Saha, R.; Rani, M.; Ramachandran, V.G. Biofilm formation by Candida species on intrauretheral catheter and its antifungal susceptibility profile. Indian J. Med. Microbiol. 2014, 32, 467-468. [CrossRef] [PubMed]

157. Chandra, J.; Mukherjee, P.K. Candida Biofilms: Development, Architecture, and Resistance. Microbiol. Spectr. 2015, 3. [CrossRef]

158. Weig, M.; Jänsch, L.; Groß, U.; De Koster, C.G.; Klis, F.M.; Groot, P.W.J. De Systematic identification in silico of covalently bound cell wall proteins and analysis of protein-polysaccharide linkages of the human pathogen Candida glabrata. Microbiology 2004, 150, 3129-3144. [CrossRef]

159. de Groot, P.W.J.J.; Kraneveld, E.A.; Yin, Q.Y.; Dekker, H.L.; Gross, U.; Crielaard, W.; de Koster, C.G.; Bader, O.; Klis, F.M.; Weig, M.; et al. The Cell Wall of the Human Pathogen Candida glabrata: Differential Incorporation of Novel Adhesin-Like Wall Proteins. Eukaryot. Cell 2008, 7, 1951-1964. [CrossRef]

160. Ielasi, F.S.; Verhaeghe, T.; Desmet, T.; Willaert, R.G. Engineering the carbohydrate-binding site of Epa1p from Candida glabrata: Generation of adhesin mutants with different carbohydrate specificity. Glycobiology 2014, 24, 1312-1322. [CrossRef] [PubMed]

161. Gabaldón, T.; Martin, T.; Marcet-Houben, M.; Durrens, P.; Bolotin-Fukuhara, M.; Lespinet, O.; Arnaise, S.; Boisnard, S.; Aguileta, G.; Atanasova, R.; et al. Comparative genomics of emerging pathogens in the Candida glabrata clade. BMC Genom. $2013,14,623$. [CrossRef] [PubMed] 
162. Hadfield, T.L.; Smith, M.B.; Winn, R.E.; Rinaldi, M.G.; Guerra, C. Mycoses caused by Candida lusitaniae. Rev. Infect. Dis. 1987, 9 , 1006-1012. [CrossRef]

163. Raja, A.; Park, J. Disseminated Candida lusitaniae: Nosocomial Acquisition Secondary to an Indwelling Urinary Catheter. Case Rep. Infect. Dis. 2021, 2021, 6632730. [CrossRef]

164. Apsemidou, A.; Füller, M.A.; Idelevich, E.A.; Kurzai, O.; Tragiannidis, A.; Groll, A.H. Candida lusitaniae Breakthrough Fungemia in an Immuno-Compromised Adolescent: Case Report and Review of the Literature. J. Fungi 2020, 6, 380. [CrossRef]

165. Hawkins, J.L.; Baddour, L.M. Candida lusitaniae Infections in the Era of Fluconazole Availability. Clin. Infect. Dis. 2003, 36, e14-e18. [CrossRef] [PubMed]

166. Perpetuini, G.; Rossetti, A.P.; Battistelli, N.; Arfelli, G.; Tofalo, R. Adhesion Properties, Biofilm Forming Potential, and Susceptibility to Disinfectants of Contaminant Wine Yeasts. Microorganisms 2021, 9, 654. [CrossRef]

167. Trofa, D.; Gácser, A.; Nosanchuk, J.D. Candida parapsilosis, an emerging fungal pathogen. Clin. Microbiol. Rev. 2008, 21, 606-625. [CrossRef] [PubMed]

168. Silva, S.; Negri, M.; Henriques, M.; Oliveira, R.; Williams, D.W.; Azeredo, J. Candida glabrata, Candida parapsilosis and Candida tropicalis: Biology, epidemiology, pathogenicity and antifungal resistance. FEMS Microbiol. Rev. 2012, 36, 288-305. [CrossRef]

169. Tavanti, A.; Davidson, A.D.; Gow, N.A.R.; Maiden, M.C.J.; Odds, F.C. Candida orthopsilosis and Candida metapsilosis spp. nov. to replace Candida parapsilosis groups II and III. J. Clin. Microbiol. 2005, 43, 284-292. [CrossRef]

170. Kossoff, E.H.; Buescher, E.S.; Karlowicz, M.G. Candidemia in a neonatal intensive care unit: Trends during fifteen years and clinical features of 111 cases. Pediatr. Infect. Dis. J. 1998, 17, 504-508. [CrossRef] [PubMed]

171. Rodriguez, D.; Almirante, B.; Park, B.J.; Cuenca-Estrella, M.; Planes, A.M.; Sanchez, F.; Gene, A.; Xercavins, M.; Fontanals, D.; Rodriguez-Tudela, J.L.; et al. Candidemia in neonatal intensive care units: Barcelona, Spain. Pediatr. Infect. Dis. J. 2006, 25, 224-229. [CrossRef] [PubMed]

172. Diekema, D.J.; Messer, S.A.; Boyken, L.B.; Hollis, R.J.; Kroeger, J.; Tendolkar, S.; Pfaller, M.A. In vitro activity of seven systemically active antifungal agents against a large global collection of rare Candida species as determined by CLSI broth microdilution methods. J. Clin. Microbiol. 2009, 47, 3170-3177. [CrossRef]

173. Liu, Y.; Kang, M.; Ye, H.; Zong, Z.; Lv, X. Analysis on clinical characteristics and drug resistance of Candida parapsilosis bloodstream infections in West China Hospital, China, from 2012 to 2015. J. Mycol. Med. 2018, 28, 222-226. [CrossRef] [PubMed]

174. Wu, Y.; Wei, D.; Gong, X.; Shen, Y.; Zhu, Y.; Wang, J.; Gao, Z. Initial use of voriconazole positively affects outcome of Candida parapsilosis bloodstream infection: A retrospective analysis. Transl. Pediatr. 2020, 9, 48086-48486. [CrossRef] [PubMed]

175. Pfaller, M.A.; Boyken, L.; Hollis, R.J.; Kroeger, J.; Messer, S.A.; Tendolkar, S.; Diekema, D.J. In vitro susceptibility of invasive isolates of Candida spp. to anidulafungin, caspofungin, and micafungin: Six years of global surveillance. J. Clin. Microbiol. 2008, 46, 150-156. [CrossRef] [PubMed]

176. Al-Sweih, N.; Khan, Z.; Khan, S.; Devarajan, L.V. Neonatal candidaemia in Kuwait: A 12-year study of risk factors, species spectrum and antifungal susceptibility. Mycoses 2009, 52, 518-523. [CrossRef] [PubMed]

177. Blyth, C.C.; Chen, S.C.A.; Slavin, M.A.; Serena, C.; Nguyen, Q.; Marriott, D.; Ellis, D.; Meyer, W.; Sorrell, T.C. Not Just Little Adults: Candidemia Epidemiology, Molecular Characterization, and Antifungal Susceptibility in Neonatal and Pediatric Patients. Pediatrics 2009, 123, 1360-1368. [CrossRef]

178. Nucci, M.; Queiroz-Telles, F.; Tobón, A.M.; Restrepo, A.; Colombo, A.L. Epidemiology of Opportunistic Fungal Infections in Latin America. Clin. Infect. Dis. 2010, 51, 561-570. [CrossRef]

179. Lockhart, S.R.; Iqbal, N.; Cleveland, A.A.; Farley, M.M.; Harrison, L.H.; Bolden, C.B.; Baughman, W.; Stein, B.; Hollick, R.; Park, B.J.; et al. Species identification and antifungal susceptibility testing of Candida bloodstream isolates from population-based surveillance studies in two U.S. cities from 2008 to 2011. J. Clin. Microbiol. 2012, 50, 3435-3442. [CrossRef]

180. das Miranda, L.N.; Rodrigues, E.C.A.; Costa, S.F.; van derHeijden, I.M.; Dantas, K.C.; Lobo, R.D.; Basso, M.; Varkulja, G.F.; Krebs, V.L.J.; Gibelli, M.A.B.C.; et al. Candida parapsilosis candidaemia in a neonatal unit over 7 years: A case series study. BMJ Open 2012, 2, e000992. [CrossRef]

181. Ziccardi, M.; Souza, L.O.P.; Gandra, R.M.; Galdino, A.C.M.; Baptista, A.R.S.; Nunes, A.P.F.; Ribeiro, M.A.; Branquinha, M.H.; Santos, A.L.S. Candida parapsilosis (sensu lato) isolated from hospitals located in the Southeast of Brazil: Species distribution, antifungal susceptibility and virulence attributes. Int. J. Med. Microbiol. 2015, 305, 848-859. [CrossRef] [PubMed]

182. de Paula Menezes, R.; de Oliveira Melo, S.G.; Bessa, M.A.S.; Silva, F.F.; Alves, P.G.V.; Araújo, L.B.; Penatti, M.P.A.; Abdallah, V.O.S.; von Dollinger de Brito Röder, D.; dos Santos Pedroso, R. Candidemia by Candida parapsilosis in a neonatal intensive care unit: Human and environmental reservoirs, virulence factors, and antifungal susceptibility. Braz. J. Microbiol. 2020, 51, 851-860. [CrossRef]

183. Abi-chacra, É.A.; Souza, L.O.P.; Cruz, L.P.; Braga-Silva, L.A.; Gonçalves, D.S.; Sodré, C.L.; Ribeiro, M.D.; Seabra, S.H.; FigueiredoCarvalho, M.H.G.; Barbedo, L.S.; et al. Phenotypical properties associated with virulence from clinical isolates belonging to the Candida parapsilosis complex. FEMS Yeast Res. 2013, 13, 831-848. [CrossRef] [PubMed]

184. Panagoda, G.J.; Ellepola, A.N.B.; Samaranayake, L.P. Adhesion of Candida parapsilosis to epithelial and acrylic surfaces correlates with cell surface hydrophobicity. Mycoses 2001, 44, 29-35. [CrossRef] [PubMed]

185. Klotz, S.A.; Drutz, D.J.; Zajic, J.E. Factors governing adherence of Candida species to plastic surfaces. Infect. Immun. 1985, 50, 97-101. [CrossRef] [PubMed] 
186. Hazen, K.C.; Plotkin, B.J.; Klimas, D.M. Influence of growth conditions on cell surface hydrophobicity of Candida albicans and Candida glabrata. Infect. Immun. 1986, 54, 269-271. [CrossRef]

187. Panagoda, G.J.; Samaranayake, L.P. The relationship between the cell length, adhesion to acrylic and relative cell surface hydrophobicity of Candida parapsilosis. Med. Mycol. 1998, 36, 373-378. [CrossRef]

188. Suzuki, T.; Miyamae, Y.; Ishida, I. Variation of colony morphology and chromosomal rearrangement in Candida tropicalis pK233. J. Gen. Microbiol. 1991, 137, 161-167. [CrossRef]

189. Okawa, Y.; Goto, K. Antigenicity of Candida tropicalis strain cells cultured at 27 and $37^{\circ} \mathrm{C}$. FEMS Immunol. Med. Microbiol. 2006, 46, 438-443. [CrossRef]

190. Chai, L.Y.A.; Denning, D.W.; Warn, P. Candida tropicalis in human disease. Crit. Rev. Microbiol. 2010, 36, 282-298. [CrossRef]

191. Eggimann, P.; Garbino, J.; Pittet, D. Epidemiology of Candida species infections in critically ill non-immunosuppressed patients. Lancet Infect. Dis. 2003, 3, 685-702. [CrossRef]

192. Álvarez-Lerma, F.; Nolla-Salas, J.; León, C.; Palomar, M.; Jordá, R.; Carrasco, N.; Bobillo, F. Candiduria in critically ill patients admitted to intensive care medical units. Intensive Care Med. 2003, 29, 1069-1076. [CrossRef]

193. Binelli, C.A.; Moretti, M.L.; Assis, R.S.; Sauaia, N.; Menezes, P.R.; Ribeiro, E.; Geiger, D.C.P.; Mikami, Y.; Miyaji, M.; Oliveira, M.S.; et al. Investigation of the possible association between nosocomial candiduria and candidaemia. Clin. Microbiol. Infect. 2006, 12, 538-543. [CrossRef] [PubMed]

194. Colombo, A.L.; Nucci, M.; Park, B.J.; Nouér, S.A.; Arthington-Skaggs, B.; Da Matta, D.A.; Warnock, D.; Morgan, J. Epidemiology of candidemia in Brazil: A nationwide sentinel surveillance of candidemia in eleven medical centers. J. Clin. Microbiol. 2006, 44, 2816-2823. [CrossRef] [PubMed]

195. Colombo, A.L.; Guimarães, T.; Silva, L.R.B.F.; de Monfardini, L.P.A.; Cunha, A.K.B.; Rady, P.; Alves, T.; Rosas, R.C. Prospective Observational Study of Candidemia in São Paulo, Brazil: Incidence Rate, Epidemiology, and Predictors of Mortality. Infect. Control Hosp. Epidemiol. 2007, 28, 570-576. [CrossRef] [PubMed]

196. Hasan, F.; Xess, I.; Wang, X.; Jain, N.; Fries, B.C. Biofilm formation in clinical Candida isolates and its association with virulence. Microbes Infect. 2009, 11, 753-761. [CrossRef]

197. Miranda, L.N.; van der Heijden, I.M.; Costa, S.F.; Sousa, A.P.I.; Sienra, R.A.; Gobara, S.; Santos, C.R.; Lobo, R.D.; Pessoa, V.P.; Levin, A.S. Candida colonisation as a source for candidaemia. J. Hosp. Infect. 2009, 72, 9-16. [CrossRef] [PubMed]

198. Kauffman, C.A.; Vazquez, J.A.; Sobel, J.D.; Gallis, H.A.; McKinsey, D.S.; Karchmer, A.W.; Sugar, A.M.; Sharkey, P.K.; Wise, G.J.; Mangi, R.; et al. Prospective Multicenter Surveillance Study of Funguria in Hospitalized Patients. Clin. Infect. Dis. 2000, 30, 14-18. [CrossRef] [PubMed]

199. Almirante, B.; Rodríguez, D.; Park, B.J.; Cuenca-Estrella, M.; Planes, A.M.; Almela, M.; Mensa, J.; Sanchez, F.; Ayats, J.; Gimenez, M.; et al. Epidemiology and predictors of mortality in cases of Candida bloodstream infection: Results from populationbased surveillance, Barcelona, Spain, from 2002 to 2003. J. Clin. Microbiol. 2005, 43, 1829-1835. [CrossRef] [PubMed]

200. Kontoyiannis, D.P.; Vaziri, I.; Hanna, H.A.; Boktour, M.; Thornby, J.; Hachem, R.; Bodey, G.P.; Raad, I.I. Risk Factors for Candida tropicalis Fungemia in Patients with Cancer. Clin. Infect. Dis. 2001, 33, 1676-1681. [CrossRef]

201. Ásmundsdóttir, L.R.; Erlendsdóttir, H.; Gottfredsson, M. Increasing incidence of candidemia: Results from a 20-year nationwide study in Iceland. J. Clin. Microbiol. 2002, 40, 3489-3492. [CrossRef]

202. Nucci, M.; Colombo, A.L. Candidemia due to Candida tropicalis: Clinical, epidemiologic, and microbiologic characteristics of 188 episodes occurring in tertiary care hospitals. Diagn. Microbiol. Infect. Dis. 2007, 58, 77-82. [CrossRef]

203. Butler, G.; Rasmussen, M.D.; Lin, M.F.; Santos, M.A.S.; Sakthikumar, S.; Munro, C.A.; Rheinbay, E.; Grabherr, M.; Forche, A.; Reedy, J.L.; et al. Evolution of pathogenicity and sexual reproduction in eight Candida genomes. Nature 2009, 459, 657-662. [CrossRef] [PubMed]

204. Kozik, A.; Karkowska-Kuleta, J.; Zajac, D.; Bochenska, O.; Kedracka-Krok, S.; Jankowska, U.; Rapala-Kozik, M. Fibronectin-, vitronectin- and laminin-binding proteins at the cell walls of Candida parapsilosis and Candida tropicalis pathogenic yeasts. BMC Microbiol. 2015, 15, 197. [CrossRef] [PubMed]

205. Oh, S.-H.; Smith, B.; Miller, A.N.; Staker, B.; Fields, C.; Hernandez, A.; Hoyer, L.L. Agglutinin-Like Sequence (ALS) Genes in the Candida parapsilosis Species Complex: Blurring the Boundaries Between Gene Families That Encode Cell-Wall Proteins. Front. Microbiol. 2019, 10, 781. [CrossRef] [PubMed]

206. Neale, M.N.; Glass, K.A.; Longley, S.J.; Kim, D.J.; Laforce-Nesbitt, S.S.; Wortzel, J.D.; Shaw, S.K.; Bliss, J.M. Role of the inducible adhesin CpAls7 in binding of Candida parapsilosis to the extracellular matrix under fluid shear. Infect. Immun. 2018, 86, e00892-17. [CrossRef] [PubMed]

207. Bertini, A.; Zoppo, M.; Lombardi, L.; Rizzato, C.; De Carolis, E.; Vella, A.; Torelli, R.; Sanguinetti, M.; Tavanti, A. Targeted gene disruption in Candida parapsilosis demonstrates a role for CPAR2_404800 in adhesion to a biotic surface and in a murine model of ascending urinary tract infection. Virulence 2016, 7, 85-97. [CrossRef]

208. Zuo, X.; Liu, Y.; Cai, X.; Zhan, L.; Hu, K. Association of different Candida species with catheter-related candidemia, and the potential antifungal treatments against their adhesion properties and biofilm-forming capabilities. J. Clin. Lab. Anal. 2021, 35, e23738. [CrossRef]

209. Satoh, K.; Makimura, K.; Hasumi, Y.; Nishiyama, Y.; Uchida, K.; Yamaguchi, H. Candida auris sp. nov., a novel ascomycetous yeast isolated from the external ear canal of an inpatient in a Japanese hospital. Microbiol. Immunol. 2009, 53, 41-44. [CrossRef] 
210. Navalkele, B.D.; Revankar, S.; Chandrasekar, P. Candida auris: A worrisome, globally emerging pathogen. Expert Rev. Anti Infect. Ther. 2017, 15, 819-827. [CrossRef]

211. de Cássia Orlandi Sardi, J.; Silva, D.R.; Soares Mendes-Giannini, M.J.; Rosalen, P.L. Candida auris: Epidemiology, risk factors, virulence, resistance, and therapeutic options. Microb. Pathog. 2018, 125, 116-121. [CrossRef]

212. Nett, J.E. Candida auris: An emerging pathogen "incognito"? PLoS Pathog. 2019, 15, e1007638. [CrossRef]

213. Spivak, E.S.; Hanson, K.E. Candida auris: An emerging fungal pathogen. J. Clin. Microbiol. 2018, 56, e01588-17. [CrossRef] [PubMed]

214. Du, H.; Bing, J.; Hu, T.; Ennis, C.L.; Nobile, C.J.; Huang, G. Candida auris: Epidemiology, biology, antifungal resistance, and virulence. PLoS Pathog. 2020, 16, e1008921. [CrossRef] [PubMed]

215. Lone, S.A.; Ahmad, A. Candida auris-The growing menace to global health. Mycoses 2019, 62, 620-637. [CrossRef] [PubMed]

216. Muñoz, J.F.; Welsh, R.M.; Shea, T.; Batra, D.; Gade, L.; Howard, D.; Rowe, L.A.; Meis, J.F.; Litvintseva, A.P.; Cuomo, C.A. Clade-specific chromosomal rearrangements and loss of subtelomeric adhesins in Candida auris. Genetics 2021, 218, iyab029. [CrossRef]

217. Ahmad, S.; Alfouzan, W. Candida auris: Epidemiology, Diagnosis, Pathogenesis, Antifungal Susceptibility, and Infection Control Measures to Combat the Spread of Infections in Healthcare Facilities. Microorganisms 2021, 9, 807. [CrossRef]

218. Chybowska, A.D.; Childers, D.S.; Farrer, R.A. Nine Things Genomics Can Tell Us About Candida auris. Front. Genet. 2020, 11, 351. [CrossRef]

219. Lockhart, S.R.; Etienne, K.A.; Vallabhaneni, S.; Farooqi, J.; Chowdhary, A.; Govender, N.P.; Colombo, A.L.; Calvo, B.; Cuomo, C.A.; Desjardins, C.A.; et al. Simultaneous Emergence of Multidrug-Resistant Candida auris on 3 Continents Confirmed by WholeGenome Sequencing and Epidemiological Analyses. Clin. Infect. Dis. 2017, 64, 134-140. [CrossRef]

220. Sharma, C.; Kumar, N.; Pandey, R.; Meis, J.F.; Chowdhary, A. Whole genome sequencing of emerging multidrug resistant Candida auris isolates in India demonstrates low genetic variation. New Microbes New Infect. 2016, 13, 77. [CrossRef]

221. Chatterjee, S.; Alampalli, S.V.; Nageshan, R.K.; Chettiar, S.T.; Joshi, S.; Tatu, U.S. Draft genome of a commonly misdiagnosed multidrug resistant pathogen Candida auris. BMC Genom. 2015, 16, 686. [CrossRef]

222. Larkin, E.; Hager, C.; Chandra, J.; Mukherjee, P.K.; Retuerto, M.; Salem, I.; Long, L.; Isham, N.; Kovanda, L.; Borroto-Esoda, K.; et al. The emerging pathogen Candida auris: Growth phenotype, virulence factors, activity of antifungals, and effect of SCY-078, a novel glucan synthesis inhibitor, on growth morphology and biofilm formation. Antimicrob. Agents Chemother. 2017, 61, e02396-16. [CrossRef]

223. Borman, A.M.; Szekely, A.; Johnson, E.M. Comparative Pathogenicity of United Kingdom Isolates of the Emerging Pathogen Candida auris and Other Key Pathogenic Candida Species. mSphere 2016, 1, e00189-16. [CrossRef] [PubMed]

224. Singh, S.; Uppuluri, P.; Mamouei, Z.; Alqarihi, A.; Elhassan, H.; French, S.; Lockhart, S.R.; Chiller, T.; Edwards, J.E., Jr.; Ibrahim, A.S. The NDV-3A vaccine protects mice from multidrug resistant Candida auris infection. PLoS Pathog. 2019, 15, e1007460. [CrossRef]

225. Ben-Ami, R.; Berman, J.; Novikov, A.; Bash, E.; Shachor-Meyouhas, Y.; Zakin, S.; Maor, Y.; Tarabia, J.; Schechner, V.; Adler, A.; et al. Multidrug-resistant candida haemulonii and C. auris, Tel Aviv, Israel. Emerg. Infect. Dis. 2017, 23, 195-203. [CrossRef] [PubMed]

226. Khatamzas, E.; Madder, H.; Jeffery, K. Neurosurgical device-associated infections due to Candida auris-Three cases from a single tertiary center. J. Infect. 2019, 78, 409-421. [CrossRef] [PubMed]

227. Kean, R.; Delaney, C.; Sherry, L.; Borman, A.; Johnson, E.M.; Richardson, M.D.; Rautemaa-Richardson, R.; Williams, C.; Ramage, G. Transcriptome Assembly and Profiling of Candida auris Reveals Novel Insights into Biofilm-Mediated Resistance. mSphere 2018, 3. [CrossRef] [PubMed]

228. Kean, R.; Ramage, G. Combined Antifungal Resistance and Biofilm Tolerance: The Global Threat of Candida auris. mSphere 2019, 4. [CrossRef] [PubMed]

229. Kean, R.; Brown, J.; Gulmez, D.; Ware, A.; Ramage, G. Candida auris: A Decade of Understanding of an Enigmatic Pathogenic Yeast. J. Fungi 2020, 6, 30. [CrossRef] [PubMed]

230. Dominguez, E.G.; Zarnowski, R.; Choy, H.L.; Zhao, M.; Sanchez, H.; Nett, J.E.; Andes, D.R. Conserved Role for Biofilm Matrix Polysaccharides in Candida auris Drug Resistance. mSphere 2019, 4. [CrossRef]

231. Berisio, R.; Vitagliano, L.; Mazzarella, L.; Zagari, A. Crystal structure of the collagen triple helix model [(Pro-Pro-Gly)10]3. Protein Sci. 2002, 11, 262-270. [CrossRef] [PubMed]

232. Bhattacharjee, A.; Bansal, M. Collagen Structure: The Madras Triple Helix and the Current Scenario. IUBMB Life 2005, 57, 161-172. [CrossRef]

233. Szekely, A.; Borman, A.M.; Johnsona, E.M. Candida auris isolates of the southern asian and south african lineages exhibit different phenotypic and antifungal susceptibility profiles in vitro. J. Clin. Microbiol. 2019, 57. [CrossRef] [PubMed]

234. Abdolrasouli, A.; Armstrong-James, D.; Ryan, L.; Schelenz, S. In vitro efficacy of disinfectants utilised for skin decolonisation and environmental decontamination during a hospital outbreak with Candida auris. Mycoses 2017, 60, 758-763. [CrossRef]

235. Singh, R.; Kaur, M.; Chakrabarti, A.; Shankarnarayan, S.A.; Rudramurthy, S.M. Biofilm formation by Candida auris isolated from colonising sites and candidemia cases. Mycoses 2019, 62, 706-709. [CrossRef]

236. Xin, H.; Mohiuddin, F.; Tran, J.; Adams, A.; Eberle, K. Experimental Mouse Models of Disseminated Candida auris Infection. mSphere 2019, 4. [CrossRef] [PubMed] 
237. Savini, V.; Catavitello, C.; Onofrillo, D.; Masciarelli, G.; Astolfi, D.; Balbinot, A.; Febbo, F.; D'Amario, C.; D'Antonio, D. What do we know about Candida guilliermondii? A voyage throughout past and current literature about this emerging yeast. Mycoses 2011, 54, 434-441. [CrossRef]

238. Cooper, C.R. Yeasts Pathogenic to Humans. Yeasts 2011, 1, 9-19. [CrossRef]

239. Kurtzman, C.P.; Suzuki, M. Phylogenetic analysis of ascomycete yeasts that form coenzyme Q-9 and the proposal of the new genera Babjeviella, Meyerozyma, Millerozyma, Priceomyces, and Scheffersomyces. Mycoscience 2010, 51, 2-14. [CrossRef]

240. Vaughan-Martini, A.; Kurtzman, C.P.; Meyer, S.A.; O’Neill, E.B. Two new species in the Pichia guilliermondii clade: Pichia caribbica sp. nov., the ascosporic state of Candida fermentati, and Candida carpophila comb. nov. FEMS Yeast Res. 2005, 5, 463-469. [CrossRef]

241. Lan, L.; Xu, J. Multiple gene genealogical analyses suggest divergence and recent clonal dispersal in the opportunistic human pathogen Candida guilliermondii. Microbiology 2006, 152, 1539-1549. [CrossRef] [PubMed]

242. Lockhart, S.R.; Messer, S.A.; Pfaller, M.A.; Diekema, D.J. Identification and susceptibility profile of Candida fermentati from a worldwide collection of Candida guilliermondii clinical isolates. J. Clin. Microbiol. 2009, 47, 242-244. [CrossRef] [PubMed]

243. Yan, W.; Gao, H.; Qian, X.; Jiang, Y.; Zhou, J.; Dong, W.; Xin, F.; Zhang, W.; Jiang, M. Biotechnological applications of the non-conventional yeast Meyerozyma guilliermondii. Biotechnol. Adv. 2021, 46, 107674. [CrossRef] [PubMed]

244. Pfaller, M.A.; Diekema, D.J.; Mendez, M.; Kibbler, C.; Erzsebet, P.; Chang, S.C.; Gibbs, D.L.; Newell, V.A.; Finquelievich, J.; Tiraboschi, N.; et al. Candida guilliermondii, an opportunistic fungal pathogen with decreased susceptibility to fluconazole: Geographic and temporal trends from the ARTEMIS DISK antifungal surveillance program. J. Clin. Microbiol. 2006, 44, 3551-3556. [CrossRef] [PubMed]

245. Pfaller, M.; Neofytos, D.; Diekema, D.; Azie, N.; Meier-Kriesche, H.U.; Quan, S.P.; Horn, D. Epidemiology and outcomes of candidemia in 3648 patients: Data from the Prospective Antifungal Therapy (PATH Alliance ${ }^{\circledR}$ ) registry, 2004-2008. Diagn. Microbiol. Infect. Dis. 2012, 74, 323-331. [CrossRef]

246. Cheng, J.W.; Liao, K.; Kudinha, T.; Yu, S.Y.; Xiao, M.; Wang, H.; Kong, F.; Xu, Y.C. Molecular epidemiology and azole resistance mechanism study of Candida guilliermondii from a Chinese surveillance system. Sci. Rep. 2017, 7, 907. [CrossRef] [PubMed]

247. Chen, C.-Y.; Huang, S.-Y.; Tang, J.-L.; Tsay, W.; Yao, M.; Ko, B.-S.; Chou, W.-C.; Tien, H.-F.; Hsueh, P.-R. Clinical features of patients with infections caused by Candida guilliermondii and Candida fermentati and antifungal susceptibility of the isolates at a medical centre in Taiwan, 2001-10. J. Antimicrob. Chemother. 2013, 68, 2632-2635. [CrossRef] [PubMed]

248. Passos, X.S.; Sales, W.S.; Maciel, P.J.; Costa, C.R.; Miranda, K.C.; de Lemos, J.A.; de Batista, M.A.; do Silva, M.R.R. Candida colonization in intensive care unit patients' urine. Mem. Inst. Oswaldo Cruz 2005, 100, 925-928. [CrossRef]

249. Tseng, T.Y.; Chen, T.C.; Ho, C.M.; Lin, P.C.; Chou, C.H.; Tsai, C.T.; Wang, J.H.; Chi, C.Y.; Ho, M.W. Clinical features, antifungal susceptibility, and outcome of Candida guilliermondii fungemia: An experience in a tertiary hospital in mid-Taiwan. J. Microbiol. Immunol. Infect. 2018, 51, 552-558. [CrossRef] [PubMed]

250. Chen, J.; Tian, S.; Li, F.; Sun, G.; Yun, K.; Cheng, S.; Chu, Y. Clinical Characteristics and Outcomes of Candidemia Caused by Meyerozyma guilliermondii Complex in Cancer Patients Undergoing Surgery. Mycopathologia 2020, 185, 975-982. [CrossRef] [PubMed]

251. Guinea, J.; Zaragoza, Ó.; Escribano, P.; Martín-Mazuelos, E.; Pemán, J.; Sánchez-Reus, F.; Cuenca-Estrella, M. Molecular identification and antifungal susceptibility of yeast isolates causing fungemia collected in a population-based study in Spain in 2010 and 2011. Antimicrob. Agents Chemother. 2014, 58, 1529-1537. [CrossRef]

252. Papon, N.; Savini, V.; Lanoue, A.; Simkin, A.J.; Crèche, J.; Giglioli-Guivarc'h, N.; Clastre, M.; Courdavault, V.; Sibirny, A.A Candida guilliermondii: Biotechnological applications, perspectives for biological control, emerging clinical importance and recent advances in genetics. Curr. Genet. 2013, 59, 73-90. [CrossRef] [PubMed]

253. Cheng, J.W.; Yu, S.Y.; Xiao, M.; Wang, H.; Kudinha, T.; Kong, F.; Xu, Y.C. Identification and antifungal susceptibility profile of candida guilliermondii and candida fermentati from a multicenter study in China. J. Clin. Microbiol. 2016, 54, 2187-2189. [CrossRef] [PubMed]

254. Hirayama, T.; Miyazaki, T.; Yamagishi, Y.; Mikamo, H.; Ueda, T.; Nakajima, K.; Takesue, Y.; Higashi, Y.; Yamamoto, Y.; Kimura, M.; et al. Clinical and microbiological characteristics of candida guilliermondii and candida fermentati. Antimicrob. Agents Chemother. 2018, 62. [CrossRef] [PubMed]

255. Ahangarkani, F.; Badali, H.; Rezai, M.S.; Shokohi, T.; Abtahian, Z.; Nesheli, H.M.; Karami, H.; Roilides, E.; Tamaddoni, A. Candidemia due to candida guilliermondii in an immunocompromised infant: A case report and review of literature. Curr. Med. Mycol. 2019, 5, 32-36. [CrossRef]

256. Tietz, H.J.; Czaika, V.; Sterry, W. Case report. Osteomyelitis caused by high resistant Candida guilliermondii. Mycoses 1999, 42, 577-580. [CrossRef] [PubMed]

257. Krcmery, V.; Barnes, A.J. Non-albicans Candida spp. causing fungaemia: Pathogenicity and antifungal resistance. J. Hosp. Infect. 2002, 50, 243-260. [CrossRef]

258. Girmenia, C.; Pizzarelli, G.; Cristini, F.; Barchiesi, F.; Spreghini, E.; Scalise, G.; Martino, P. Candida guilliermondii fungemia in patients with hematologic malignancies. J. Clin. Microbiol. 2006, 44, 2458-2464. [CrossRef] [PubMed]

259. Pemán, J.; Bosch, M.; Cantón, E.; Viudes, Á.; Jarque, I.; Gómez-García, M.; García-Martínez, J.M.; Gobernado, M. Fungemia due to Candida guilliermondii in a pediatric and adult population during a 12-year period. Diagn. Microbiol. Infect. Dis. 2008, 60, 109-112. [CrossRef] [PubMed] 
260. Chakrabarti, A.; Chatterjee, S.S.; Rao, K.L.N.; Zameer, M.M.; Shivaprakash, M.R.; Singhi, S.; Singh, R.; Varma, S.C. Recent experience with fungaemia: Change in species distribution and azole resistance. Scand. J. Infect. Dis. 2009, 41, 275-284. [CrossRef]

261. Zepelin, M.B.; Kunz, L.; Rüchel, R.; Reichard, U.; Weig, M.; Groß, U. Epidemiology and antifungal susceptibilities of Candida spp. to six antifungal agents: Results from a surveillance study on fungaemia in Germany from July 2004 to August 2005. J. Antimicrob. Chemother. 2007, 60, 424-428. [CrossRef]

262. Barchiesi, F.; Spreghini, E.; Tomassetti, S.; Della Vittoria, A.; Arzeni, D.; Manso, E.; Scalise, G. Effects of caspofungin against Candida guilliermondii and Candida parapsilosis. Antimicrob. Agents Chemother. 2006, 50, 2719-2727. [CrossRef]

263. Savini, V.; Catavitello, C.; Di Marzio, I.; Masciarelli, G.; Astolfi, D.; Balbinot, A.; Bianco, A.; Pompilio, A.; Di Bonaventura, G.; D'Amario, C.; et al. Pan-azole-Resistant Candida guilliermondii from a Leukemia Patient's Silent Funguria. Mycopathologia 2010, 169, 457-459. [CrossRef]

264. Marcos-Zambrano, L.J.; Puig-Asensio, M.; Pérez-García, F.; Escribano, P.; Sánchez-Carrillo, C.; Zaragoza, O.; Padilla, B.; CuencaEstrella, M.; Almirante, B.; Martín-Gómez, M.T.; et al. Candida guilliermondii complex is characterized by high antifungal resistance but low mortality in 22 cases of candidemia. Antimicrob. Agents Chemother. 2017, 61. [CrossRef] [PubMed]

265. Ruan, S.Y.; Chien, J.Y.; Hou, Y.C.; Hsueh, P.R. Catheter-related fungemia caused by Candida intermedia. Int. J. Infect. Dis. 2010, 14, e147-e149. [CrossRef] [PubMed]

266. Jurado-Martín, I.; Marcos-Arias, C.; Tamayo, E.; Guridi, A.; de Groot, P.W.J.; Quindós, G.; Eraso, E. Candida duobushaemulonii: An Old But Unreported Pathogen. J. Fungi 2020, 6, 374. [CrossRef] [PubMed]

267. Viswanathan, R.; Randhawa, H. Candida viswanathii sp. novo Isolated from a Case of Meningitis. Available online: https: //www.cabdirect.org/cabdirect/abstract/19601301642 (accessed on 18 June 2021).

268. Sandhu, D.K.; Sandhu, R.S.; Misra, V.C. Isolation of candida viswanathii from cerebrospinal fluid. Med. Mycol. 1976, 14, 251-254. [CrossRef]

269. Randhawa, H.S.; Mishra, S.K.; Damodaran, V.N.; Prakash, A.; Chowdhary, A.; Khan, Z.U. Pathogenicity of Candida viswanathii for normal and cortisone-treated mice. J. Mycol. Med. 2015, 25, 287-292. [CrossRef]

270. Kurtzman, C.P.; Robnett, C.J.; Basehoar-Powers, E. Phylogenetic relationships among species of Pichia, Issatchenkia and Williopsis determined from multigene sequence analysis, and the proposal of Barnettozyma gen. nov., Lindnera gen. nov. and Wickerhamomyces gen. nov. FEMS Yeast Res. 2008, 8, 939-954. [CrossRef]

271. Minter, D.W. Cyberlindnera, a replacement name for Lindnera Kurtzman et al., nom. illegit. Mycotaxon 2009, 110, 473-476. [CrossRef]

272. Dooley, D.P.; Beckius, M.L.; McAllister, C.K.; Jeffery, B.S. Prostatitis Caused by Hansenula fabianii. J. Infect. Dis. 1990, 161, 1040-1041. [CrossRef]

273. Bhally, H.S.; Jain, S.; Shields, C.; Halsey, N.; Cristofalo, E.; Merz, W.G. Infection in a neonate caused by Pichia fabianii: Importance of molecular identification. Med. Mycol. 2006, 44, 185-187. [CrossRef]

274. Jindal, N.; Arora, S.; Dhuria, N.; Arora, D. Cyberlindnera (Pichia) fabianii infection in a neutropenic child: Importance of molecular identification. JMM Case Rep. 2015, 2. [CrossRef]

275. Grenouillet, F.; Millon, L.; Chamouine, A.; Thiriez, G.; Schulze, O.; Leroy, J. Pichia fabianii fungemia in a neonate. Pediatr. Infect. Dis. J. 2010, 29, 191. [CrossRef] [PubMed]

276. Wu, Y.; Wang, J.; Li, W.; Jia, H.; Che, J.; Lu, J.; Liu, L.; Cheng, Y. Pichia fabianii blood infection in a premature infant in China: Case report. BMC Res. Notes 2013, 6, 77. [CrossRef] [PubMed]

277. Fernández-Ruiz, M.; Guinea, J.; Puig-Asensio, M.; Zaragoza, Ó.; Almirante, B.; Cuenca-Estrella, M.; Aguado, J.M.; Project, C.; REIPI, G.-G. (SEIMC) and Fungemia due to rare opportunistic yeasts: Data from a population-based surveillance in Spain. Med. Mycol. 2017, 55, 125-136. [CrossRef]

278. Hof, H.; Amann, V.; Tauber, C.; Paulun, A. Peritonitis in a neonate due to Cyberlindnera fabianii, an ascomycetic yeast. Infection 2017, 45, 921-924. [CrossRef]

279. Katagiri, S.; Gotoh, M.; Tone, K.; Akahane, D.; Ito, Y.; Ohyashiki, K.; Makimura, K. Fatal Cyberlindnera fabianii fungemia in a patient with mixed phenotype acute leukemia after umbilical cord blood transplantation. Int. J. Hematol. 2016, 103, 592-595. [CrossRef] [PubMed]

280. Desai, M.; Nitta, B.; Dhanani, H.; Djurkovic, S.; Katugaha, S. Multiple organ dysfunction syndrome and death secondary to Cyberlindnera fabianii. Med. Mycol. Case Rep. 2019, 26, 1-4. [CrossRef] [PubMed]

281. Valenza, G.; Valenza, R.; Brederlau, J.; Frosch, M.; Kurzai, O. Identification of Candida fabianii as a cause of lethal septicaemia. Mycoses 2006, 49, 331-334. [CrossRef] [PubMed]

282. Hamal, P.; Ostransky, J.; Dendis, M.; Horváth, R.; Ruzicka, F.; Buchta, V.; Vejsova, M.; Sauer, P.; Hejnar, P.; Raclavsky, V. A case of endocarditis caused by the yeast Pichia fabianii with biofilm production and developed in vitro resistance to azoles in the course of antifungal treatment. Med. Mycol. 2008, 46, 601-605. [CrossRef]

283. Yun, J.W.; Park, K.S.; Ki, C.S.; Lee, N.Y. Catheter-related bloodstream infection by Lindnera fabianii in a neutropenic patient. J. Med. Microbiol. 2013, 62, 922-925. [CrossRef]

284. Gabriel, F.; Noel, T.; Accoceberry, I. Lindnera (Pichia) fabianii blood infection after mesenteric ischemia. Med. Mycol. 2012, 50, 310-314. [CrossRef] [PubMed]

285. Al-Sweih, N.; Ahmad, S.; Khan, S.; Joseph, L.; Asadzadeh, M.; Khan, Z. Cyberlindnera fabianii fungaemia outbreak in preterm neonates in Kuwait and literature review. Mycoses 2019, 62, 51-61. [CrossRef] [PubMed] 
286. Lee, J.I.; Yu, S.; Park, J.S.; Joo, E.-J.; Shin, J.H.; Kwon, M.-J. Successful Treatment of Fungemia Caused by Cyberlindnera fabianii with Anidulafungin: A Case Report. Ann. Clin. Microbiol. 2015, 18, 94. [CrossRef]

287. Mlinarić-Missoni, E.; Hatvani, L.; Kocsubé, S.; Vágvölgyi, C.; Škarić, I.; Lukić-Grlić, A. Cyberlindnera fabianii in the neonatal and paediatric intensive care unit: Case reports. JMM Case Rep. 2015, 2. [CrossRef]

288. Baghdadi, J.; Hemarajata, P.; Humphries, R.; Kelesidis, T. First Report of Ventriculoperitoneal Shunt Infection due to Cyberlindnera fabianii. Case Rep. Infect. Dis. 2015, 2015, 1-6. [CrossRef]

289. Kumar, A.; Prakash, A.; Singh, A.; Kumar, H.; Hagen, F.; Meis, J.F.; Chowdhary, A. Candida haemulonii species complex: An emerging species in India and its genetic diversity assessed with multilocus sequence and amplified fragment-length polymorphism analyses. Emerg. Microbes Infect. 2016, 5, 1-12. [CrossRef] [PubMed]

290. Yarrow, D.; Meyer, S.A. Proposal for amendment of the diagnosis of the genus Candida Berkhout nom. cons. Int. J. Syst. Bacteriol. 1978, 28, 611-615. [CrossRef]

291. Douglass, A.P.; Offei, B.; Braun-Galleani, S.; Coughlan, A.Y.; Martos, A.A.R.R.; Ortiz-Merino, R.A.; Byrne, K.P.; Wolfe, K.H. Population genomics shows no distinction between pathogenic Candida krusei and environmental Pichia kudriavzevii: One species, four names. PLoS Pathog. 2018, 14, e1007138. [CrossRef] [PubMed]

292. Mixão, V.; Hansen, A.P.; Saus, E.; Boekhout, T.; Lass-Florl, C.; Gabaldón, T. Whole-genome sequencing of the opportunistic yeast pathogen candida inconspicua uncovers its hybrid origin. Front. Genet. 2019, 10, 383. [CrossRef]

293. Guitard, J.; Atanasova, R.; Brossas, J.Y.; Meyer, I.; Gits, M.; Marinach, C.; Vellaissamy, S.; Angoulvant, A.; Mazier, D.; Hennequin, C. Candida inconspicua and candida norvegensis: New insights into identification in relation to sexual reproduction and genome organization. J. Clin. Microbiol. 2015, 53, 1655-1661. [CrossRef]

294. Guitard, J.; Angoulvant, A.; Letscher-Bru, V.; L'Ollivier, C.; Cornet, M.; Dalle, F.; Grenouillet, F.; Lacroix, C.; Vekhoff, A.; Maury, E.; et al. Invasive infections due to Candida norvegensis and Candida inconspicua: Report of 12 cases and review of the literature. Med. Mycol. 2013, 51, 795-799. [CrossRef]

295. Majoros, L.; Kardos, G.; Szabó, B.; Kovács, M.; Maráz, A. Fluconazole susceptibility testing of Candida inconspicua clinical isolates: Comparison of four methods. J. Antimicrob. Chemother. 2005, 55, 275-276. [CrossRef] [PubMed]

296. Pfaller, M.A.; Diekema, D.J.; Gibbs, D.L.; Newell, V.A.; Ellis, D.; Tullio, V.; Rodloff, A.; Fu, W.; Ling, T.A. Results from the artemis disk global antifungal surveillance study, 1997 to 2007: A 10.5-year analysis of susceptibilities of candida species to fluconazole and voriconazole as determined by CLSI standardized disk diffusion. J. Clin. Microbiol. 2010, 48, 1366-1377. [CrossRef] [PubMed]

297. D'Antonio, D.; Violante, B.; Mazzoni, A.; Bonfini, T.; Capuani, M.A.; D'Aloia, F.; Iacone, A.; Schioppa, F.; Romano, F. A nosocomial cluster of Candida inconspicua infections in patients with hematological malignancies. J. Clin. Microbiol. 1998, 36, 792-795. [CrossRef] [PubMed]

298. Baily, G.G.; Moore, C.B.; Essayag, S.M.; de Wit, S.; Burnie, J.P.; Denning, D.W. Candida inconspicua, a Fluconazole-Resistant Pathogen in Patients Infected with Human Immunodeficiency Virus. Clin. Infect. Dis. 1997, 25, 161-163. [CrossRef] [PubMed]

299. Nho, S.; Anderson, M.J.; Moore, C.B.; Denning, D.W. Species differentiation by internally transcribed spacer PCR and HhaI digestion of fluconazole-resistant Candida krusei, Candida inconspicua, and Candida norvegensis strains. J. Clin. Microbiol. 1997, 35, 1036-1039. [CrossRef] [PubMed]

300. Szabó, Z.; Sóczó, G.; Miszti, C.; Hermann, P.; Rozgonyi, F. In vitro activity of fluconazole and amphotericin B against Candida inconspicua clinical isolates as determined by the time-kill method. Acta Microbiol. Immunol. Hung. 2008, 55, 53-61. [CrossRef] [PubMed]

301. Pérez-Hansen, A.; Lass-Flörl, C.; Lackner, M.; Group, R.Y.S.; Aigner, M.; Alastruey-Izquierdo, A.; Arikan-Akdagli, S.; Bader, O.; Becker, K.; Boekhout, T.; et al. Antifungal susceptibility profiles of rare ascomycetous yeasts. J. Antimicrob. Chemother. 2019, 74, 2649-2656. [CrossRef] [PubMed]

302. Boraston, A.B.; Bolam, D.N.; Gilbert, H.J.; Davies, G.J. Carbohydrate-binding modules: Fine-tuning polysaccharide recognition. Biochem. J. 2004, 382, 769-781. [CrossRef]

303. Guillén, D.; Sánchez, S.; Rodríguez-Sanoja, R. Carbohydrate-binding domains: Multiplicity of biological roles. Appl. Microbiol. Biotechnol. 2009, 85, 1241-1249. [CrossRef]

304. Sidar, A.; Albuquerque, E.D.; Voshol, G.P.; Ram, A.F.J.; Vijgenboom, E.; Punt, P.J. Carbohydrate Binding Modules: Diversity of Domain Architecture in Amylases and Cellulases From Filamentous Microorganisms. Front. Bioeng. Biotechnol. $2020,8,871$. [CrossRef] [PubMed]

305. Li, P.; Li, S.; Cheng, L.; Luo, L. Analyzing the relation between the microbial diversity of DaQu and the turbidity spoilage of traditional Chinese vinegar. Appl. Microbiol. Biotechnol. 2014, 98, 6073-6084. [CrossRef] [PubMed]

306. Bourdichon, F.; Casaregola, S.; Farrokh, C.; Frisvad, J.C.; Gerds, M.L.; Hammes, W.P.; Harnett, J.; Huys, G.; Laulund, S.; Ouwehand, A.; et al. Food fermentations: Microorganisms with technological beneficial use. Int. J. Food Microbiol. 2012, 154, 87-97. [CrossRef] [PubMed]

307. Radecka, D.; Mukherjee, V.; Mateo, R.Q.; Stojiljkovic, M.; Foulquié-Moreno, M.R.; Thevelein, J.M. Looking beyond Saccharomyces: The potential of non-conventional yeast species for desirable traits in bioethanol fermentation. FEMS Yeast Res. 2015, 15, fov053. [CrossRef]

308. Mukherjee, V.; Radecka, D.; Aerts, G.; Verstrepen, K.J.; Lievens, B.; Thevelein, J.M. Phenotypic landscape of non-conventional yeast species for different stress tolerance traits desirable in bioethanol fermentation. Biotechnol. Biofuels 2017, 10, 216. [CrossRef] 
309. Xiao, H.; Shao, Z.; Jiang, Y.; Dole, S.; Zhao, H. Exploiting Issatchenkia orientalis SD108 for succinic acid production. Microb. Cell Fact. 2014, 13, 121. [CrossRef] [PubMed]

310. Wang, Z.; Zhuge, J.; Fang, H.; Prior, B.A. Glycerol production by microbial fermentation: A review. Biotechnol. Adv. 2001, 19, 201-223. [CrossRef]

311. Nagarathnamma, T.; Chunchanur, S.K.; Rudramurthy, S.M.; Vineetha, K.R.; Ramamurthy, K.; Joseph, J.; Ambica, R. Outbreak of Pichia kudriavzevii fungaemia in a neonatal intensive care unit. J. Med. Microbiol. 2017, 66, 1759-1764. [CrossRef] [PubMed]

312. Kumura, H.; Tanoue, Y.; Tsukahara, M.; Tanaka, T.; Shimazaki, K. Screening of Dairy Yeast Strains for Probiotic Applications. J. Dairy Sci. 2004, 87, 4050-4056. [CrossRef]

313. Greppi, A.; Saubade, F.; Botta, C.; Humblot, C.; Guyot, J.P.; Cocolin, L. Potential probiotic Pichia kudriavzevii strains and their ability to enhance folate content of traditional cereal-based African fermented food. Food Microbiol. 2017, 62, 169-177. [CrossRef] [PubMed]

314. Passoth, V.; Fredlund, E.; Druvefors, U.Ä.; Schnürer, J. Biotechnology, physiology and genetics of the yeast Pichia anomala. FEMS Yeast Res. 2006, 6, 3-13. [CrossRef]

315. Petruzzi, L.; Capozzi, V.; Berbegal, C.; Corbo, M.R.; Bevilacqua, A.; Spano, G.; Sinigaglia, M. Microbial resources and enological significance: Opportunities and benefits. Front. Microbiol. 2017, 8, 995. [CrossRef]

316. Walker, G.M. Pichia anomala: Cell physiology and biotechnology relative to other yeasts. Antonie van Leeuwenhoek 2010, 99 , 25-34. [CrossRef] [PubMed]

317. Sabel, A.; Martens, S.; Petri, A.; König, H.; Claus, H. Wickerhamomyces anomalus AS1: A new strain with potential to improve wine aroma. Ann. Microbiol. 2013, 64, 483-491. [CrossRef]

318. Padilla, B.; Gil, J.V.; Manzanares, P. Challenges of the Non-Conventional Yeast Wickerhamomyces anomalus in Winemaking. Fermentation 2018, 4, 68. [CrossRef]

319. Cappelli, A.; Ulissi, U.; Valzano, M.; Damiani, C.; Epis, S.; Gabrielli, M.G.; Conti, S.; Polonelli, L.; Bandi, C.; Favia, G.; et al. A Wickerhamomyces anomalus Killer Strain in the Malaria Vector Anopheles stephensi. PLoS ONE 2014, 9, e95988. [CrossRef] [PubMed]

320. Zhao, L.; Wang, Y.; Dhanasekaran, S.; Guo, Z.; Chen, S.; Zhang, X.; Zhang, H. Efficacy of Wickerhamomyces anomalus yeast in the biocontrol of blue mold decay in apples and investigation of the mechanisms involved. BioControl 2021, 66, 547-558. [CrossRef]

321. Raynaldo, F.A.; Dhanasekaran, S.; Ngea, G.L.N.; Yang, Q.; Zhang, X.; Zhang, H. Investigating the biocontrol potentiality of Wickerhamomyces anomalus against postharvest gray mold decay in cherry tomatoes. Sci. Hortic. (Amst.) 2021, $285,110137$. [CrossRef]

322. Barchiesi, F.; Tortorano, A.M.; Di Francesco, L.F.; Rigoni, A.; Giacometti, A.; Spreghini, E.; Scalise, G.; Viviani, M.A. Genotypic variation and antifungal susceptibilities of Candida pelliculosa clinical isolates. J. Med. Microbiol. 2005, 54, 279-285. [CrossRef]

323. Lin, H.C.; Lin, H.Y.; Su, B.H.; Ho, M.W.; Ho, C.M.; Lee, C.Y.; Lin, M.H.; Hsieh, H.Y.; Lin, H.C.; Li, T.C.; et al. Reporting an outbreak of Candida pelliculosa fungemia in a neonatal intensive care unit. J. Microbiol. Immunol. Infect. 2013, 46, 456-462. [CrossRef] [PubMed]

324. Yılmaz-Semerci, S.; Demirel, G.; Taştekin, A. Wickerhamomyces anomalus blood stream infection in a term newborn with pneumonia. Turk. J. Pediatr. 2017, 59, 349-351. [CrossRef]

325. Noni, M.; Stathi, A.; Velegraki, A.; Malamati, M.; Kalampaliki, A.; Zachariadou, L.; Michos, A. Rare Invasive Yeast Infections in Greek Neonates and Children, a Retrospective 12-Year Study. J. Fungi 2020, 6, 194. [CrossRef]

326. Storgårds, E.; Tapani, K.; Hartwall, P.; Saleva, R.; Suihko, M.L. Microbial attachment and biofilm formation in brewery bottling plants. J. Am. Soc. Brew. Chem. 2006, 64, 8-15. [CrossRef]

327. Ruiz, J.; Ortega, N.; Martín-Santamaría, M.; Acedo, A.; Marquina, D.; Pascual, O.; Rozès, N.; Zamora, F.; Santos, A.; Belda, I. Occurrence and enological properties of two new non-conventional yeasts (Nakazawaea ishiwadae and Lodderomyces elongisporus) in wine fermentations. Int. J. Food Microbiol. 2019, 305, 108255. [CrossRef]

328. Ji, Z.-H.; Jia, J.H.; Bai, F.-Y. Four novel Candida species in the Candida albicans/Lodderomyces elongisporus clade isolated from the gut of flower beetles. Antonie van Leeuwenhoek 2008, 95, 23-32. [CrossRef] [PubMed]

329. Huh, W.K.; Falvo, J.V.; Gerke, L.C.; Carroll, A.S.; Howson, R.W.; Weissman, J.S.; O'Shea, E.K. Global analysis of protein localization in budding yeast. Nature 2003, 425, 686-691. [CrossRef] [PubMed]

330. James, S.A.A.; Collins, M.D.D.; Roberts, I.N.N. The genetic relationship of Lodderomyces elongisporus to other ascomycete yeast species as revealed by small-subunit rRNA gene sequences. Lett. Appl. Microbiol. 1994, 19, 308-311. [CrossRef]

331. Lockhart, S.R.; Messer, S.A.; Pfaller, M.A.; Diekema, D.J. Lodderomyces elongisporus masquerading as Candida parapsilosis as a cause of bloodstream infections. J. Clin. Microbiol. 2008, 46, 374-376. [CrossRef] [PubMed]

332. Ahmad, S.; Khan, Z.U.; Johny, M.; Ashour, N.M.; Al-Tourah, W.H.; Joseph, L.; Chandy, R. Isolation of lodderomyces elongisporus from the catheter tip of a fungemia patient in the Middle East. Case Rep. Med. 2013, 2013. [CrossRef] [PubMed]

333. Hatanaka, S.; Nakamura, I.; Fukushima, S.; Ohkusu, K.; Matsumoto, T. Catheter-Related Bloodstream Infection Due to Lodderomyces elongisporus. Jpn. J. Infect. Dis. 2016, 69, 520-522. [CrossRef] [PubMed]

334. Al-Obaid, K.; Ahmad, S.; Joseph, L.; Khan, Z. Lodderomyces elongisporus: A bloodstream pathogen of greater clinical significance. New Microbes New Infect. 2018, 26, 20-24. [CrossRef] [PubMed]

335. Lee, H.Y.; Kim, S.J.; Kim, D.; Jang, J.; Sung, H.; Kim, M.N.; Choi, C.M. Catheter-related Bloodstream Infection due to Lodderomyces elongisporus in a Patient with Lung Cancer. Ann. Lab. Med. 2018, 38, 182-184. [CrossRef] 
336. Koh, B.; Halliday, C.; Chan, R. Concurrent bloodstream infection with Lodderomyces elongisporus and Candida parapsilosis. Med. Mycol. Case Rep. 2020, 28, 23-25. [CrossRef] [PubMed]

337. Thompson, C.M.; Warner, N.; Hurt, C.B.; Alby, K.; Miller, M.B. The brief case: A case of prosthetic valve endocarditis due to lodderomyces elongisporus. J. Clin. Microbiol. 2021, 59, 1225-1245. [CrossRef]

338. Lee, A.C.; Fujio, Y. Microflora of banh men, a fermentation starter from Vietnam. World J. Microbiol. Biotechnol. 1999, 15, 51-55. [CrossRef]

339. Simoncini, N.; Rotelli, D.; Virgili, R.; Quintavalla, S. Dynamics and characterization of yeasts during ripening of typical Italian dry-cured ham. Food Microbiol. 2007, 24, 577-584. [CrossRef]

340. Simpson, V.R.; Borman, A.M.; Fox, R.I.; Mathews, F. Cutaneous mycosis in a Barbastelle bat (Barbastella barbastellus) caused by Hyphopichia burtonii. J. Vet. Diagn. Investig. 2013, 25, 551-554. [CrossRef]

341. Chamroensakchai, T.; Kanjanabuch, T.; Saikong, W.; Panya, W.; Thaweekote, S.; Eiam-Ong, S.; Hurdeal, V.G.; Hyde, K.D. The first human report of Hyphopichia burtonii, initially misdiagnosed as sterile peritonitis in a patient on peritoneal dialysis. Med. Mycol. Case Rep. 2021, 33, 26-29. [CrossRef]

342. Quirós, M.; Martorell, P.; Valderrama, M.J.; Querol, A.; Peinado, J.M.; de Silóniz, M.I. PCR-RFLP analysis of the IGS region of rDNA: A useful tool for the practical discrimination between species of the genus Debaryomyces. Antonie van Leeuwenhoek, Int. J. Gen. Mol. Microbiol. 2006, 90, 211-219. [CrossRef]

343. Gupta, A.J.; Mi, H.; Wroe, C.; Jaques, B.; Talbot, D. Fatal Candida famata peritonitis complicating sclerosing peritonitis in a peritoneal dialysis patient. Nephrol. Dial. Transplant. 2006, 21, 2036-2037. [CrossRef]

344. St-Germain, G.; Laverdiere, M. Torulopsis candida, a new opportunistic pathogen. J. Clin. Microbiol. 1986, 24, 884-885. [CrossRef]

345. Wagner, D.; Sander, A.; Bertz, H.; Finke, J.; Kern, W.V. Breakthrough invasive infection due to Debaryomyces hansenii (teleomorph Candida famata) and Scopulariopsis brevicaulis in a stem cell transplant patient receiving liposomal amphotericin B and caspofungin for suspected aspergillosis. Infection 2005, 33, 397-400. [CrossRef]

346. Castanheira, M.; Woosley, L.N.; Diekema, D.J.; Jones, R.N.; Pfaller, M.A. Candida guilliermondii and other species of Candida misidentified as Candida famata: Assessment by Vitek 2, DNA sequencing analysis, and matrix-assisted laser desorption ionization-time of flight mass spectrometry in two global antifungal surveillance programs. J. Clin. Microbiol. 2013, 51, 117-124. [CrossRef]

347. Kim, S.H.; Shin, J.H.; Mok, J.H.; Kim, S.Y.; Song, S.A.; Kim, H.R.; Kook, J.K.; Chang, Y.H.; Bae, I.K.; Lee, K. Misidentification of Candida guilliermondii as C. Famata among strains isolated from blood cultures by the VITEK 2 system. BioMed Res. Int. 2014, 2014, 250408. [CrossRef]

348. Nishikawa, A.; Sugita, T.; Shinoda, T. Differentiation between Debaryomyces hansenii/Candida famata complex and Candida guilliermondii by polymerase chain reaction. FEMS Immunol. Med. Microbiol. 2006, 19, 125-129. [CrossRef]

349. Nishikawa, A.; Tomomatsu, H.; Sugita, T.; Ikeda, R.; Shinoda, T. Taxonomic position of clinical isolates of Candida famata. J. Med. Vet. Mycol. 1996, 34, 411-419. [CrossRef]

350. Gibson, B.; Liti, G. Saccharomyces pastorianus: Genomic insights inspiring innovation for industry. Yeast 2015, 32, 17-27. [CrossRef]

351. Aucott, J.N.; Fayen, J.; Grossnicklas, H.; Morrissey, A.; Lederman, M.M.; Salata, R.A. Invasive infection with Saccharomyces cerevisiae: Report of three cases and review. Clin. Infect. Dis. 1990, 12, 406-411. [CrossRef]

352. Posteraro, B.; Sanguinetti, M.; D’Amore, G.; Masucci, L.; Morace, G.; Fadda, G. Molecular and epidemiological characterization of vaginal Saccharomyces cerevisiae isolates. J. Clin. Microbiol. 1999, 37, 2230-2235. [CrossRef] [PubMed]

353. Sobel, J.D.; Vazquez, J.; Lynch, M.; Meriwether, C.; Zervos, M.J. Vaginitis Due to Saccharomyces cerevisiae: Epidemiology, Clinical Aspects, and Therapy. Clin. Infect. Dis. 1993, 16, 93-99. [CrossRef]

354. Pérez-Torrado, R.; Querol, A. Opportunistic strains of Saccharomyces cerevisiae: A potential risk sold in food products. Front. Microbiol. 2016, 6, 1522. [CrossRef] [PubMed]

355. Enache-Angoulvant, A.; Hennequin, C. Invasive Saccharomyces Infection: A Comprehensive Review. Clin. Infect. Dis. 2005, 41, 1-10. [CrossRef] [PubMed]

356. Anoop, V.; Rotaru, S.; Shwed, P.S.; Tayabali, A.F.; Arvanitakis, G. Review of current methods for characterizing virulence and pathogenicity potential of industrial Saccharomyces cerevisiae strains towards humans. FEMS Yeast Res. 2015, 15 , fov057. [CrossRef]

357. Lherm, T.; Monet, C.; Nougière, B.; Soulier, M.; Larbi, D.; Le Gall, C.; Caen, D.; Malbrunot, C. Seven cases of fungemia with Saccharomyces boulardii in critically ill patients. Intensive Care Med. 2002, 28, 797-801. [CrossRef] [PubMed]

358. Cassone, M.; Serra, P.; Mondello, F.; Girolamo, A.; Scafetti, S.; Pistella, E.; Venditti, M. Outbreak of Saccharomyces cerevisiae Subtype boulardii Fungemia in Patients Neighboring Those Treated with a Probiotic Preparation of the Organism. J. Clin. Microbiol. 2003, 41, 5340-5343. [CrossRef] [PubMed]

359. Muñoz, P.; Bouza, E.; Cuenca-Estrella, M.; Eiros, J.M.; Pérez, M.J.; Sánchez-Somolinos, M.; Rincón, C.; Hortal, J.; Peláez, T. Saccharomyces cerevisiae Fungemia: An Emerging Infectious Disease. Clin. Infect. Dis. 2005, 40, 1-10. [CrossRef] [PubMed]

360. de Llanos, R.; Querol, A.; Pemán, J.; Gobernado, M.; Fernández-Espinar, M.T. Food and probiotic strains from the Saccharomyces cerevisiae species as a possible origin of human systemic infections. Int. J. Food Microbiol. 2006, 110, 286-290. [CrossRef] [PubMed]

361. Williams, J.S.; Mufti, G.J.; Powell, S.; Salisbury, J.R.; Higgins, E.M. Saccharomyces cerevisiae emboli in an immunocompromised patient with relapsed acute myeloid leukaemia. Clin. Exp. Dermatol. 2007, 32, 395-397. [CrossRef] 
362. Seng, P.; Cerlier, A.; Cassagne, C.; Coulange, M.; Legré, R.; Stein, A. Saccharomyces cerevisiae osteomyelitis in an immunocompetent baker. IDCases 2016, 5, 1-3. [CrossRef] [PubMed]

363. Pfaller, M.A.; Diekema, D.J. Epidemiology of invasive mycoses in North America. Crit. Rev. Microbiol. 2010, 36, 1-53. [CrossRef]

364. Kliemann, D.A.; Antonello, V.S.; Severo, L.C.; Pasqualotto, A.C. Saccharomyces cerevisiae oesophagitis in a patient with oesophageal carcinoma. J. Infect. Dev. Ctries. 2011, 5, 493-495. [CrossRef] [PubMed]

365. Kelesidis, T.; Pothoulakis, C. Efficacy and safety of the probiotic Saccharomyces boulardii for the prevention and therapy of gastrointestinal disorders. Ther. Adv. Gastroenterol. 2012, 5, 111-125. [CrossRef]

366. Landaburu, M.F.; López Daneri, G.A.; Relloso, S.; Zarlenga, L.J.; Vinante, M.A.; Mujica, M.T. Fungemia following Saccharomyces cerevisiae var. boulardii probiotic treatment in an elderly patient. Rev. Argent. Microbiol. 2020, 52, 27-30. [CrossRef] [PubMed]

367. Verstrepen, K.J.; Reynolds, T.B.; Fink, G.R. Origins of variation in the fungal cell surface. Nat. Rev. Microbiol. 2004, 2, 533-540. [CrossRef]

368. Hennequin, C.; Kauffmann-Lacroix, C.; Jobert, A.; Viard, J.P.; Ricour, C.; Jacquemin, J.L.; Berche, P. Possible role of catheters in Saccharomyces boulardii fungemia. Eur. J. Clin. Microbiol. Infect. Dis. 2000, 19, 16-20. [CrossRef]

369. Donlan, R.M.; Costerton, J.W. Biofilms: Survival mechanisms of clinically relevant microorganisms. Clin. Microbiol. Rev. 2002, 15, 167-193. [CrossRef] [PubMed]

370. Jabra-Rizk, M.A.; Falkler, W.A.; Meiller, T.F. Fungal Biofilms and Drug Resistance. Emerg. Infect. Dis. 2004, 10, 14-19. [CrossRef] [PubMed]

371. Sen, S.; Mansell, T.J. Yeasts as probiotics: Mechanisms, outcomes, and future potential. Fungal Genet. Biol. 2020, $137,103333$. [CrossRef] [PubMed]

372. Pais, P.; Almeida, V.; Yılmaz, M.; Teixeira, M.C. Saccharomyces boulardii: What Makes It Tick as Successful Probiotic? J. Fungi 2020, 6, 78. [CrossRef] [PubMed]

373. Czerucka, D.; Piche, T.; Rampal, P. Review article: Yeast as probiotics-Saccharomyces boulardii. Aliment. Pharmacol. Ther. 2007, 26, 767-778. [CrossRef] [PubMed]

374. Thygesen, J.B.; Glerup, H.; Tarp, B. Saccharomyces boulardii fungemia caused by treatment with a probioticum. BMJ Case Rep. 2012, 2012, bcr0620114412. [CrossRef] [PubMed]

375. Appel-da-Silva, M.C.; Narvaez, G.A.; Perez, L.R.R.; Drehmer, L.; Lewgoy, J. Saccharomyces cerevisiae var. boulardii fungemia following probiotic treatment. Med. Mycol. Case Rep. 2017, 18, 15-17. [CrossRef] [PubMed]

376. Khatri, I.; Tomar, R.; Ganesan, K.; Prasad, G.S.; Subramanian, S. Complete genome sequence and comparative genomics of the probiotic yeast Saccharomyces boulardii. Sci. Rep. 2017, 7, 371. [CrossRef] [PubMed]

377. Edwards-Ingram, L.; Gitsham, P.; Burton, N.; Warhurst, G.; Clarke, I.; Hoyle, D.; Oliver, S.G.; Stateva, L. Genotypic and physiological characterization of Saccharomyces boulardii, the probiotic strain of Saccharomyces cerevisiae. Appl. Environ. Microbiol. 2007, 73, 2458-2467. [CrossRef] [PubMed] 